\title{
Das Holstein-Interglazial von Tönisberg im Rahmen des niederrheinischen Pleistozäns
}

\author{
Von Eugen KarL KeMPF, Köln
}

\author{
Mit 7 Abbildungen und 16 Tabellen im Text
}

$\mathrm{Zus}$ a m men f assung: Am Niederrhein durchteufte ein neurer Schacht nahe der Ortschaft Tönisberg den Schaephuysener Höhenzug, eine Stauchendmoräne der Saale-Eiszeit. Dabei wurde ein $54 \mathrm{~m}$ mächtiges Pleistozän-Profil aufgeschlossen, welches sich von unten nach oben aus Ablagerungen der Mittleren Mittelterrasse, der Kempen-Krefelder Schichten (Holstein-Interglazial) und der Unteren Mittelterrasse zusammensetzt. Die Basis des Profils wird von oberoligozänen Meeressanden gebildet.

In den Sedimenten der Mittleren Mittelterrasse konnte als besonderes Merkmal eine dreifache sekundäre Fossilführung nachgewiesen werden (Fauna aus marinem Oberoligozän sowie tertiäre und pleistozäne Pflanzenreste). Mit deren Hilfe und anhand anderer Merkmale sind die Ablagerungen der Mittleren Mittelterrasse weiter nordwärts $\mathrm{zu}$ verfolgen. In diesem Zusammenhang ergaben sich ferner reichlich Gründe, die zu einer Einstufung der „Moerser Schichten“ in das frühe Holstein-Interglazial führten. Der Úbergang von den Ablagerungen der Mittleren Mittelterrasse zu den interglazialen Sedimenten erfolgt allmählich; die Mittlere Mittelterrasse ist daher in den Grenzbereich von Elster-Eiszeit und Holstein-Interglazial zu stellen.

Die große Mächtigkeit der interglazialen Ablagerungen ist sekundär; sie ist auf die stauchende Wirkung des saale-eiszeitlichen Inlandeises zurückzuführen. Die interglazialen Sedimente (Sand, Kalkgyttja, toniger Torf) lieferten reichlich tierische und pflanzliche Fossilien, von denen die Mollusken, die Ostrakoden sowie die makroskopischen Pflanzenreste (überwiegend Früchte und Samen) eingehend bearbeitet wurden. Außerdem wurden pollenanalytische Untersuchungen durchgeführt.

Das Material einiger neuer Bohrungen ermöglichte vergleichende Untersuchungen mit den „Krefelder Schichten“ der sogenannten Inselberge und den „Kempener Schichten“ aus dem Untergrund der Stadt Krefeld. In der Fossilführung und im stratigraphischen Aufbau ergaben sich zahlreiche übereinstimmende Merkmale. Die „Krefelder Schichten“ des Schaephuysener Höhenzuges und der Inselberge sowie die „Kempener Schichten“ aus dem Untergrund der Stadt Krefeld werden deshalb gleichgestellt. Als Bezeichnung für diese holstein-interglazialen Ablagerungen am Niederrhein wurde der Name Kempen-Krefelder Schichten gewählt.

Um die klimatischen Verhältnisse während der Bildungszeit der holstein-interglazialen Sedimente am Niederrhein beurteilen zu können, wurden die fossil nachgewiesenen Pflanzen anhand von Florenbeschreibungen der letzten $120 \mathrm{Jahre}$ mit ihrem rezenten Vorkommen im Niederrheingebiet verglichen. Demnach entsprach das Klima des Holstein-Interglazials weitgehend dem der Jetztzeit, wobei höhere Niederschläge und etwas höhere Temperaturen auch einigen Pflanzen Lebensmöglichkeiten verliehen, die heute in diesem Gebiet nicht mehr vorkommen.

Die Lagerungsverhältnisse im Pleistozän von Schacht Tönisberg und die Beobachtungen, die beim Abteufen dieses Schachtes in Verbindung mit dem Gefrierverfahren gemacht werden konnten, sprechen dafür, daß die von K. N. Thомe $(1958,1959)$ geäußerten Ansichten zur Entstehung der Stauchmoränenwälle am Niederrhein richtig sind. Im Gegensatz zu dessen Ansichten lassen sich allerdings mehrere Gründe dafür anführen, daß im Bereich des Moerser Lobus zuerst die Kamper Staffel und erst später die Neußer Staffel aufgestaucht wurde. In diesem Zusammenhang erscheint auch die Einstufung der Krefelder Mittelterrasse in das Drenthe-Stadium der Saale-Eiszeit am wahrscheinlichsten.

In Tabelle 15 wird die zeitliche Eingliederung der mittel- und jungpleistozänen Ablagerungen des Niederrheingebietes so dargestellt, wie sie sich nach den durchgeführten Untersuchungen ergibt.

$\mathrm{S}$ u $\mathrm{m} \mathrm{m}$ a r $\mathrm{y}$ : Near the village of Tönisberg (Lower Rhine district) a new shaft penetrated the Schaephuysen hills, which is an upsqueezed terminal moraine of the Saale glaciation. It turned out that the Pleistocene amounts to almost 180 feet; from base to top it consists of Middle MiddleTerrace (Mittlere Mittelterrasse), Kempen-Krefeld-Beds (Holstein-Interglacial), and Lower MiddleTerrace (Untere Mittelterrasse). Pleistocene rests on marine sands of Upper Oligocene age.

Within the sediments of the Middle Middle-Terrace the occurence of reworked fossils seems to be a significant character. The assemblage is composed of three major constituents: marine faunal relicts of Upper Oligocene age as well as Tertiary and Quaternary plant remains. The reworked 
fossils and additional features made it possible to trace the Middle Middle-Terrace farther to the north. It could be concluded that the "Moers-Beds" ("Moerser Schichten") ought to be placed in the early Holstein-Interglacial. There is a gradual change from the deposits of the Middle Middle-Terrace to the interglacial sediments. Therefore the Middle Middle-Terrace can be regarded as a transitional layer between the Elster-Glacial and the Holstein-Interglacial.

The great thickness of interglacial deposits is due to the upsqueezing effects of the Saale ice sheet. The interglacial sediments (sand, chalky gyttja, argillaceous peat) yielded many fossils of which the molluscs, the ostracods, and the macroscopic plant remains (mainly fruits and seeds) were studied in detail. Furthermore palynological investigations were undertaken.

The samples from some new boreholes allowed comparative investigations with the „KrefeldBeds" of the isolated hills west of Moers (Inselberge) and the "Kempen-Beds" which are distributed below the city of Krefeld. As redards fossils and stratigraphical sequence several similarities could be detected. Therefore the "Krefeld-Beds" of the Schaephuysen hills and those of Moers are regarded as time equivalents of the „Kempen-Beds“. The term Kempen-Krefeld-Beds was chosen for these Holstein-Interglacial deposits in the Lower Rhine district.

The description of the prevailing climatic conditions during the deposition of the HolsteinInterglacial beds in the Lower Rhine district is based on the nature of the fossil content. The recent distribution of the identified plant species within the Lower Rhine district was noted by means of publications on local plant communities covering more than a century. According to these data the climate of the Holstein-Interglacial essentially corresponded to that of the present day. A greater rainfall and slightly higher temperatures allowed, however, some plant species to thrive which nowadays do not occur in this area.

The sequence and structure of the Pleistocene, exposed in the shaft of Tönisberg, proves the opinions of K. N. Tноме $(1958,1959)$, regarding the origin of the upsqueezed terminal moraines in the Lower Rhine district, to be right. This is further underlined by observations which could be made during shaft sinking, as a freezing technique was applied. In contrast to the opinions of K. N. Thome reasons are advanced to show that, within the area of the Moers ice lobe (Moerser Lobus), the Kamp ridge (Kamper Staffel) was the first to be squeezed up and that the squeezing up of the Neuss ridge (Neußer Staffel) was the later event. Also in connection with this the stratigraphical position of the Krefeld Middle-Terrace (Krefelder Mittelterrasse) within the Drenthe stage (Drenthe-Stadium) of the Saale-Glacial appears to be most probable.

On figure 15 the stratigraphical sequence of middle and late Pleistocene deposits of the Lower Rhine district is listed, according to the results indicated above.

\section{N H A L T S ÜB E R S I C H T}

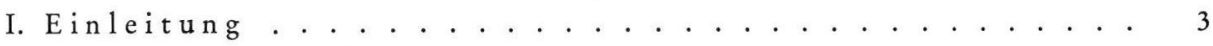

II. Die pleistozänen Schichten von Schacht Tönisberg... . 6

1. Liegende Kiese und Sande (Mittlere Mittelterrasse, Rinnenschotter) . . . . . . 6

A. Beschreibung der Einzelschichten . . . . . . . . . . . . . . . 6

B. Geröllbestand . . . . . . . . . . . . . . . . . . . . . . . 8

C. Charakteristische Merkmale . . . . . . . . . . . . . . . . . . . 9

2. Interglaziale Fluß- und Stillwasserablagerungen (Kempen-Krefelder Schichten, Holstein-Interglazial) . . . . . . . . . . . . . . . . . . . . . 10

A. "Krefelder Schichten" in situ . . . . . . . . . . . . . . . . . 11

B. Aufgeschobene, in sich gestörte "Krefelder Schichten“ . . . . . . . . . . 11

C. Aufgeschobene, in sich ungestörte „Krefelder Schichten“ . . . . . . . . . . 13

3. Hangende Kiese und Sande (Untere Mittelterrasse) . . . . . . . . . . . . . . 13

III. Die sekundäre Fossilführung der Mittleren Mittelterrasse 14

1. Fossilien aus marinem Tertiär . . . . . . . . . . . . . . . . 14

2. Fossilien aus limnisch-terrestrischem Tertiär . . . . . . . . . . . . . 16

3. Fossilien aus limnisch-terrestrischem Pleistozän . . . . . . . . . . . . . . . . 19

4. Folgerungen auf Grund der sekundären Fossilführung . . . . . . . . . . . . 19

A. Zur Verbreitung der Rinnenschotter . . . . . . . . . . . . . . . . . 19

B. Die zeitliche Einstufung der "Moerser Schichten“ . . . . . . . . . . . 22 
IV. Die Fossilführung der interglazialen Ablagerungen... 24

1. Die Fauna . . . . . . . . . . . . . . . . . . 25

A. Mollusken . . . . . . . . . . . . . . . . . . . . . . 25

B. Ostrakoden . . . . . . . . . . . . . . . . . . . . . . . . . . . . . 28

C. Bryozoen . . . . . . . . . . . . . . . . . . . . . . . . . . . . . 29

D. Vertebraten . . . . . . . . . . . . . . . . . . . 29

2. Die Flora ...... . . . . . . . . . . . . . . . . 31

A. Makroskopische Pflanzenreste . . . . . . . . . . . . . . . . . . 31

B. Pollenanalytische Untersuchungen . . . . . . . . . . . . . . . . . . . 33

3. Charakteristische Fossilien aus den holstein-interglazialen Ablagerungen am Niederrhein . . . . . . . . . . . . . . . . 38

V. Vergleichende Untersuchungen in den „Krefelder Schichten" der Inselberge ................. 39

VI. Vergleichende Untersuchungen in den "Kempener Schichten“ . . 42

VII. Klimatische Verhältnisse im Niederrheingebiet während des Holstein-Interglazials ............ . 46

VIII. Zur Entstehung der Stauchendmoränen a m Niederrhein . . 50

IX. Dank . . . . . . . . . . . . . . . . . 52

X. Schriftenverzeichnis ................ . . 52

\section{Einleitung}

In den Jahren 1960 und 1961 teufte die Niederrheinische Bergwerks-A.G. (N.B.A.G.) nahe der Ortschaft Tönisberg bei Krefeld ihren Schacht 4 ab. Diesem neuen Schacht entstammt im wesentlichen das Material zu der vorliegenden Arbeit. Den vergleichenden Untersuchungen dienten etliche Proben aus Bohrungen und Tagesaufschlüssen der näheren und weiteren Umgebung.

Der Schacht 4 der N.B.A.G. liegt etwa $10 \mathrm{~km}$ nordwestlich von Krefeld auf dem Meßtischblatt Nieukerk (Nr. 4504). Seine genaue geographische Lage wird durch die Gauß-Krüger-Koordinaten R 34030 und H 97555 gegeben. Da er nur wenige hundert Meter westlich der Ortschaft Tönisberg liegt, wird er in den weiteren Ausführungen kurz als Schacht Tönisberg bezeichnet.

Die niederrheinische Landschaft wird im wesentlichen von den Ablagerungen der Niederterrasse des Rheins gebildet und ist daher verhältnismäßig eintönig. Das Gebiet nördlich von Krefeld zeichnet sich dadurch aus, daß die Ebene dort von einigen Erhebungen unterbrochen wird, die aus Ablagerungen der Mittelterrassen des Rheins bestehen und sich als Stauchendmoränen der Saale-Eiszeit oder als Reste von solchen erwiesen haben. Bei den südlichsten handelt es sich dabei um den Schaephuysener oder Tönisberger Höhenzug und um die sogenannten Inselberge, zu denen der Egels-, Hülser, Gulix-, Rayer, Eyller, Dachs-, Kamper und Niersen-Berg gehören. Nach Norden zu schließen sich weitere und höhere Erhebungen bei Xanten und Kleve an, die zu den wesentlich größeren Stauchendmoränen der Niederlande hinüberleiten.

Die nachfolgenden Untersuchungen behandeln vor allem den Schaephuysener Höhenzug und die Inselberge. Der innere Aufbau dieser Gebilde war bisher nur unzureichend bekannt aus Kiesgruben-Aufschlüssen und Bohrungen. Großes Interesse wurde deshalb dem neuen Schacht Tönisberg entgegengebracht, als bekannt wurde, daß für diesen als 


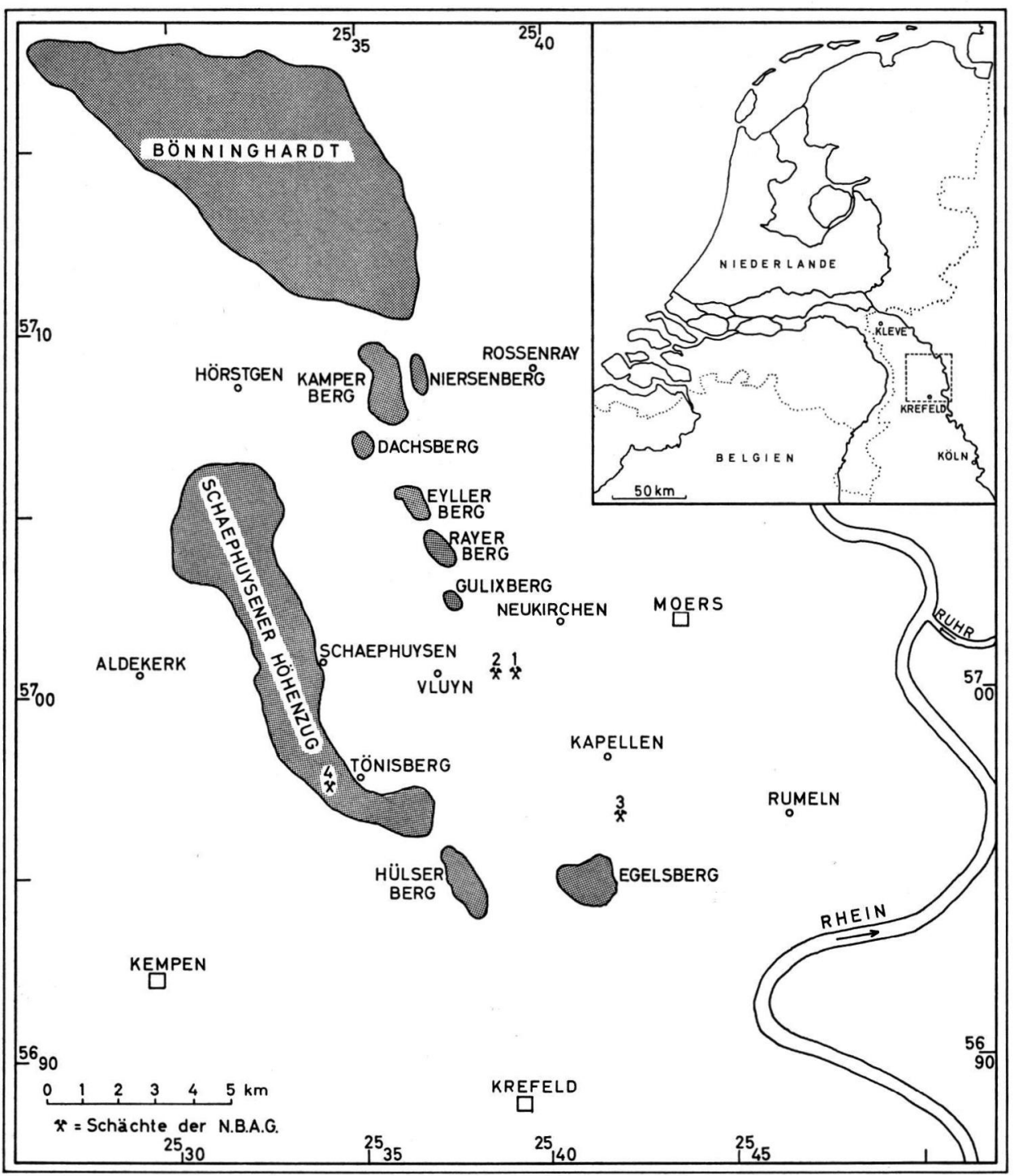

Abb. 1. Uberblick über das Arbeitsgebiet und die Lage von Schacht Tönisberg in bezug auf die Eisrandbildungen der Saale-Eiszeit am Niederrhein.

Lagepunkt der Mühlenberg, eine kleine Erhebung innerhalb des Schaephuysener Höhenzuges, gewählt worden war. Der Schacht mußte demnach die Schichten des Stauchendmoränenwalles durchteufen und über dessen inneren Aufbau Auskunft geben.

Eine ausführliche Übersicht über die bisherigen Untersuchungen im Pleistozän des Arbeitsgebietes findet sich in der Diplom-Arbeit des Verfassers (E. K. KEMPF 1963). Die notwendigen Angaben über die stratigraphische Eingliederung der interglazialen Ablagerungen im Verlauf früherer Untersuchungen finden sich in den entsprechenden Kapiteln („Krefelder Schichten“: Kap. II. 2; „Kempener Schichten“: Kap. VI; „Moerser Schichten“: Kap. III. 4. B). 


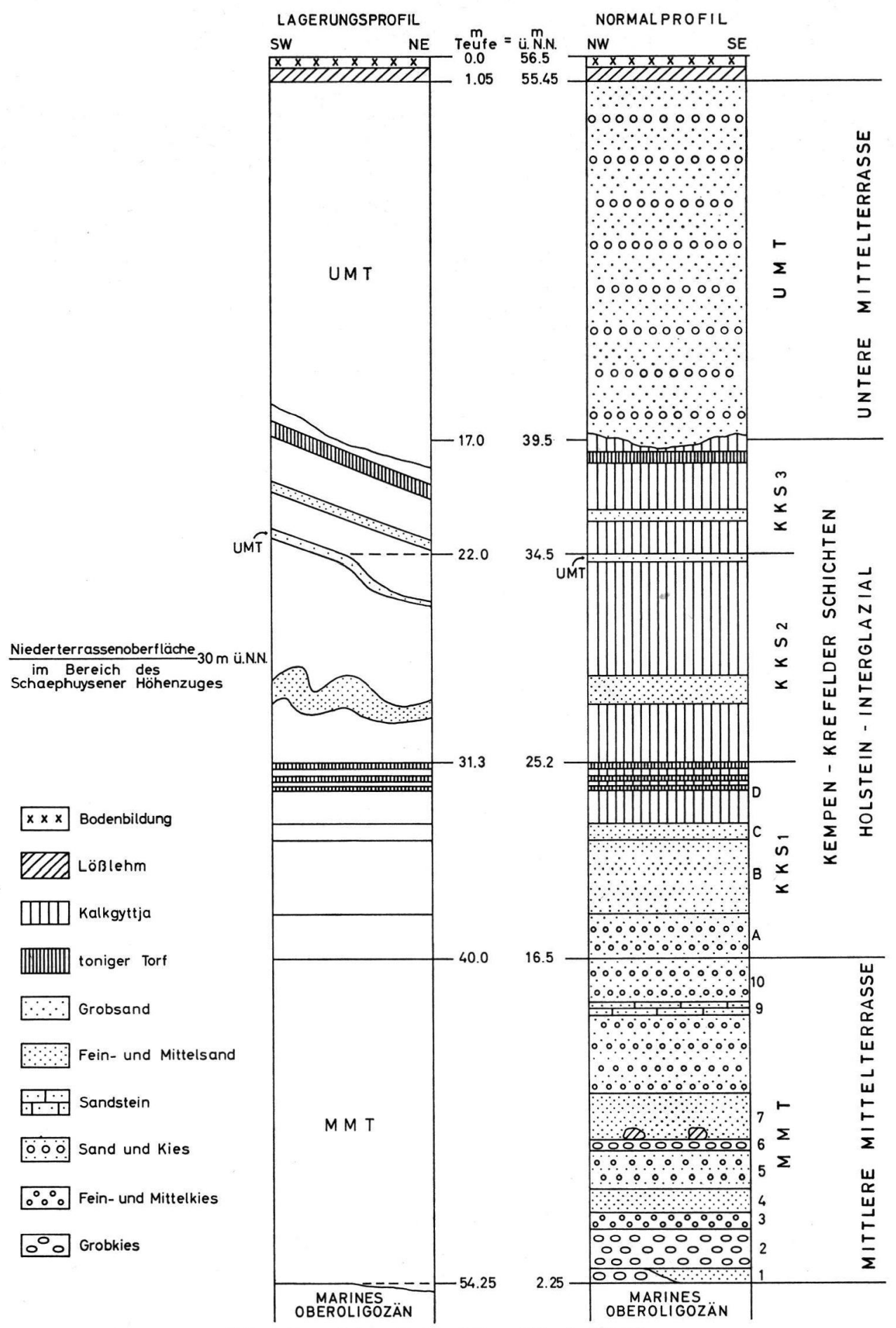

Abb. 2. Das Pleistozän-Profil von Schacht Tönisberg. 
In der vorliegenden Arbeit wird besonders die Stratigraphie und die Fossilführung der „Krefelder“ und der „Kempener Schichten“ kritisch untersucht. Die Mollusken, die Ostrakoden und die makroskopischen Pflanzenreste (vorwiegend Früchte und Samen) wurden eingehend bearbeitet, wodurch die Zahl der bisher aus diesen Ablagerungen bekannten Arten wesentlich erweitert wird. Pollenanalytische Untersuchungen wurden durchgeführt, um genügend Vergleichsmöglichkeiten mit den bisherigen Untersuchungen dieser Ablagerungen zu erhalten. Für die „Krefelder“ und die „Kempener Schichten“ ergeben sich so zahlreiche übereinstimmende Merkmale, daß sie unter der Bezeichnung Kempen-Krefelder Schichten zusammengefaßt und als Ablagerungen des Holstein-Interglazials aufgefaßt werden.

Ferner wird das Profil des Pattberg-Schachtes bei Moers neu gedeutet, wodurch die "Moerser Schichten" in den Grenzbereich von Mittlerer Mittelterrasse und Kempen-Krefelder Schichten gestellt werden. Da es sich bei den „Moerser Schichten“ nicht um autochthone Ablagerungen handelt, stellen sie kein abgrenzbares Schichtglied dar. Die Bezeichnung „Moerser Schichten“ ist deshalb unzulässig und damit hinfällig.

\section{Die pleistozänen Schichten von Schacht Tönisberg}

Das Pleistozän-Profil, welches beim Abteufen von Schacht Tönisberg aufgeschlossen wurde, hat eine Mächtigkeit von $54 \mathrm{~m}$ (vgl. Abb. 2). Es erstreckt sich von 2,5 bis $56,5 \mathrm{~m}$ über N. N. und ist durch eine mehr als $20 \mathrm{~m}$ mächtige Folge fossilführender interglazialer Sedimente ausgezeichnet. $\mathrm{Da}$ diese interglazialen Ablagerungen in die übrigen Kiese und Sande eingeschaltet sind, ergibt sich ganz natürlich eine Dreiteilung des Profils. Von unten nach oben können folgende Einheiten unterschieden werden: auf $14 \mathrm{~m}$ Kiese und Sande der Mittleren Mittelterrasse (Rinnenschotter) folgen etwa $23 \mathrm{~m}$ Fluß- und Stillwasserablagerungen des Holstein-Interglazials (Kempen-Krefelder Schichten) und $17 \mathrm{~m}$ Kiese und Sande der Unteren Mittelterrasse. Die Basis des Profils wird von oberoligozänen Meeressanden gebildet.

\section{Liegende Kiese und Sande (Mittlere Mittelterrasse, Rinnenschotter)}

\section{A. Beschreibung der Einzelschichten}

In diesem Profilbereich lassen sich von unten nach oben 10 Profilabschnitte unterscheiden, die nachfolgend beschrieben werden. Alle Angaben über die Korngröße der Sedimente beruhen auf Siebanalysen, welche vom Verfasser im Geologischen Landesamt in Krefeld durchgeführt wurden. Die Benennung von Siebfraktionen ist bisher weder national noch international geregelt; sie erfolgt im vorliegenden Fall nach der im Geologischen Landesamt in Krefeld üblichen Methode, die in J. Kalterherberg \& H. Karrenberg 1958 erläutert worden ist.

$$
\text { Profilabschnitt } 1: 54,5-53,75, \mathrm{~m} \text { Teufe }
$$

Die Sedimentation der Liegenden Kiese und Sande wird eingeleitet durch die Ablagerung einer Kiesbank von 0,5 m Mächtigkeit. Die Kornverteilung innerhalb dieser Bank läßt eine Abnahme der Korngröße von unten nach oben erkennen: über Grob- und Mittelkies mit einzelnen Steinen folgen Feinkies und schließlich Grobsand. Im Kies fanden sich reichlich Fossilien, die aus aufgearbeitetem marinen Tertiär stammen, welches im Liegenden der pleistozänen Schichten ansteht.

An der westlichen Schachtseite war die Kiesbank in ihrer ganzen Mächtigkeit erhalten. Nach Osten hin keilte sie allmählich aus und wurde anfangs teilweise und schließlich vollkommen durch Feinsand vertreten (vgl. E. K. KempF 1963: Abb. 2 sowie Taf. 1, Fig. 1 und 2).

Der Feinsand ist in seiner ganzen Mächtigkeit recht einheitlich in Korngröße und Lagerung. Schrägschichtung konnte nicht beobachtet werden. An der Basis des Feinsandes fand sich eine Lage von Steinen; in die obersten 10 bis $20 \mathrm{~cm}$ waren reichlich Pflanzenreste eingeschwemmt worden. Im Feinsand verteilt konnten ferner Mikrofossilien aus aufgearbeitetem marinen Tertiär nachgewiesen werden. 
Die Steinlage an der Basis des Feinsandes wird als Erosionsrest gedeutet und als Beweis dafür angesehen, daß die Kiesbank zu einem Teil erodiert wurde. Für diese Ansicht spricht ferner die Beobachtung, daß die Feinsande des marinen Oberoligozäns, welche im Schacht Tönisberg das Liegende des Pleistozäns bilden, als oberste Schicht eine 10 bis $15, \mathrm{~cm}$ mächtige Ausbleichungs- beziehungsweise Verwitterungszone aufweisen. Diese Zone findet sich jedoch nur unter der Kiesbank; wo letztere durch Feinsand vertreten wird, fehlt die Verwitterungszone. Die Unterkante des Pleistozäns reicht in diesem Fall etwas tiefer hinab bis zu einer Teufe von $54,5 \mathrm{~m}$. Bei der Erosionsform, welche durch den Schacht nur zu einem Teil aufgeschlossen wurde, handelt es sich um eine Rinne von mindestens $10 \mathrm{~m}$ Breite, die später mit Feinsand zusedimentiert wurde.

$$
\text { Profilabschnitt 2: 53,75-51,95 m Teufe }
$$

Zum Hangenden hin folgen mehrere Kiesbänke (Grobkies und Mittelkies mit etwas Feinkies, etwas Grobsand und etwas Mittelsand) von insgesamt 1,8 m Mächtigkeit. Bereits im Anstehenden wurden darin umgelagerte Fossilien aus marinem Tertiär beobachtet. Im Teufenbereich 52,7-53,0 m fand sich in diesen Kiesen eine Sandlinse (Mittelsand überwiegend mit wenig Mittelkies). In die oberste Kiesbank war eine Rinne von $20 \mathrm{~cm}$ Tiefe und $30 \mathrm{~cm}$ Breite eingeschnitten und mit Feinsand und umgelagerten Pflanzenresten aufgefüllt worden.

$$
\text { Profilabschnitt } 3: 5,1,95-51,25 \mathrm{~m} \mathrm{Teufe}
$$

Darüber folgt eine Kiesbank von $70 \mathrm{~cm}$ Mächtigkeit (Mittelkies mit etwas Feinkies, etwas Grobsand und etwas Feinsand). Auch in dieser Bank fanden sich umgelagerte Fossilien aus marinem Tertiär. Alle Sedimente der Profilabschnitte 1 bis 3 sind von relativ heller, gelblich-grauer Farbe.

$$
\text { Profilabschnitt } 4: 51,25-50,25 \mathrm{~m} \mathrm{Teufe}
$$

Uberlagert werden die Kiesbänke von einer $1 \mathrm{~m}$ mächtigen graubraunen Sandschicht (Feinsand überwiegend mit etwas Mittelsand und wenig Schluff). Darin finden sich bis $\mathrm{zu} 1 \mathrm{~cm}$ mächtige Lagen von eingeschwemmten Pflanzenresten. Die graubraune Färbung des Sandes ist auf den Schluff-Anteil zurückzuführen, der einen hohen Fe-Gehalt aufweist.

$$
\text { Profilabschnitt 5: } 50,25-48,45 \mathrm{~m} \mathrm{Teufe}
$$

Es setzt nun eine Wechsellagerung von 5 bis $35 \mathrm{~cm}$ mächtigen Lagen von Sand (Mittelsand überwiegend mit etwas Feinsand) und Kies (Feinkies mit etwas Mittelkies, etwas Grobsand und etwas Mittelsand) ein. Beide Sedimente sind gelblichgrau gefärbt und mengenmäßig etwa zu gleichen Teilen vertreten. Vereinzelt fanden sich umgelagerte Fossilien.

$$
\text { Profilabschnitt 6:48,45-48,15 m Teufe }
$$

Darüber folgt eine gröbere Kiesbank (Mittelkies vorwiegend mit etwas Grobkies und wenig Feinkies), die meist $35, \mathrm{~cm}$ mächtig ist, stellenweise aber auf 10 bis $15 \mathrm{~cm}$ oder fast ganz ausdünnt. Auf dieser Kiesbank fanden sich verstreut einige Steine und Blöcke (vgl. E. K. KEMPF 1963: Taf. 2 , Fig. 1 und 2; Taf. 3, Fig. 1 und 2). Im Anschnitt hatten die Steine eine Größe bis zu $25 \times 15 \mathrm{~cm}$; sie bestanden aus Quarz oder Quarzit. Die Blöcke waren bis zu $30 \times 50 \mathrm{~cm}$ groß und bestanden aus kalkhaltigem, schluffigem Ton, der durch Limonit mehr oder weniger verfestigt war. Es ist wahrscheinlich, daß die Steine und Blöcke durch Eisschollen-Drift auf dem damaligen Rhein zu ihrem jetzigen Fundort gelangten.

\section{Profilabschnitt $7: 48,15-46,05, \mathrm{~m} \mathrm{Teufe}$}

Uber der Kiesbank folgen mehrere Lagen von Sand (Mittelsand überwiegend mit etwas Feinsand und wenig Grobsand), die insgesamt eine Mächtigkeit von 2,1 $\mathrm{m}$ haben. Die unterste Sandlage ist $60 \mathrm{~cm}$ mächtig, nach oben hin folgen dann immer geringmächtigere Lagen. Eingeschwemmte Pflanzenreste finden sich meist auf Schrägschichtungsflächen (vgl. E. K. KEMPF: 1963, Taf. 3, Fig. 1).

Profilabschnitt 8 und 10:46,05-42,5 m und 42,0-40,25 m Teufe

Die Sedimentation der Liegenden Kiese und Sande wird abgeschlossen durch eine 5,8 m mächtige Folge von Sand (Grobsand und Mittelsand mit wenig Feinsand) und Kies (Feinkies vorwiegend mit etwas Sand). Die Mächtigkeit der einzelnen Sandlagen beträgt meist 30 bis $50 \mathrm{~cm}$, während die Kieslagen nur 5 bis $10 \mathrm{~cm}$ mächtig sind. Die Kiese treten also mengenmäßig gegenüber den Sanden deutlich zurück. Im Sand fanden sich auf den Schichtflächen eingeschwemmte Pflanzenreste.

$$
\text { Profilabschnitt 9: 42,5-42,0 m Teufe }
$$

In dieser vorstehend beschriebenen Sedimentfolge findet sich eine Lage, die zu leicht absandendem Sandstein verfestigt ist. Die Verfestigung ist im wesentlichen auf Brauneisen zurückzuführen, welches sich in einigen Bändern von wenigen $\mathrm{cm}$ Dicke auch stärker angereichert findet. Es besteht die Möglichkeit, daß dieser verfestigte Profilabschnitt mit dem vorhandenen unteren Grundwasserhorizont in Verbindung gebracht werden kann. Da das Sediment in diesem Teufenbereich aus abbautechnischen Gründen gefroren war, konnte der untere Grundwasserhorizont an sich im Aufschluß nicht erkannt werden. 


\section{B. Gerö 11 bestand}

Nur die Horizonte 1, 2, 3, 5 und 6 lieferten in hinreichender Menge Material der Fraktion $>6 \mathrm{~mm}$, um eine Aussage über die Verteilung der einzelnen Geröllkomponenten machen zu können. Es wurden 5 Geröllgruppen unterschieden, deren prozentuale Anteile aus Tabelle 1 hervorgehen.

$$
\mathrm{T} \text { a be } 11 \mathrm{e} 1
$$

Geröllanalysen der Fraktion $>6,0 \mathrm{~mm}$ von Proben der Horizonte 1 bis 6 der Mittleren Mittelterrasse von Schacht Tönisberg.

\begin{tabular}{|c|c|c|c|c|c|c|}
\hline $\begin{array}{c}\text { Horizont } \\
\mathrm{Nr} .\end{array}$ & $\begin{array}{l}\text { Zahl der } \\
\text { Gerölle } \\
>6 \mathrm{~mm}\end{array}$ & $\begin{array}{c}\text { Quarz } \\
\%\end{array}$ & $\begin{array}{c}\text { Lydit }+ \\
\text { Radiolarit } \\
\%\end{array}$ & $\begin{array}{c}\text { Feuerstein } \\
\%\end{array}$ & $\begin{array}{c}\text { Quarzit, } \\
\text { Sandstein + } \\
\text { Grauwacke } \\
\%\end{array}$ & $\begin{array}{c}\text { Porphyr } \\
\%\end{array}$ \\
\hline $\begin{array}{l}6 \\
5 \\
3 \\
2 \\
1\end{array}$ & $\begin{array}{l}900 \\
300 \\
300 \\
900 \\
900\end{array}$ & $\begin{array}{l}46,7 \\
49,3 \\
51,0 \\
55,8 \\
53,1\end{array}$ & $\begin{array}{l}1,0 \\
0,5 \\
1,3 \\
1,7 \\
1,8\end{array}$ & $\begin{array}{l}0,4 \\
0,2 \\
0,6 \\
1,5\end{array}$ & $\begin{array}{l}51,3 \\
49,1 \\
46,9 \\
41,3 \\
43,3\end{array}$ & $\begin{array}{l}0,6 \\
1,1 \\
0,6 \\
0,6 \\
0,3\end{array}$ \\
\hline \multicolumn{2}{|c|}{ Mittelwert: } & 51,2 & 1,3 & 0,5 & 46,4 & 0,6 \\
\hline
\end{tabular}

Die Quarzgruppe umfaßt alle Körner, die ganz oder wenigstens zur Hälfte aus Quarz bestehen. Die Milchquarz-Körner wurden nicht gesondert gezählt. Im Durchschnitt ergibt sich für die untersuchten Proben ein Quarzanteil von etwa 51\%. Dieser Wert liegt um 4\% \% über dem Durchschnitt, den G. C. MaARLEveld (1956) bei seinen Untersuchungen von Proben der Mittleren Mittelterrasse aus dem Gebiet von Krefeld erhielt. Dies dürfte zu einem Teil dadurch begründet sein, daß bei den einzelnen Proben der Quarzanteil je nach Korngrößenfraktion verschieden ist. So ergaben sich z. B. innerhalb einer Probe aus Horizont 1 Unterschiede im Quarzanteil von über 6\% (vgl. Tabelle 2).

\section{Tabelle 2}

Geröllanalysen verschiedener Korngrößenfraktionen einer Probe aus Horizont 1 der Mittleren Mittelterrasse von Schacht Tönisberg.

\begin{tabular}{|c|c|c|c|c|c|c|}
\hline $\begin{array}{c}\text { Zahl } \\
\text { der } \\
\text { Gerölle }\end{array}$ & $\begin{array}{c}\text { Korngrößen- } \\
\text { fraktion } \\
\text { mm }\end{array}$ & $\begin{array}{c}\text { Quarz } \\
\%\end{array}$ & $\begin{array}{c}\text { Lydit }+ \\
\text { Radiolarit } \\
\%\end{array}$ & Feuerstein & $\begin{array}{c}\text { Quarzit, } \\
\text { Sandstein + } \\
\text { Grauwacke } \\
\%\end{array}$ & $\begin{array}{c}\text { Porphyr } \\
\%\end{array}$ \\
\hline $\begin{array}{l}100 \\
500 \\
300 \\
900\end{array}$ & $\begin{array}{l}>30 \\
30-15 \\
15-6 \\
6-2\end{array}$ & $\begin{array}{l}52,8 \\
54,5 \\
49,8 \\
56,4\end{array}$ & $\begin{array}{l}3,6 \\
2,0 \\
0,4 \\
-\end{array}$ & $\begin{array}{l}3,6 \\
1,4 \\
0,8 \\
-\end{array}$ & $\begin{array}{l}40,0 \\
41,5 \\
49,0 \\
43,6\end{array}$ & $\begin{array}{l}\overline{0,6} \\
-\end{array}$ \\
\hline \multicolumn{2}{|c|}{ Mittelwert: } & 53,4 & 1,5 & 1,45 & 43,5 & 0,15 \\
\hline
\end{tabular}

Es schien demnach angebracht, beim Vergleich des Geröllbestandes verschiedener Sedimentlagen nur engbegrenzte Korngrößenfraktionen auszuwählen. Um einen größeren Vertikalbereich untersuchen zu können, kam im vorliegenden Fall dafür ausschließlich die Feinkiesfraktion 6 bis $2 \mathrm{~mm}$ in Frage, bei der allerdings nur Quarz- und NichtquarzAnteile unterschieden werden können.

Wie das Ergebnis zeigt (vgl. Tabelle 3), treten auch in engbegrenzten Korngrößenbereichen Schwankungen auf, die bis zu 10\% erreichen können. Der Quarzanteil ist also keineswegs so konstant, wie man ihn gerne haben möchte, um damit Aussagen für die 


\section{Tabelle 3}

Quarz- und Nichtquarz-Anteile der Korngrößen-Fraktion 6-2 mm von Proben der Mittleren Mittelterrasse und der Kempen-Krefelder Schichten 1 (in situ) aus Schacht Tönisberg.

\begin{tabular}{l|c|c|c|c}
\hline Profilbereich & Horizont & $\begin{array}{c}\text { Zahl der } \\
\text { Gerölle } \\
6-2 \mathrm{~mm}\end{array}$ & $\begin{array}{c}\text { Quarz } \\
\%\end{array}$ & $\begin{array}{c}\text { Nichtquarz } \\
\%\end{array}$ \\
\hline Kempen- & C & 100 & 56,8 & 43,2 \\
Krefelder & B & 200 & 62,9 & 37,1 \\
Schichten & B & 200 & 60,0 & 40,0 \\
1(in situ) & A & 600 & 56,6 & 43,4 \\
\hline & 8 & 300 & 65,5 & 34,5 \\
Mittlere & 7 & 150 & 59,1 & 40,9 \\
Mittelterrasse & 3 & 300 & 63,0 & 37,0 \\
& 1 & 900 & 56,4 & 43,6
\end{tabular}

Stratigraphie machen zu können. Nur solche Terrassen können allein auf Grund des Quarzgehaltes auseinandergehalten werden, bei denen sich die Quarzanteile sehr stark voneinander unterscheiden.

Die Lydit-Radiolarit-Gruppe weist in den untersuchten Horizonten Werte unter 2\% auf (vgl. Tabelle 1). Der prozentuale Anteil dieser Geröllgruppe steigt jedoch innerhalb einzelner Proben mit zunehmender Korngröße an (vg1. Tabelle 2).

Die gleichen Verhältnisse finden wir auch bei der Feuerstein-Gruppe. Bei den Feuersteinen lassen sich zwei Varietäten unterscheiden (vgl. K. H. KAISER 1956), die etwa in gleicher Menge auftreten: ellipsoidförmige, bläulichweiße, mit einer Patina versehene „Feuersteineier" und unregelmäßig geformte, bräunliche, ebenfalls mit einer Patina versehene „"Gekrösefeuersteine“. Beide Varietäten sind sicher mehrfach umgelagert und aus dem Kreidegebiet von Aachen-Maastricht herzuleiten. Nordische Feuersteine fanden sich nicht, wie überhaupt in den Sedimenten der Mittleren Mittelterrasse nordische Geschiebe fehlen.

Anteile von 40 bis 50\% weist die Gruppe Quarzit-Sandstein-Grauwacke auf. Es handelt sich dabei im wesentlichen um Material aus dem Rheinischen Schiefergebirge.

An vulkanischem Material fand sich nur Porphyr, der selten Anteile von mehr als $1 \%$ erreicht.

\section{Charakteristische Merkmale}

Die Ablagerungen der Mittleren Mittelterrasse, welche in Schacht Tönisberg aufgeschlossen wurden, weisen einige charakteristische Merkmale auf, die nachfolgend zusammengefaßt werden.

1. Sediment

Die Ablagerungen sind relativ feinkörnig; Sand ist mengenmäßig stärker vertreten als Kies. Grobkies findet sich nur in wenigen Bänken nahe der Basis. Die im Profil höchste Kiesbank ist durch auflagernde große Steine und Blöcke ausgezeichnet. Die Quarz-Anteile der Fraktion $>6 \mathrm{~mm}$ betragen 45 bis $55 \%$, die der Fraktion 6 bis $2 \mathrm{~mm} 55$ bis 65\%.

2. Höh en lage

Die Basis der Mittleren Mittelterrasse, die im Arbeitsgebiet der Tertiäroberfläche entspricht, liegt nur wenige Meter über oder gar unter Normalnull. Von jüngeren Rheintalbildungen wurde diese Tiefe nicht wieder erreicht.

3. Überlagerung

In den meisten bisher bekannten Vorkommen werden die Ablagerungen der Mittleren 
Mittelterrasse von holstein-interglazialen Sedimenten überlagert. Dabei ist zwischen den beiden Einheiten keine scharfe Grenze, sondern ein allmählicher Übergang zu beobachten.

4. Sekundäre Fossilführung

Die Sedimente der Mittleren Mittelterrasse sind ausgezeichnet durch eine dreifache sekundäre Fossilführung. In der Hauptsache finden sich Fossilien aus dem marinen Tertiär des Untergrundes; daneben kommen aber auch Pflanzenreste aus tertiären und aus pleistozänen limnisch-terrestrischen Ablagerungen vor (vgl. Kap. III).

Auf Grund vorstehender Merkmale ist es möglich, diese Ablagerungen auch in Bohrungen zu erkennen, wodurch ihre Verbreitung vor allem in nördlicher Richtung verfolgt werden kann (vgl. Kap. III. 4. A).

\section{Interglaziale Fluß- und Stillwasserablagerungen (Kempen-Krefelder Schich- ten, Holstein-Interglazial)}

Bei den interglazialen Sedimenten, die im Schacht Tönisberg in einer Mächtigkeit von etwa $23 \mathrm{~m}$ aufgeschlossen wurden, handelt es sich um Ablagerungen, für welche A. STEEGER (1931b) die Bezeichnung „Krefelder Schichten“ vorschlug.

Im Verlauf dieser Arbeit wird erneut begründet, daß die „Krefelder Schichten“ mit den „Kempener Schichten“ gleichzusetzen sind, weil beide Schichten Ablagerungen des Holstein-Interglazials am Niederrhein darstellen. Unter der Bezeichnung „Krefelder Schichten" wird heute von den einzelnen Autoren Verschiedenes verstanden (z. B. „Krefelder Schichten“ im Sinne von H. KARRENBERG \& U. REIN 1951 = „Krefelder“ u n d „Kempener Schichten“, in der Auffassung von A. STEeger 1931b und 1952). Um eine Eindeutigkeit in der Bezeichnungsweise zu erhalten, wird für die holstein-interglazialen Ablagerungen am Niederrhein der Name Kempen-Krefelder Schichten vorgeschlagen. Dieser Name ist auch insofern treffend, als diese interglazialen Sedimente zuerst und bisher überwiegend im Landkreis Kempen-Krefeld nachgewiesen wurden.

Im Verlauf der vorliegenden Arbeit werden, um an bisherige Untersuchungen anknüpfen zu können, häufig noch die Bezeichnungen „Krefelder Schichten“ und „Kempener Schichten " im Sinne von A. STEEgER $(1931 \mathrm{~b}, 1952)$ benutzt; diese und andere Schichtenbezeichnungen von A. STEEgER werden jedoch in Anführungszeichen gesetzt, weil sie mit dem jetzigen Forschungsstand nicht mehr vereinbar sind.

Auf Grund der Lagerungsverhältnisse können die interglazialen Sedimente von Schacht Tönisberg in drei Profilbereiche untergliedert werden: auf $8,7 \mathrm{~m}$ „Krefelder Schichten " in situ lagern $9 \mathrm{~m}$ aufgeschobene, in sich gestörte und $5 \mathrm{~m}$ aufgeschobene, in sich ungestörte „Krefelder Schichten“. Die große Mächtigkeit der interglazialen Ablagerungen ist also nicht auf eine entsprechende Sedimentation zurückzuführen, sondern auf die stauchende Wirkung des Inlandeises.

Als „Krefelder Schichten“ bezeichnete A. STEEgER (1931b, 1952) fossilführende Tonund Feinsandschichten, die sich in gestörter Lagerung oder als isolierte Schollen in den Stauchendmoränen zwischen Krefeld und Kleve fanden. Beim Abteufen von Schacht Tönisberg wurden „Krefelder Schichten“ erstmals in ungestörter Lagerung aufgeschlossen, also in situ. Läßt man die „Kempener Schichten“ außer Betracht, so ist zunächst die von A. STEEgER gegebene Definition der „Krefelder Schichten“ auch auf ungestörte Interglazialablagerungen unter den Stauchendmoränen auszudehnen.

Das holstein-zeitliche Alter des Interglazials ist stratigraphisch gesichert. Die Abgrenzung gegenüber jüngeren Interglazialablagerungen ist dadurch gegeben, daß die interglazialen Sedimente mitsamt der auflagernden Unteren Mittelterrasse vom saale-zeitlichen Inlandeis gestaucht worden sind. Gegenüber älteren Interglazialablagerungen wird die Grenze dadurch gezogen, daß sich im Liegenden der interglazialen Sedimente die Ablagerungen einer Mittelterrasse (Mittlere Mittelterrasse, Rinnenschotter) finden. 


\section{A. „Krefelder Schichten“"in situ (vgl. Abb. 2: KKS 1)}

Als „Krefelder Schichten“ in situ werden die horizontal lagernden Schichten von $40 \mathrm{~m}$ bis $31,3 \mathrm{~m}$ Teufe bezeichnet. Von unten nach oben ist in der Schichtenfolge eine Abnahme der Korngröße zu beobachten. Folgende 4 Profilabschnitte können unterschieden werden:

$$
\text { Profilabschnitt A: 40,0-38,0 m Teufe }
$$

Von diesem Abschnitt wurden 4 Proben auf ihre Kornverteilung untersucht. Der Mittelwert ergab: Grobsand und Mittelsand mit wenig Feinkies und wenig Mittelkies. Der Kies bildete feine Lagen im Sand. Das Sediment ist hellgrau gefärbt. Wie in den tiefen Horizonten der Mittleren Mittelterrasse finden sich auch in diesem Profilabschnitt Fossilien aus aufgearbeitetem marinem Oberoligozän; sie erreichen allerdings nicht die Arten- und Individuenzahl wie in den Schichten nahe der Pleistozän-Basis. Neben diesen eindeutig umgelagerten Fossilien treten die ersten Süßwasser-Mollusken auf. Im Bereich 39,0 bis 38,5 m waren Reste einer vertikalen Durchwurzelung der Schichten zu beobachten.

$$
\text { Profilabschnitt B: } 38,0-34,7 \mathrm{~m} \mathrm{Teufe}
$$

Der Mittelwert von 5, Korngrößenanalysen ergab für diesen Abschnitt: Mittelsand und Feinsand mit etwas Grobsand. Das Sediment ist kalkhaltig und von graublauer Farbe. Aus diesem Bereich stammen die meisten Süßwasser-Mollusken. Doppelklappige Exemplare von Unio fanden sich in einer Bank angereichert. Auch Pflanzenreste kamen in diesem Abschnitt reichlich vor, besonders die Reste von Alnus.

$$
\text { Profilabschnitt C: } 34,7-34,0 \mathrm{~m} \mathrm{Teufe}
$$

Die Korngrößenanalyse ergab für diesen Bereich: Feinsand vorwiegend, mit etwas Mittelsand und etwas Schluff. Auch dieses Sediment ist kalkhaltig, von graublauer Farbe und fossilführend. In einer Schicht fanden sich reichlich Blattreste, die nicht eindeutig bestimmt wurden, mit großer Wahrscheinlichkeit aber der Gattung Alnus zuzuorden sind, weil sich auch die Nüßchen dieser Gattung in diesem Profilabschnitt sehr zahlreich fanden.

$$
\text { Profilabschnitt D: } 34,0-31,3 \mathrm{~m} \text { Teufe }
$$

Dieser Profilabschnitt besteht im wesentlichen aus Kalkgyttja von hellgrauer bis graublauer Farbe. In der oberen Hälfte finden sich drei 10 bis $20 \mathrm{~cm}$ mächtige Lagen von tonigem Torf. Die mittlere Lage ist so stark inkohlt, daß man sie beinahe als tonige Braunkohle bezeichnen könnte. Von 34 bis $33 \mathrm{~m}$ und von 32 bis $31,5 \mathrm{~m}$ Teufe ist die Kalkgyttja sandstreifig. Alle Proben des Profilabschnitts D sind fossilführend.

Der Ubbergang von den Sedimenten der Mittleren Mittelterrasse zu den Ablagerungen des Holstein-Interglazials erfolgt allmählich; die Grenze zwischen den beiden Einheiten ist nicht scharf und daher nicht eindeutig zu fassen. Auf jeden Fall liegt diese in Schacht Tönisberg im Teufenbereich 38 bis $40 \mathrm{~m}$, also im vorstehend beschriebenen Profilabschnitt A. Dessen stratigraphische Stellung ist somit etwas unsicher. Er wurde zum Interglazial gerechnet, weil in diesem Abschnitt erstmals interglaziale Süßwasser-Mollusken auftreten. Für eine Zuordnung zur Mittleren Mittelterrasse würde die Tatsache sprechen, daß sich in diesem Abschnitt nochmals Fossilien aus aufgearbeitetem marinem Oberoligozän vorfinden. Ihre Arten- und Individuenzahl ist zwar nicht so groß wie in den tiefen Horizonten der Rinnenschotter, auch ist das Sediment feinkörniger, doch besteht hier immerhin eine gewisse Übereinstimmung.

$\mathrm{Da}$ die Profilabschnitte $\mathrm{A}$ bis $\mathrm{D}$ nur Schichten in horizontaler Lagerung umfassen und Störungen irgendwelcher Art nicht nachgewiesen werden konnten, wurde dieser Profilbereich als "Krefelder Schichten" in situ bezeichnet. Daß diese sich im Untergrund der Stauchmoränenwälle finden, deutet darauf hin, daß für die Schuppen und Schollen von „Krefelder Schichten“ in den Stauchmoränen nur sehr geringe Transportweiten angenommen werden können.

\section{B. Aufgeschobene, in sich gestörte "Krefelder Schichten“}

(vgl. Abb. 2: KKS 2)

Über den "Krefelder Schichten“ in situ folgt von 31,3 bis $22,0 \mathrm{~m}$ Teufe ein Bereich, in dem sich interglaziale Sedimente in stark gestörter Lagerung vorfinden. Die Sedimente bestehen in der Hauptsache aus Kalkgyttja. Darin eingeschaltet findet sich eine Feinsand- 
bank, die bis $1 \mathrm{~m}$ mächtig sein kann. In der Kalkgyttja kommt Feinsand außerdem mehrfach in Form dünner Lagen und Linsen vor. Im oberen Teil des Profilbereichs treten auch einige Torflagen auf, die aber jeweils nur wenige $\mathrm{cm}$ Mächtigkeit erreichen.

Im Normalprofil können von oben nach unten folgende Schichten unterschieden werden:

$22,0-27,75 \mathrm{~m}$ Kalkgyttja mit dünnen Torf- und Feinsandlagen,

27,75-28,75 $\mathrm{m}$ Feinsand mit dünnen Tonlagen,

28,75-30,9 m Kalkgyttja,

30,9 -31,2 m Kalkgyttja mit Feinsandlinsen und -lagen,

31,2 -31,3 $\mathrm{m}$ sandstreifige Kalkgyttja mit ausgewalzten Unio-Klappen.

Die Lagerungsverhältnisse sind sehr unterschiedlich. Die tiefsten Schichten von 30,9 bis $31,3 \mathrm{~m}$ Teufe zeigen ein schwaches Einfallen von 5 bis $10^{\circ} \mathrm{NE}$. In der darüberfolgenden Kalkgyttja steigt das Einfallen bis auf $20^{\circ} \mathrm{NE}$ an. Mit der mächtigeren Feinsandeinschaltung tritt alsdann eine Verfaltung der Schichten auf. Die Feinsandbank zeigt nur wenige Falten, bei denen der Abstand zwischen den Faltenachsen 1 bis $3 \mathrm{~m}$ beträgt. In der darüberlagernden Kalkgyttja findet sich dagegen eine Spezialfältelung im Dezimeterund Zentimeterbereich. Flachgepreßte Holzstücke, die sich in der Kalkgyttja häufig auf Schichtflächen finden, haben diese Fältelung mitgemacht. Die Faltenachsen weisen im Mittelwert ein Streichen von $125^{\circ}$ auf. Höhere Teile der Kalkgyttja zeigen keine Faltenbilder mehr, sondern nur noch ein Einfallen der Schichten von 60 bis $30^{\circ}$ NE. Spitzwinklig abgeschnittene, steiler einfallende Schichten deuten darauf hin, daß in diesem Bereich Überschiebungen stattgefunden haben. Darauf weisen auch Rutschstreifen hin, die in diesem Abschnitt mehrfach zu beobachten waren. In sich sind die Schichten außerdem sehr stark verschuppt und verwürgt, so daß sie häufig nur einige Dezimeter weit verfolgt werden konnten.

Im gesamten Profilbereich zeigen Schichten und Faltenachsen ein generelles Streichen um $125^{\circ}$. Berücksichtigt man ferner das Einfallen der Schichten, so ist der vom Inlandeis bewirkte Druck hauptsächlich aus nordöstlicher Richtung herzuleiten. Auf diese Druckrichtung weist auch die Morphologie des Schaephuysener Höhenzuges im Bereich von Schacht Tönisberg hin (vgl. Abb. 1).

Die Kalkgyttja lieferte in reichem Maße pflanzliche und tierische Fossilien; ebenso die eingeschalteten tonigen Torfe. Die Feinsande waren dagegen fossilleer, obgleich sie in ihrem Aussehen den fossilführenden Sanden der "Krefelder Schichten “ in situ weitgehend entsprachen.

Die aufgeschobenen, in sich gestörten „Krefelder Schichten “ werden überlagert und damit abgegrenzt gegen den darüber folgenden Profilbereich (K K S 3) durch eine im Durchschnitt $25 \mathrm{~cm}$ mächtige Grobsandbank. Der Grobsand ist bräunlich gefärbt und entspricht damit den Hangenden Kiesen und Sanden von Schacht Tönisberg, die der Unteren Mittelterrasse zuzuordnen sind. Die Grobsandbank ist in der Schachtmitte flexurartig gebogen, so daß sich ein Einfallen ergibt, welches zwar überwiegend bei $30^{\circ} \mathrm{NE}$ liegt, stellenweise aber bis zu $80^{\circ} \mathrm{NE}$ erreichen kann. Im Bereich der Flexur konnten an einigen Stellen steil einfallende Abscherungsflächen beobachtet werden, die mit tonigem Material belegt sind und im Profil Grobsand scharf von Grobsand trennen. Abgescherte Grobsandschollen endigen stumpf in der hangenden Kalkgyttja. In der NW-SE-Richtung konnte in der Grobsandbank eine Bruchschollentektonik im Kleinen beobachtet werden. Die Verwerfungsflächen waren nicht mit Tonmaterial belegt; sie grenzten die einzelnen Schollen scharf gegeneinander ab. Alle Erscheinungen deuten darauf hin, daß bei der Aufschiebung des darüber folgenden Profilbereichs (K K S 3) die Grobsandbank im gefrorenen Zustand durch Druck stark beansprucht worden ist. 
C. Aufgeschobene, in sich ungestörte "Krefelder Schichten“ (vgl. Abb. 2: KKS 3)

Dieser höchste Profilbereich der „Krefelder Schichten“ von 22 bis durchschnittlich $17 \mathrm{~m}$ Teufe ist eindeutig als Ganzes aufgeschoben worden.

Im Normalprofil können von oben nach unten folgende Ablagerungen unterschieden werden:

$$
\text { von } \begin{array}{rll}
16,75 \text { bzw. } & 17,0-17,6 \mathrm{~m} & \text { Kalkgyttja, } \\
17,6-18,05 \mathrm{~m} & \text { toniger Torf, } \\
18,05-20,15 \mathrm{~m} & \text { Kalkgyttja, } \\
& 20,15-20,45 \mathrm{~m} & \text { Feinsand, } \\
20,45-22,0 \mathrm{~m} & \text { Kalkgytja. }
\end{array}
$$

Die Oberfläche des Profilbereiches ist unregelmäßig. Die Kalkgyttja ist an und nahe der Oberfläche infolge Oxydation verändert. Sie zeigt Braunfärbung, geringeren Kalkgehalt und weitgehende Zersetzung des Fossilinhaltes. Ansonsten gleichen die Sedimente den bisher beschriebenen. Mit Ausnahme des Feinsandes sind alle übrigen Ablagerungen reich an Fossilien. Horizontierte Proben wurden von diesem Profilbereich in lückenloser Folge entnommen. Die Mehrzahl davon wurde u. a. auch pollenanalytisch untersucht (vgl. Kap. IV. 2. B.).

Die Schichten fallen bei einem Streichen von 140 bis $170^{\circ}$ mit 25 bis $30^{\circ} \mathrm{NE}$ ein. Rutschstreifen, die gelegentlich auf Schichtflächen beobachtet wurden, deuten darauf hin, daß mit einigen schichtparallelen Gleitungen gerechnet werden muß. Andere Störungen waren in diesem Profilbereich nicht nachzuweisen, so daß die Schichtenfolge als ursprüngliche Sedimentationsfolge angesehen werden kann.

Mit Ausnahme des Feinsandes sind alle übrigen Schichten wasserstauend. Als Sohlschicht verursachen sie einen zweiten, oberen Grundwasserhorizont. Dieses oberflächennahe Grundwasser hat im Bereich des Schaephusener Höhenzuges zwar nur die östliche Hälfte als Einzugsgebiet. Da die Sohlschicht stark geneigt ist und von grobkörnigem Material überlagert wird, können sich jedoch - besonders in niederschlagsreichen Jahren - starke Wasserbewegungen ergeben. Diese Tatsache war z. B. beim Abteufen von Schacht Tönisberg ein großes Hindernis.

\section{Hangende Kiese und Sande (Untere Mittelterrasse)}

Dieser Profilbereich von Schacht Tönisberg erstreckt sich von etwa $17 \mathrm{~m}$ bis $1,05 \mathrm{~m}$ Teufe; er war nahezu abgeteuft, als dem Verfasser die vorliegende Arbeit übertragen wurde.

Das Profil wurde ohne Probenentnahme durch Herrn Vermessungssteiger G. HENnig von der Markscheiderei der N.B.A.G. aufgenommen, wobei er von oben nach unten folgende Schichten unterschieden hat:
$1,05-1,15 \mathrm{~m}$ Kies,
$1,15-3,25 \mathrm{~m}$ sandiger Lehm,
$3,25-4,10 \mathrm{~m}$ unsauberer Grobkies,
4,10-11,30 m ungleichmäßige Lagerung von unsauberen lehmigen Sanden und Kiesen, teilweise mit grünblauem Ton in Linsen und Lagen von
$11,30-12,40 \mathrm{~m}$ gelbbraunem Fein- und Mittelsand,
$12,40-12,60 \mathrm{~m}$ gelbbrauner Feinsand,
$12,60-13,65 \mathrm{~m}$
$13,65-14,45 \mathrm{~m}$
schwarzblauer sandiger Ton,
blaugrauer Ton mit unreinen gelben Tonbändern,
$14,45-17,00 \mathrm{~m}$
gelbbrauner Feinsand mit Feinkieslagen,
Fein- und Mittelkies, der in gelbbraunen Mittel- und Grobsand mit Linsen von graublauem Ton übergeht. 
Die Schichten der Hangenden Kiese und Sande sind durch die stauchende Wirkung des saale-zeitlichen Inlandeises (Drenthe-Vorstoß) in ihrer Lagerung gestört. Wie andere Aufschlüsse in der Umgebung von Schacht Tönisberg zeigen, kann sich die Schichtenfolge in diesem Profilbereich auf kurze Entfernung sehr stark ändern. Eine detaillierte Profilbeschreibung ist daher nur dort sinnvoll, wo sich diese Ablagerungen im ungestörten Schichtenverband vorfinden.

Die Sedimente der Hangenden Kiese und Sande sind durch Kiesgruben an den Rändern der Stauchmoränenwälle und Inselberge bereits häufig aufgeschlossen worden. Auf Grund der bisherigen Untersuchungen (Geröllbestand, Gehalt an Schwermineralien) werden diese Sedimente als Ablagerungen der Unteren Mittelterrasse angesehen.

Im Profil von Schacht Tönisberg unterscheiden sich die Hangenden Kiese und Sande (Untere Mittelterrasse) von den Liegenden Kiesen und Sanden (Mittlere Mittelterrasse) durch folgende Merkmale:

die Sedimente sind überwiegend bräunlich gefärbt, der Quarzanteil der Fraktion > 6 mm liegt im Mittelwert bei 40\%, eine sekundäre Fossilführung ist nicht vorhanden, in den obersten Schichten finden sich nordische Geschiebe.

In dem aus Schacht Tönisberg und den Aufschlüssen der näheren Umgebung stammenden Material der Unteren Mittelterrasse fanden sich als einwandfreie nordische Geschiebe nur solche von Rapakiwi-Granit, deren größtes etwa 40 x $60 \mathrm{~cm}$ maß.

Bemerkenswert ist noch, daß sich in den Hangenden Kiesen und Sanden zwei große Blöcke fanden, die aus dem Gebiet südlich des jetzigen Fundorts stammen: ein Braunkohlenquarzitblock von $60 \times 100 \mathrm{~cm}$ Größe und ein Block von $120 \times 140 \mathrm{~cm}$ Größe, der aus sandigem Tonschiefer bestand.

Uberlagert werden die Ablagerungen der Unteren Mittelterrasse in Schacht Tönisberg von einem etwa $100 \mathrm{~cm}$ mächtigen Löß. Dieser Löß ist auf größere Erstreckung zu verfolgen. Seine Mächtigkeit ist allerdings sehr unterschiedlich; sie schwankt zwischen 30 und $300 \mathrm{~cm}$. Da die geringsten Mächtigkeiten auf den kleinen Erhebungen des Schaephuysener Höhenzuges, die größten Mächtigkeiten dagegen an seinen Flanken zu beobachten sind, ist es sehr wahrscheinlich, daß ein Teil des ursprünglich sedimentierten Lößmaterials als Schwemmlöß die Hohlformen zusedimentiert hat, welche sich an den Flanken des Höhenzuges befanden.

\section{Die sekundäre Fossilführung der Mittleren Mittelterrasse}

Bereits bei der Probenentnahme konnte in mehreren Schichtgliedern der Liegenden Kiese und Sande eine Fossilführung erkannt werden. Es handelte sich in allen Fällen um umgelagerte Fossilien auf sekundärer Lagerstätte.

Um diese Fossilführung genauer kennenzulernen, wurde von allen Proben aus diesem Profilbereich zunächst die Fraktion $>6 \mathrm{~mm}$ ausgelesen. Die umfangreicheren Fraktionen 6-2 $\mathrm{mm}$ und 2-0,6 $\mathrm{mm}$ wurden dann mit Hilfe von Tetrachlorkohlenstoff in eine leichte und eine schwere Fraktion zerlegt. Davon wurde die leichte Fraktion ausgelesen; bei der schweren Fraktion wurde jeweils nur noch eine Stichprobe auf Fossilführung gemacht.

Das Ergebnis dieser Untersuchungen ist, daß sich die sekundäre Fossilführung aus drei verschiedenen Komponenten zusammensetzt: 1. Fossilien aus marinem Tertiär, 2. Fossilien aus limnisch-terrestrischem Tertiär und 3. Fossilien aus limnisch-terrestrischem Pleistozän. Die einzelnen Komponenten werden nachfolgend ausführlich besprochen.

\section{Fossilien aus marinem Tertiär}

Der überwiegende Teil der sekundären Fossilführung besteht aus Resten einer marinen Tertiär-Fauna. Sie fand sich vor allem in den Profilabschnitten 1 und 2; aber auch in den Abschnitten 3, 5 und 6 kamen solche Fossilien noch vor. Die Erhaltung ist nicht besonders 
gut. Zu einem großen Teil fanden sich nur Schalenbruchstücke, die außerdem mehr oder weniger starke Spuren von Abrollung sowie kreidige Verwitterung zeigten. Trotzdem waren die Reste aber noch so charakteristisch, daß eine große Zahl von Arten eindeutig bestimmt werden konnte (vgl. Tabelle 4).

$$
\text { Tabe } 11 \text { e } 4
$$

Fossilien aus marinem Tertiär, welche in den Sedimenten der Mittleren Mittelterrasse von Schacht Tönisberg auf sekundärer Lagerstätte gefunden wurden (unter Profilabschnitt 1 ist hier vor allem der Kiesanteil zu verstehen).

\begin{tabular}{|c|c|c|c|c|c|c|}
\hline \multirow[t]{2}{*}{ Fossilien } & \multicolumn{5}{|c|}{$\begin{array}{l}\text { Profilabschnitt der Mittleren } \\
\text { Mittelterrasse }\end{array}$} & \multirow{2}{*}{$\begin{array}{c}\text { Zahl } \\
\text { der } \\
\text { Exemplare }\end{array}$} \\
\hline & 1 & 2 & 3 & 5 & 6 & \\
\hline $\begin{array}{l}\text { L a m e } 11 \text { i b r a n c h i a t e n : } \\
\text { Nucula sp. } \\
\text { Nuculana westendorpi (NYST) } \\
\text { Yoldia glaberrima (v. MüNSTER) } \\
\text { Anadara diluvii speyeri (SEMPER) } \\
\text { Glycimeris philippii (DESHAYES) } \\
\text { Limopsis cf. aurita (BROCCHI) } \\
\text { Chlamys ambigna (PHILIPPI) } \\
\text { Chlamys sp. } \\
\text { Pecten sp. } \\
\text { Palliolum sp. } \\
\text { Astarte concentrica GOLDFUSS } \\
\text { Astarte koeneni SPEYER } \\
\text { Astarte pygmaea (v. MÜNSTER) } \\
\text { Cardita orbicularis (SOWERBY) } \\
\text { Cyprina rotundata AGASSIZ } \\
\text { Phacoides borealis (LINNE) } \\
\text { Cavilucina schloenbachi (v. KOENEN) } \\
\text { Laevicardium cingulatum (GOLDFUSS) } \\
\text { Cardium kochi SEMPER } \\
\text { Panopea sp. } \\
\text { Varicorbula gibba (OLIVI) } \\
\text { Holz mit Bohrgängen von Teredo }\end{array}$ & $\begin{array}{l}\times \\
\times \\
\times \\
\times \\
\times \\
\times \\
\times\end{array}$ & 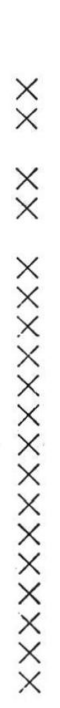 & $\begin{array}{l}x \\
x\end{array}$ & & & $\begin{array}{r}2 \\
2 \\
2 \\
1 \\
4 \\
7 \\
2 \\
15 \\
3 \\
1 \\
5 \\
1 \\
1 \\
3 \\
2 \\
3 \\
1 \\
3 \\
1 \\
1 \\
16 \\
1\end{array}$ \\
\hline $\begin{array}{l}\text { S c a p h o p o d e } \mathrm{n}: \\
\text { Dentalium kickxi Nyst } \\
\text { Dentalium polypleurum SEIFERT }\end{array}$ & $\stackrel{x}{x}$ & $\begin{array}{l}x \\
x\end{array}$ & $x$ & & & $\begin{array}{r}20 \\
4\end{array}$ \\
\hline $\begin{array}{l}\text { Ve r m e s: } \\
\text { Ditrupa incurva RENIER }\end{array}$ & & $x$ & & & & 2 \\
\hline $\begin{array}{l}\text { Ga st ro pod e } \mathrm{n}: \\
\text { Haustator geinitzi (SPEYER) } \\
\text { Ecphora cf. koeneni Goerges }\end{array}$ & $\stackrel{x}{x}$ & $x$ & & & & $\begin{array}{r}20 \\
1\end{array}$ \\
\hline $\begin{array}{l}\text { Crust a c e en : } \\
\text { Balanus stellaris BronN } \\
\text { Ostrakoden }\end{array}$ & $\stackrel{x}{x}$ & $x$ & $x$ & $\begin{array}{l}x \\
x\end{array}$ & $x$ & $\begin{array}{r}14 \\
4\end{array}$ \\
\hline $\begin{array}{l}\text { Co el e n t e r a t e n : } \\
\text { Caryophyllia granulata v. MüNSTER }\end{array}$ & $x$ & $x$ & & & & 3 \\
\hline $\begin{array}{l}\text { F o r a m in if e r e } \mathrm{n}: \\
\text { u. a.: Elphidium subnodosum (v. MüNSTER) } \\
\text { Palmula oblonga (v. MüNSTER) } \\
\text { Frondicularia cuneata (v. MüNSTER) } \\
\text { Lenticulina arcuata (PHILIPPI) } \\
\text { Lenticulina gladia (PHILIPI) }\end{array}$ & $x$ & $\begin{array}{l}x \\
x \\
x\end{array}$ & $\begin{array}{l}x \\
\stackrel{x}{x} \\
x \\
\stackrel{x}{x} \\
x\end{array}$ & $\begin{array}{l}x \\
x \\
x\end{array}$ & $\begin{array}{l}x \\
x\end{array}$ & $\begin{array}{r}100 \\
34 \\
4 \\
1 \\
5 \\
1\end{array}$ \\
\hline Otolithen: & & $x$ & & & & 2 \\
\hline
\end{tabular}


Im wesentlichen handelt es sich bei diesen Fossilien um Lamellibranchiaten. Daneben kommen in geringerer Arten- und Individuenzahl auch Vermes, Gastropoden, Scaphopoden, Crustaceen, Coelenteraten, Foraminiferen und Otolithen vor. Mit Ausnahme von Ecphora cf. koeneni Goerges 1952 konnten alle gefundenen Arten auch im Liegenden der Mittleren Mittelterrasse in den oberoligozänen Meeressanden von Schacht Tönisberg auf primärer Lagerstätte nachgewiesen werden. Bei Ecphora koeneni handelt es sich ebenfalls um eine oberoligozäne Art; weil diese im vorliegenden Fall aber nicht eindeutig bestimmt werden konnte, für die Bestimmung hingegen auch eine miozäne Art in Betracht kommt, wurde sie vorstehend besonders erwähnt. Die sicher bestimmten Arten lassen jedenfalls den Schluß zu, daß ausschließlich marines Oberoligozän aufgearbeitet wurde. Das Vorkommen von Chlamys ambigna (PhILIPPI) weist nach H.-J. ANDERson (1958) auf OberEochatt hin.

Es ist demnach anzunehmen, daß sich die primäre Lagerstätte der marinen TertiärFauna nicht weit von ihrem jetzigen Fundort befand. Bei der Tiefenerosion des Rheins zur Zeit der Mittleren Mittelterrasse wurden die obersten Schichten des Untergrundes, der aus marinen Meeressanden des Tertiärs besteht, aufgearbeitet. Die darin enthaltenen Fossilien wurden einige $100 \mathrm{~m}$ bis wenige $\mathrm{km}$ weit transportiert und kamen dann in den Sedimenten der Mittleren Mittelterrasse zur Ablagerung.

Andere Vorkommen im Niederrheingebiet mit einer gleichartigen, teilweise noch reichhaltigeren sekundären Fossilführung wurden bereits von E. KöNIGS (1893/94, 1895) und A. StEeger (1913a) bekanntgemacht. Diese und einige weitere Vorkommen, welche in neuerer Zeit durch Bohrungen erschlossen wurden, finden in Kapitel III. 4. eine eingehende Besprechung.

\section{Fossilien aus limnisch-terrestrischem Tertiär}

Pflanzenreste fanden sich mit einigen Lücken im ganzen Profilbereich der Mittleren Mittelterrasse. Ihr Vorkommen richtete sich im Gegensatz zu den marinen Tertiärfossilien, die zum größten Teil in den Kiesbänken vorkamen, nach dem Vorherrschen der sandigen Sedimentkomponente. Besonders angereichert kamen sie in den Profilabschnitten 4 und 7 vor. In den meisten Fällen handelte es sich um Pflanzenreste, die auf Schicht- oder Schrägschichtungsflächen (vgl. E. K. KEMPF 1963: Taf. 3, Fig. 1) zusammengeschwemmt worden sind, wo sie Linsen von wenigen $\mathrm{cm}$ Mächtigkeit und einigen dm Erstreckung bilden. In einem Fall war auch eine kleine Erosionsrinne in der Oberfläche einer Kiesbank mit Sand und Pflanzenresten zusedimentiert worden. Jedenfalls befinden sich die Pflanzenreste immer eindeutig auf sekundärer Lagerstätte.

Besonders auffällig waren bereits bei der Profilaufnahme im Schacht die vielen Gerölle von stark inkohltem Holz und von Braunkohle, so daß alle eingeschwemmten Pflanzenreste zunächst als aufgearbeitetes Braunkohlentertiär angesehen wurden. Die genaueren Untersuchungen ergaben jedoch, daß neben sicheren Resten aus dem Braunkohlentertiär ebenso sichere Reste aus interglazialen Pleistozän-Ablagerungen unter den Pflanzenfossilien zu finden waren.

Als Reste aus aufgearbeitetem Braunkohlentertiär sind vor allem die zahlreichen Gerölle von Lignit, Metalignit und Braunkohle anzusehen. Die Bezeichnungen Lignit und Metalignit werden im Sinne von F. KirchHeimer (1937) gebraucht. Als Lignit werden demnach Stücke angesprochen, bei denen im Bruch die Holzstruktur noch gut zu erkennen ist; beim Metalignit weist die Bruchfläche starken Glanz auf und läßt makroskopisch die Holzstruktur nicht mehr erkennen.

Neben diesen Geröllen konnten die Samen folgender Tertiärpflanzen bestimmt werden: Stratiotes kaltennordheimensis (Zenker) KeILHaCk, Stratiotes websteri (Brogniart) Zinndorf, Brasenia victoria (CASPary) Weberbauer. Ferner fanden sich Pilzfruchtkörper von Rosellinites areolatus (Fresenius \& v. Meyer) Kirchheimer. Von den aus pleisto- 
zänen Sedimenten stammenden Pflanzenresten unterscheiden sich die vorstehend angeführten bereits im Aussehen durch die wesentlich stärkere Inkohlung. Eine Übersicht, in welchen Profilabschnitten der Mittleren Mittelterrasse die einzelnen tertiären Pflanzenreste gefunden wurden, ergibt sich aus Tabelle 5.

Tabelle 5

Pflanzenreste aus limnisch-terrestrischem Tertiär, welche in den Sedimenten der Mittleren Mittelterrasse von Schacht Tönisberg auf sekundärer Lagerstätte gefunden wurden.

\begin{tabular}{|c|c|c|c|c|c|c|c|c|}
\hline \multirow[t]{2}{*}{ Pflanzenreste } & \multicolumn{7}{|c|}{$\begin{array}{c}\text { Profilabschnitte der Mittleren } \\
\text { Mittelterrasse }\end{array}$} & \multirow[t]{2}{*}{$\begin{array}{l}\text { Zahl der } \\
\text { Exemplare }\end{array}$} \\
\hline & 1 & 2 & 3 & 4 & 5 & 7 & 8 & \\
\hline $\begin{array}{l}\text { Gerölle von Lignit, Metalignit und Braun- } \\
\text { kohle }\end{array}$ & $x$ & $x$ & $x$ & $x$ & $x$ & $x$ & $x$ & 100 \\
\hline Stratiotes kaltennordheimensis & & & & $x$ & $x$ & & & 2 \\
\hline Stratiotes websteri & & & & & $x$ & $x$ & $x$ & 4 \\
\hline $\begin{array}{l}\text { Stratiotes sp. (Formenkreis: } \\
\quad \text { websteri - kaltennordheimensis) }\end{array}$ & & & & $x$ & $x$ & & $x$ & 12 \\
\hline Brasenia victoria & & & & $x$ & & & & 1 \\
\hline Rosellinites areolatus & & & & & & $x$ & $x$ & 4 \\
\hline
\end{tabular}

Die primäre Lagerstätte der angeführten Pflanzenreste wird man kaum jemals eindeutig ermitteln können. Naheliegend ist natürlich, die Fossilien aus dem Braunkohlentertiär der Niederrheinischen Bucht herzuleiten.

Die Gerölle von Lignit, Metalignit und Braunkohle dürften ursprünglich wohl dem Braunkohlen-Hauptflöz entstammen. Solche Gerölle finden sich auch in den jungtertiären Deckschichten der Braunkohle bereits auf sekundärer Lagerstätte, so daß bei diesen mit einer mehrfachen Umlagerung gerechnet werden muß.

Die Samen von Stratiotes kaltennordheimensis sind im niederrheinischen Braunkohlentertiär noch nicht eindeutig nachgewiesen worden. Zwar kennt man Stratiotes-Samen aus tonigen Einschaltungen nahe der Basis des Hauptflözes, welche als Stratiotes cf. kaltennordheimensis bestimmt wurden (H. Weyland, P. W. Thomson \& H. Manke 1954; P. W. THOMson 1958), doch müssen diese Bestimmungen überprüft werden, um die wirklich vorliegende Art zu ermitteln. Sicher nachgewiesen wurde die Art dagegen im Miozän von Westerburg im Westerwald.

Die Samen von Stratiotes websteri sind bisher aus den Sedimenten der NiederrheinischenBucht nicht bekannt geworden. Sie sind vielleicht aus dem Cyrenen-Mergel des Mainzer Beckens herzuleiten, wo die Art in Westdeutschland bisher ausschließlich nachgewiesen wurde.

Samen von Brasenia wurden in der Niederrheinischen Bucht bisher vom Swisterberg bei Weilerswist (H. Grebe 1955) und von Brunssum (C. \& E. M. REID 1915) beschrieben. Ferner wurde von G. Schultz (1962) aus dem Tagebau Victor bei Zülpich ein Fund von ? Brasenia purpurea Micheaux gemeldet, doch ist bei diesem Samen vorerst nur sicher, daß er von einer Nymphaeacee stammt; mit Brasenia purpurea oder Brasenia victoria ist er keinesfalls identisch. Außerdem kommen die Früchte und Samen, die G. Schultz anführt, selbst schon auf sekundärer Lagerstätte vor, weil sie - ähnlich wie bei den Vorkommen nahe Düren - in Sande eingeschwemmt sind, welche die Braunkohle überlagern. Möglicherweise kann der Same von Brasenia victoria aus Schacht Tönisberg vom Swisterberg bei Weilerswist hergeleitet werden. Es muß allerdings bemerkt werden, daß der vorliegende Same eine wesentlich stärkere Inkohlung zeigt als die von dort bekannten. 
Die Pilzfruchtkörper von Rosellinites areolatus kommen im Tertiär der Niederrheinischen Bucht vor. Sie wurden bisher bei Brunssum (C. \& E. M. REID 1915) und sekundär in den Decksanden der Braunkohle bei Düren (Aufsammlungen des Verfassers) nachgewiesen.

Von den tertiären Pflanzenresten, die in den Sedimenten der Mittleren Mittelterrasse von Schacht Tönisberg gefunden wurden, sind die Samen von Stratiotes kaltennordbeimensis bereits sekundär aus pleistozänen Sedimenten gemeldet worden.

Aus der Niederrheinischen Bucht liegt nur eine Fundmeldung vor. Im Jahr 1931 fand K. Bertsch (K. Bertsch, A. Steeger \& U. Steusloff 1931) in dem Material einer Bohrung bei Neuwerk in einer geringmächtigen Schicht mit Pflanzenresten, die in eine Feinkies-Bank einer Mittelterrasse eingeschaltet war, zwei Samen der Gattung Stratiotes. R. KRÄUSEL bestimmte einen Samen als Stratiotes aloides, den anderen als Stratiotes kaltennordbeimensis. Die Bestimmung des letztgenannten Samens wurde später von

Tabelle 6

Pflanzenreste aus limnisch-terrestrischem Pleistozän, welche in den Sedimenten der Mittleren Mittelterrasse auf sekundärer Lagerstätte gefunden wurden (unter Profilabschnitt 1 ist hier nur der Sandanteil zu verstehen).

\begin{tabular}{|c|c|c|c|c|c|c|c|c|c|c|}
\hline \multirow[t]{2}{*}{$\begin{array}{l}\text { Pflanzen- } \\
\text { arten: }\end{array}$} & \multicolumn{8}{|c|}{$\begin{array}{c}\text { Profilabschnitte der } \\
\text { Mittleren Mittelterrasse }\end{array}$} & \multirow[t]{2}{*}{$\begin{array}{l}\text { Zahl der } \\
\text { Exemplare }\end{array}$} & \multirow[t]{2}{*}{$\begin{array}{l}\text { Gefundene } \\
\text { Pflanzenteile }\end{array}$} \\
\hline & 1 & 2 & 3 & 4 & 5 & 6 & 7 & 8 & & \\
\hline $\begin{array}{c}\text { Campylium stella- } \\
\text { tum (ScHREBER) }\end{array}$ & $x$ & & & $x$ & $x$ & & & $x$ & 40 & Blättchen \\
\hline Ranunculus sp. & & & & & $x$ & & & & 1 & Nüßchen \\
\hline $\begin{array}{l}\text { Ranunculus aquatilis } \\
\text { LINNE }\end{array}$ & & & & $x$ & & & & & 1 & Nüßchen \\
\hline $\begin{array}{l}\text { Ranunculus lingua } \\
\text { LiNNE }\end{array}$ & & & & $x$ & & & & & 1 & Nüßchen \\
\hline $\begin{array}{l}\text { Ranunculus cf. repens } \\
\text { LINNE }\end{array}$ & & & & & & & $x$ & $x$ & 2 & Nüßchen \\
\hline $\begin{array}{l}\text { Ceratophyllum } \\
\text { demersum LiNNE }\end{array}$ & & & & $x$ & & & & $x$ & $\begin{array}{l}1 \\
3\end{array}$ & $\begin{array}{l}\text { Nuß } \\
\text { Blattzähne }\end{array}$ \\
\hline Prunus spinosa LinNe & & & & & & & & $x$ & 1 & Steinkern \\
\hline Trapa natans LINNE & & & & $x$ & & & & & 2 & Dornenspitzen \\
\hline Myriopbyllum sp. & & & & $x$ & & & & $x$ & 2 & Steinkerne \\
\hline Hippuris vulgaris $\mathrm{L}$. & & & & & & & & $x$ & 1 & Nuß \\
\hline Alnus sp. & & & & & & & & $x$ & $\begin{array}{l}3 \\
3\end{array}$ & $\begin{array}{l}\text { Nüßchen } \\
\text { Zapfen- } \\
\text { spindeln }\end{array}$ \\
\hline $\begin{array}{l}\text { Betula pubescens } \\
\text { EHRH. }\end{array}$ & & & & & & & & $x$ & $\begin{array}{r}11 \\
5\end{array}$ & $\begin{array}{l}\text { Nüßchen } \\
\text { Frucht- } \\
\text { schuppen }\end{array}$ \\
\hline Urtica cf. urens L. & & & & & & & & $x$ & 1 & Nüßchen \\
\hline Lycopus europaeus L. & & & & & & & & $x$ & 1 & Teilfrucht \\
\hline $\begin{array}{l}\text { Sagittaria sagittifolia } \\
\text { LINNE }\end{array}$ & & & & & & & & $x$ & 1 & Same \\
\hline $\begin{array}{l}\text { Stratiotes intermedius } \\
\text { (HARTZ) CHANDL. }\end{array}$ & & & & $x$ & & & & $x$ & 2 & Samen \\
\hline Potamogeton sp. & $x$ & & & $x$ & & & $x$ & $x$ & 24 & Steinkerne \\
\hline $\begin{array}{l}\text { Potamogeton pusillus } \\
\text { LinNe }\end{array}$ & & & & & & & & $x$ & 1 & Steinkern \\
\hline Scirpus lacustris L. & $x$ & $x$ & $x$ & $x$ & $x$ & $x$ & $\times$ & $x$ & 23 & Nüßchen \\
\hline Carex sp. & $x$ & $x$ & & $x$ & & & $x$ & $x$ & 6 & Nüßchen \\
\hline
\end{tabular}


R. KRÄUSEL (1937) revidiert; in Wirklichkeit handelte es sich um einen Samen von Stratiotes intermedius. Diese Fundmeldung erwies sich also als nicht zutreffend.

Zutreffende Fundmeldungen liegen dagegen aus den Niederlanden und aus Dänemark vor. Im Jahr 1942 berichteten F. FlorschüTz \& F. P. JonkER ohne weiteren Kommentar über den Fund einiger Samen von Stratiotes kaltennordbeimensis in der Niederterrasse bei Haarlem. Ein Same wurde abgebildet, wonach die Bestimmung als sicher anzusehen ist. Ebenso eindeutig dürfte der Fund solcher Samen in den pleistozänen Amber-Pine-Beds von Dänemark sein (Valby Bakke bei Kopenhagen), über die N. HARTz (1909) berichtete.

\section{Fossilien aus limnisch-terrestrischem Pleistozän}

Die übrigen Pflanzenreste, in der Mehrzahl Früchte und Samen, entstammen interglazialen Pleistozän-Ablagerungen. Für diese Ansicht spricht neben der geringen Inkohlung der Pflanzenreste auch die artliche Zusammensetzung der Flora, welche aus Tabelle 6 ersichtlich ist.

Mit Ausnahme von Betula pubescens EHRH. fanden sich alle übrigen Pflanzenarten auch in den holstein-interglazialen Sedimenten von Schacht Tönisberg.

Die gefundenen Fossilien geben keinen eindeutigen Hinweis auf die altersmäßige Stellung der pleistozänen Ablagerungen, aus denen sie ursprünglich herzuleiten sind. $\mathrm{Da}$ die Sedimente der Mittleren Mittelterrasse, in denen diese Fossilien sekundär auftreten, von den meisten Autoren in den Endabschnitt der Elster-Kaltzeit eingestuft werden, müßte für die Pflanzenreste eine Herkunft aus prae-holstein-zeitlichen Interglazial-Ablagerungen angenommen werden. Die artliche Zusammensetzung der Flora spricht aber mehr für ein holstein-interglaziales Alter der primären Sedimente. Es ergibt sich hier also ein Hinweis dafür, daß zumindest höhere Teile der Mittleren Mittelterrasse erst im Holstein-Interglazial zur Ablagerung kamen. Für diese Annahme spricht auch der allmähliche Übergang von den Sedimenten der Mittleren Mittelterrasse zu den eindeutig interglazialen Sedimenten, wie er in Schacht Tönisberg zu beobachten war. Gegen eine Einstufung der gesamten Mittleren Mittelterrasse in das Holstein-Interglazial spricht eigentlich nur der Profilabschnitt 6 mit den auflagernden Tonblöcken, für deren Transport EisschollenDrift unter kaltzeitlichen Bedingungen angenommen werden könnte. Allerdings ist es ebensogut möglich, daß ein solcher Block-Transport durch Eisgang während eines extremen Winters im Interglazial erfolgte.

Auf jeden Fall bestehen sehr enge Beziehungen zwischen den Ablagerungen der Mittleren Mittelterrasse und denen des Holstein-Interglazials. Die in den höheren Schichten der Mittleren Mittelterrasse vor allem sekundär auftretenden Pleistozän-Fossilien, von denen einige (z. B. Trapa natans und Stratiotes intermedius) eindeutig interglazialen Charakter besitzen, sprechen dafür, daß im frühen Holstein-Interglazial eine Zeitlang ein Wechsel von Sedimentation und Erosion stattgefunden hat. Ein weiterer Hinweis auf diese Möglichkeiten ergibt sich aus dem Profil der pleistozänen Schichten von Schacht Pattberg 1 bei Repelen (vgl. Kap. III. 4. B.).

\section{Folgerungen auf Grund der sekundären Fossilführung}

\section{A. Zur Verbreitung der Rinnenschotter}

Die erodierende Tätigkeit des Rheins erreichte im Niederrheingebiet kurz vor Ablagerung der Rinnenschotter (Mittlere Mittelterrasse) die größte Tiefe. In jüngeren Zeiten wurde dieses tiefe Niveau nicht mehr erreicht, was vielleicht durch tektonische Absenkung des Gebietes begünstigt wurde. Die sekundäre Führung mariner Tertiär- Fossilien, die aus dem Untergrund der näheren Umgebung herzuleiten ist, darf daher in Verbindung mit anderen Eigenschaften (vgl. Kap. II. 1. C.) im Niederrheingebiet nördlich der Terrassenkreuzung als ein charakteristisches Merkmal der Rinnenschotter angesehen werden. 
A. QuaAs (1917), der diese durch E. Königs (1893/94, 1895) und A. Steeger (1913a) bekanntgewordene sekundäre Fossilführung vom Viersener Horst herleitete, warnte davor, die sekundäre Fossilführung als ein leitendes Merkmal zu verwenden, weil weitere mögliche Umlagerungen am Material nicht zu erkennen seien.

Diesen warnenden Ansichten ist zu entgegnen:

1. Die sekundäre Fossilführung entstammt nicht dem Viersener Horst, sondern dem tertiären Untergrund der pleistozänen Sedimente; aus diesem Grund ist für nördlichere Teile des Niederrheingebietes, wo die oberoligozänen Sedimente von marinen Ablagerungen des Miozäns überlagert werden, als sekundäre Fossilführung eine dem marinen Miozän entstammende zu erwarten.

2. Die Ablagerungen der Mittleren Mittelterrasse liegen im Niederrheingebiet nördlich der Terrassen-Kreuzung mit wenigen Ausnahmen so tief, daß sie von jüngeren Erosionen des Rheins nicht wieder erreicht wurden. Die Möglichkeit weiterer Umlagerungen des Materials war daher sehr gering.

3. Eine weitere Umlagerung der sich bereits auf sekundärer Lagerstätte befindlichen Fossilien aus dem marinen Tertiär würde vermutlich zu deren Zerstörung geführt haben; jedenfalls wäre höchstens noch ein vereinzeltes Auftreten solcher Fossilien zu erwarten.

Nachfolgend werden Terrassensedimente des Rheins von mehreren Stellen im Niederrheingebiet als Ablagerungen der Mittleren Mittelterrasse gedeutet, weil sie sekundär Fossilien aus marinem Tertiär führen. Nach Möglichkeit werden außer dieser sekundären Fossilführung auch andere charakteristische Merkmale der Rinnenschotter bei der stratigraphischen Eingliederung solcher Vorkommen hinzugezogen, z. B. die Überlagerung durch das Holstein-Interglazial oder die Lage der Basis des Schichtenverbandes in bezug auf Normalnull, um auf diese Weise eine größtmögliche Sicherheit zu erreichen. Es ergibt sich aus diesen Deutungen, daß die Rinnenschotter in nördlicher Richtung weiter als bisher verfolgt werden können.

Erstmals berichtete E. KöNIGs $(1893 / 94,1895)$ über marine Tertiär-Fossilien auf sekundärer Lagerstätte. Er fand sie nördlich von Krefeld in pleistozänen Kiesen und Sanden des Egelsberges (vgl. Abb. 1), die bis heute keine genaue zeitliche Einstufung erfahren haben. Aus dem reich gesammelten Fossilmaterial, welches zum großen Teil eine ähnliche kreidige Verwitterung wie die Mehrzahl der Exemplare aus Schacht Tönisberg aufwies, konnte E. Lienenklaus (in E. KöNigs 1893/94, 1895) über 100 Arten bestimmen. Mit Ausnahme der mitteloligozänen Leda deshayesiana (Duch.), die wahrscheinlich falsch bestimmt und mit Leda gracilis Deshayes [= Synonym von Nuculana westendorpi (Nyst)] verwechselt wurde, entstammen alle Arten dem marinen Oberoligozän des Untergrundes.

Die Angaben, die E. KöNIGs (1893/94, 1895) über die Lage seiner Fundpunkte gemacht hat, lassen darauf schließen, daß sich die Fundschichten an der Westseite des Egelsberges in einer Höhe zwischen 28,5 und $38,0 \mathrm{~m}$ ü.N.N. befunden haben müssen (vgl. Abb. 3). $\mathrm{Daß}$ es sich trotz dieser relativ hohen Lage um Ablagerungen der Mittleren Mittelterrasse handeln kann, ergibt sich aus dem Nachweis, daß die Tertiäroberfläche im Bereich des Egelsberges mit 24,7 bis $26,5 \mathrm{~m}$ ü.N.N. über $20 \mathrm{~m}$ höher liegt, als es normalerweise im Arbeitsgebiet der Fall ist. Die Rinnenschotter sind hier also mitsamt dem tertiären Untergrund durch Gletscherstauchung oder wahrscheinlicher durch bruchtektonische Vorgänge in eine höhere Lage gebracht worden.

Uber weitere Vorkommen mariner Tertiärfossilien auf sekundärer Lagerstätte berichtete A. Steeger (1913a). Er konnte sie an folgenden Stellen der Niederrheinischen Bucht nachweisen (vgl. Abb. 1): im unteren Bereich der „Hauptterrasse“ des Hülser Berges in der südlichen Carstanjenschen Kiesgrube, am Nordende des Schaephuysener Höhenzuges in der Kiesgrube südlich vom Oermter Berg, am Niersenberg, am Monreberg bei Kalkar 


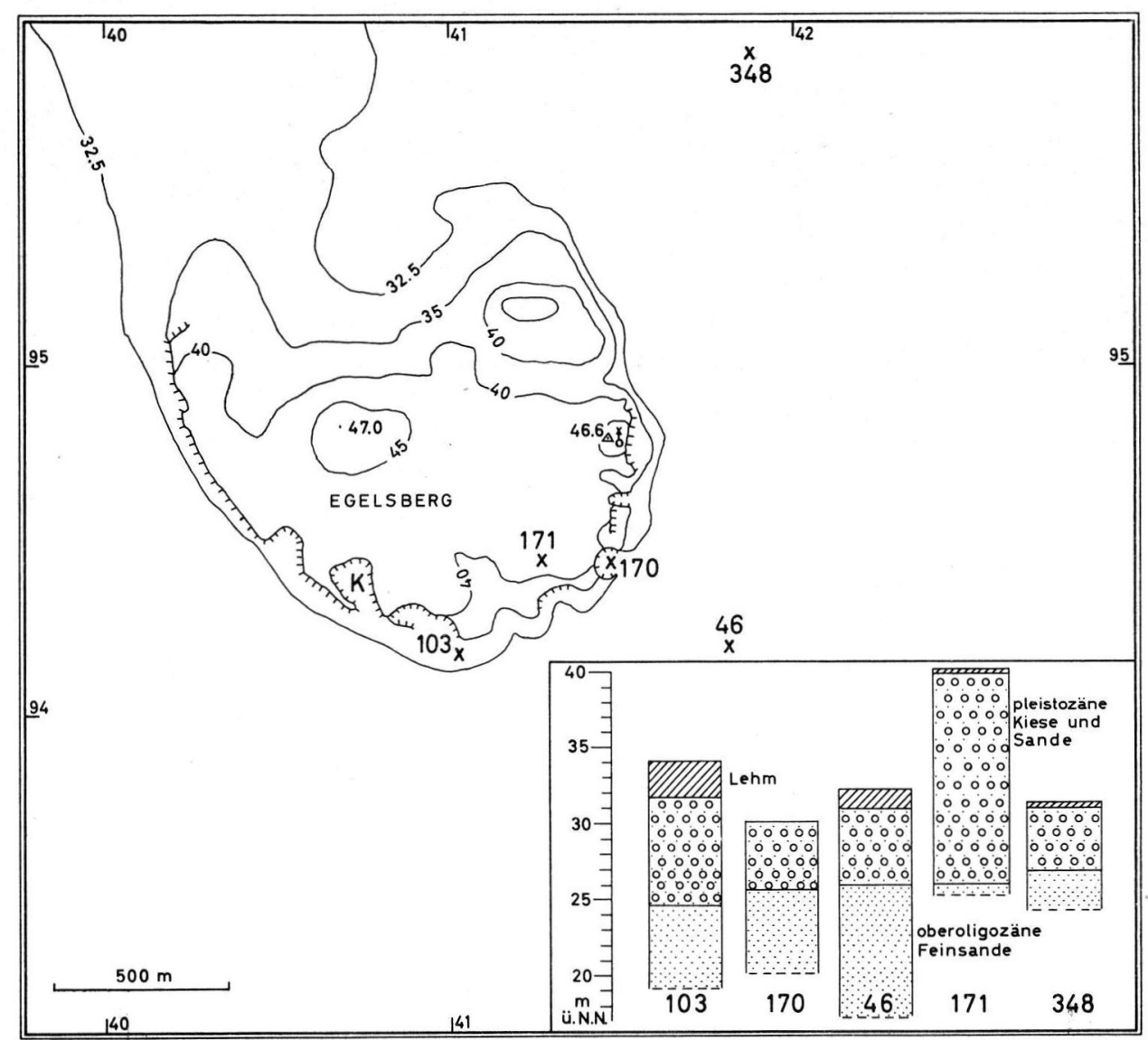

Abb. 3. Der Egelsberg bei Krefeld und Bohrprofile aus seiner Umgebung. $\mathrm{K}=$ vermutliche Fundstelle von E. KöNigs, x $170=$ Lage und Nummer der Bohrung.

(= Kalkarberg ?) und am Westrande der Bönninghardt. Am Oermter Berg, Niersenberg und Monreberg kamen die Fossilien in stark gestörten Schichten vor, so daß eine Abgrenzung gegen die übrigen Schichten nicht möglich war. Am Hülser Berg und an der Bönninghardt dagegen konnte eindeutig festgestellt werden, daß die sekundäre Fossilführung den liegenden, hellen, quarzreichen Kiesen eigen ist, wogegen darüber ein bräunlicher, verlehmter, fossilfreier Kies liegt.

A. STEEger konnte zunächst also nachweisen, daß ebensolche Ablagerungen wie die vom Egelsberg auch weiter nördlich vorkommen. Er schloß daraus, daß es sich bei den Ablagerungen vom Egelsberg nicht um eine Einzelerscheinung handele, sondern vielmehr um einen Erosionsrest eines ehemals weit verbreiteten zusammenhängenden Rheinschotters, der sich am Aufbau der Inselberge nicht unwesentlich beteiligte. Wie das PleistozänProfil von Schacht Tönisberg zeigt, entsprechen die liegenden, hellen, quarzreichen Kiese den Ablagerungen der Mittleren Mittelterrasse.

Im Jahr 1927 beschrieb A. STEeger (1927b) die pleistozänen Schichten aus dem Pattberg-Schacht 1, der bei Repelen, nordwestlich von Moers, abgeteuft wurde. In den untersten Abschnitten des Profils konnte ebenfalls eine sekundäre Fossilführung nachgewiesen werden. Uberhaupt zeigt die untere Hälfte des Profils so viel Ähnlichkeit mit dem Profil der Liegenden Kiese und Sande von Schacht Tönisberg, daß an einer Gleichstellung 
dieser beiden Horizonte nicht gezweifelt werden kann. Eine eingehende stratigraphische Umdeutung des Pleistozän-Profils von Pattberg-Schacht 1 bei Repelen erfolgt in Kapitel III. 4. B.

Die Ablagerungen der Mittleren Mittelterrasse konnten auf Grund ihrer tiefen Lage in bezug auf Normalnull und der bezeichnenden sekundären Fossilführung ferner in vielen Bohrungen der letzten Jahrzehnte nachgewiesen werden. Im Bereich der Stadt Krefeld handelt es sich zum Beispiel um die Bohrungen der Punkte R 37497/H 89718 und R 37330/H 90000; zwischen Egelsberg und Hülser Berg um die Bohrung Klied der N.B.A.G. (R 38550/H 94055); im Bereich des Schaephuysener Höhenzuges um die Bohrungen der Punkte R 34600/H 97470, R 35775/H 97870, R 35690/H 98080, R 35410/ $\mathrm{H} 98170$, R 34300/H 00970 und des Punktes R 33180/H 01895. Vorstehend wurden nur Bohrungen erwähnt (Schichtenverzeichnisse im Archiv des Geologischen Landesamtes in Krefeld), die Profile erschlossen haben, welche nach den verschiedensten Merkmalen mit dem Profil der Rinnenschotter aus Schacht Tönisberg übereinstimmten. Die Zahl solcher Bohrungen hätte größer sein können, wenn die Schichtenverzeichnisse von Geologen und nicht von Bohrmeistern aufgestellt worden wären.

Jedenfalls sind die Ablagerungen der Mittleren Mittelterrasse über Krefeld hinaus weiter nördlich bis in die Höhe von Repelen sicher zu verfolgen. Die bisher nachgewiesenen Vorkommen von Sedimenten der Mittleren Mittelterrasse reichen aber noch nicht aus, um eine Verbreitungskarte dieser Ablagerungen zu zeichnen. Es muß deshalb in den kommenden Jahren versucht werden, anhand vorhandener und vor allem zukünftiger Bohrungen die Ausdehnung der Rinnenschotter in ihrer Breite, in südlicher Richtung und besonders, um Anschluß an gleichaltrige Ablagerungen in den Niederlanden zu erhalten, in nördlicher Richtung zu verfolgen.

\section{B. Diezeitliche Einstufung der "Moerser Schichten“}

Als „Moerser Schichten“ wurden von A. STEEgER (1931b) zwei fossilführende Horizonte bezeichnet, die von ihm (1927b) aus dem Pattberg-Schacht 1 bei Repelen beschrieben worden waren. Die stratigraphische Stellung dieser Schichten, die als interglaziale oder interstadiale Ablagerungen angesehen wurden, ist bis heute ungewiß geblieben. Von den meisten Autoren wurden diese Schichten als Eem-Interglazial angesehen. Eine letzte eingehende Diskussion erfuhren diese Ablagerungen durch A. SteEger (1952a).

Wichtig für die zeitliche Einstufung der „Moerser Schichten“ ist vor allem die stratigraphische Stellung der in ihrem Liegenden auftretenden Kiese und Sande. Wie vorstehend bereits erwähnt wurde, stimmen diese Ablagerungen so sehr mit den Liegenden Kiesen und Sanden von Schacht Tönisberg überein, daß sie mit diesen gleichgestellt und als Sedimente der Mittleren Mittelterrasse angesehen werden (vgl. Abb. 2 mit Abb. 4). Die Ubereinstimmung erstreckt sich auf die sekundäre Führung mariner Tertiärfossilien in den untersten Kiesbänken $\left(A_{1}\right.$ und $\left.A_{2}\right)$, auf das Vorkommen von Braunkohlengeröllen und Pflanzenresten in verschiedenen höheren Schichten $\left(B_{1}, B_{2}, U\right.$ und $\left.O\right)$, auf eine Grobkiesbank mit großen Blöcken (zwischen $\mathrm{B}_{2}$ und $\mathrm{C}$ ) und auf die Lage der Basis des Schichtenverbandes in bezug auf Normalnull.

Die „Moerser Schichten“, die aus einem Unteren und einem Oberen Pflanzenlager bestehen, entsprechen demnach den höheren Schichten der Mittleren Mittelterrasse von Schacht Tönisberg, welche die Mehrzahl der umgelagerten pleistozänen Pflanzenreste geliefert haben, und werden diesen gleichgesetzt. Die „Moerser Schichten“ sind also nicht als primäre Interglazial-Ablagerungen anzusehen, sondern als Sande der Mittleren Mittelterrasse, in die interglaziale Pflanzenreste sekundär eingeschwemmt wurden.

Dieses Vorgehen mag zunächst ein wenig befremden. Betrachtet man das PleistozänProfil von Pattberg-Schacht 1 aber etwas genauer (vgl. Abb. 4), so stellt man fest, daß das Untere Pflanzenlager aus einer $100 \mathrm{~cm}$ mächtigen Sandschicht besteht. Ton und Torf, die 


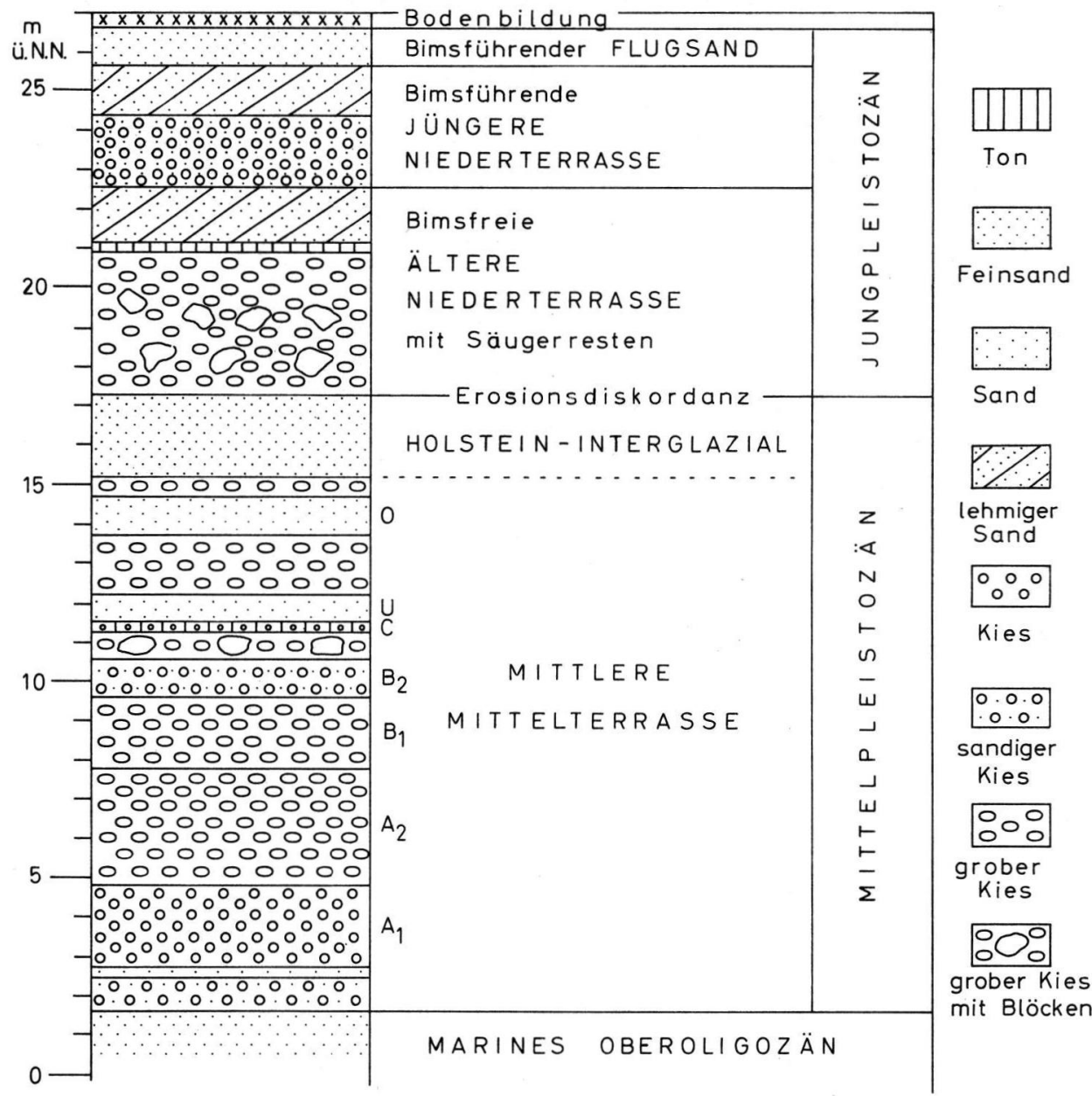

Abb. 4. Das Pleistozän-Profil von Pattberg-Schacht 1 bei Repelen nach den Angaben von A. Steeger (1927b) in neuer Ausdeutung. $A_{1}$ und $A_{2}=$ marine Tertiärfossilien auf sekundärer Lagerstätte; $\mathrm{B}_{1}$ und $\mathrm{B}_{2}=$ Braunkohlengerölle; $\mathrm{C}=$ Kies mit „Mangankruste“; $\mathrm{U}=$ unteres Pflanzenlager; $\mathrm{O}=$ oberes Pflanzenlager.

pollenanalytisch untersucht wurden (K. Bertsch \& A. STEEger 1927), kommen hierin nur als Nester und Schmitzen vor (A. STEEgER 1952a). Die makroskopischen Pflanzenreste sind eingeschwemmt worden (A. STEEger 1952a). Neben der geringen Mächtigkeit der Pflanzenlager spricht also auch der Sedimentcharakter gegen ihre Wertung als primäre interglaziale Ablagerungen.

Die Feinsande, welche im Pattberg-Schacht 1 über den beiden Pflanzenlagern folgen, werden entsprechend den Verhältnissen in Schacht Tönisberg als fluviatile Sedimente des Holstein-Interglazials gewertet. $\mathrm{Daß}$ dies mit großer Wahrscheinlichkeit richtig ist, ergibt sich daraus, daß in dieser Höhenlage im benachbarten Schacht Norddeutschland nach A. STEeger (1952a) eine braunkohlenartige Schicht zwischen Sandschichten aufgefunden wurde, die von K. JESSEN (briefl. Mitteilung in A. STEEgER 1952a) pollenanalytisch untersucht wurde, wobei sich Abies-Anteile bis zu 23\% ergaben, die für das holstein-zeitliche Alter der Ablagerung sprechen. 
Im Profil von Pattberg-Schacht 1 fehlen die tonigen und torfigen Sedimente des Holstein-Interglazials. Diese sind vielleicht mit den auflagernden Schichten der Unteren Mittelterrasse vom saale-zeitlichen Inlandeis abgeschert worden. Statt dessen folgen im Profil mit deutlicher Erosionsdiskordanz Ablagerungen der Niederterrasse, wobei nach A. Steeger (1927b) eine bimsfreie Ältere von einer bimsführenden Jüngeren Niederterrasse zu unterscheiden ist.

\section{Die Fossilführung der interglazialen Ablagerungen}

Auf Grund der bisherigen Untersuchungen, die im Arbeitsgebiet an tonigen und feinsandigen pleistozänen Ablagerungen vorgenommen worden waren, mußte mit einer Fossilführung gerechnet werden. Deshalb wurde diesen Schichten, als sie in Schacht Tönisberg aufgeschlossen wurden, größte Aufmerksamkeit geschenkt. So konnten bereits bei der Entnahme der ersten Proben einzelne Fossilien gefunden werden. Die Proben wurden daraufhin in möglichst engem Abstand genommen und systematisch auf ihre Fossilführung untersucht.

Um die Fossilien aus den Proben zu gewinnen, wurden jeweils 500 bis 1000 g Probenmaterial teils ohne Verwendung von Chemikalien 30 Minuten lang in Wasser gekocht, zum Teil mit Hilfe von $\mathrm{H}_{2} \mathrm{O}_{2}$ zum Zerfall gebracht und anschließend durch ein Sieb mit 0,1 oder 0,2 mm Maschenweite geschlämmt. Die auf solche Art und Weise erhaltenen Schlämmrückstände wurden im Trockenschrank bei etwa $60^{\circ} \mathrm{C}$ getrocknet und dann durch Trockensiebung in mehrere Fraktionen zerlegt. Die einzelnen Fraktionen ließen sich gegenüber dem Gesamtrückstand wesentlich leichter auslesen. Bei den sandhaltigen Proben wurden die getrockneten Schlämmrückstände mit Hilfe von Tetrachlorkohlenstoff in eine leichte und eine schwere Fraktion zerlegt. In der leichten Fraktion fanden sich dann die Fossilien sehr stark angereichert. Eine Verunreinigung durch rezentes Material ist bei den Proben aus Schacht Tönisberg im Gegensatz zu solchen, die Tagesaufschlüssen entnommen werden, so gut wie ausgeschlossen.

An dieser Stelle ist es angebracht, folgenden Hinweis zu geben: Die schluffigen, tonigen und torfigen Sedimente des Holstein-Interglazials, die aus Schacht Tönisberg zu Tage gefördert wurden, blieben nicht in Schachtnähe liegen, sondern wurden in die Nähe der Stadt Moers gefahren. Dort wurden sie in eine alte Kiesgrube gekippt, welche sich im Bereich der Niederterrasse befindet. Inzwischen ist diese Kiesgrube, in der auch karbonisches Gestein aus der Kohlenwäsche der N.B.A.G. verkippt wurde, bis zur ursprünglichen Geländeoberfläche zugeschïttet worden. Ihre ehemalige Ausdehnung auf dem Meßtischblatt Moers wird von den Punkten mit folgenden Koordinaten markiert: R 41700/H 00500, R 41750/H 00600, R 42000/H 00550, R 41750/H 00350. Durch vorstehende Angaben soll vermieden werden, daß diese holstein-interglazialen Sedimente in künttigen Zeiten einmal in den Ablagerungen der Niederterrasse „entdeckt“ werden.

Interglaziale Ablagerungen sind im Niederrheingebiet zwischen den Schottern der einzelnen Rheinterrassen verhältnismäßig häufig. A. STEEgER (1931b, 1952) hat wiederholt darauf hingewiesen, daß es wichtig sei, die Fossilführung dieser Sedimente eingehend $\mathrm{zu}$ untersuchen. Trotzdem sind unsere Kenntnisse hierüber bisher sehr lückenhaft geblieben. Den ersten Arbeiten über makroskopische Fossilien aus solchen Ablagerungen von G. Fliegel (\& J. Stoller 1910, 1913), A. Steeger (1911) und P. G. Krause (1911, 1914a, 1918) folgten die Arbeiten von K. Bertsch \& A. Steeger (1927) und K. Bertsch, A. Steeger und U. Steusloff (1931). Seitdem wurden im eigentlichen Arbeitsgebiet nur noch pollenanalytische Untersuchungen durchgeführt. Aus der näheren Umgebung sind die Arbeiten über die Interglazialvorkommen von Vogelheim bei Essen (R. KRÄUsEL 1937) und Frimmersdorf bei Grevenbroich (G. v. D. Brelie, K. Kilpper \& R. Teichmüller 1959) zu nennen, die neben pollenanalytischen Untersuchungen auch eine Bearbeitung der makroskopischen Pflanzenreste enthalten. Bei den beiden letztgenannten Vorkommen 
ist aber noch nicht sicher, ob es sich wirklich um Ablagerungen des Holstein-Interglazials handelt. Für die warmzeitlichen Ablagerungen von Frimmersdorf ist ein holstein-interglaziales Alter sehr wahrscheinlich, zumal der Verfasser in den dortigen Sedimenten ebenfalls Azolla interglacialica nachweisen konnte.

Als sichere Ablagerungen des Holstein-Interglazials galten am Niederrhein bisher nur die „Krefelder Schichten“. Aus diesen waren jedoch nur relativ wenige Fossilien bekanntgeworden, so daß auf dieser Grundlage weder ein Vergleich mit anderen holstein-interglazialen Vorkommen (z. B. Neede in den Niederlanden, Hoxne in England, PaludinenSchichten von Berlin) noch mit rezenten Verhältnissen im Niederrheingebiet angestellt werden konnte. Um diese Lücke zu schließen wurde versucht, durch die vorliegende Arbeit ein möglichst vollständiges Bild von der Fauna und Flora des Holstein-Interglazials am Niederrhein zu erhalten.

Die pollenanalytischen Untersuchungen der letzten Jahre haben gezeigt, daß die "Krefelder Schichten" und ähnliche interglaziale Ablagerungen am Niederrhein keine Vegetationsphasen-Abfolge erkennen lassen. Allein auf Grund pollenanalytischer Untersuchungen ist daher eine sichere Alterseinstufung dieser Sedimente nicht möglich. Es ist aus diesem Grunde notwendig und für alle zukünftigen Untersuchungen anzuraten, die Makrofossilien weitgehend zu berücksichtigen.

Die Bearbeitung des gesammelten Fossilmaterials ergab, daß die meisten Fossilien rezent bekannten Arten zuzuordnen sind. Diese Tatsache wurde bereits früher von vielen Bearbeitern solcher Ablagerungen erkannt und häufig als Anlaß dafür genommen, die nachgewiesenen Fossilien nicht $\mathrm{zu}$ beschreiben und nicht abzubilden, sondern ausschließlich in Form einer Fossilliste namentlich zu erwähnen. Das Belegmaterial zu den meisten derartigen Arbeiten ist infolge Kriegseinwirkung oder aus anderen Gründen verlorengegangen. Es ist daher nicht möglich, die von solchen Autoren durchgeführten Bestimmungen zu überprüfen. Zweifel an der Richtigkeit dieser oder jener Bestimmung können von nachfolgenden Bearbeitern nicht beseitigt werden; sie bleiben zum Nachteil der Wissenschaft immer bestehen. Aus diesem Grunde muß allgemein gefordert werden, daß auch Fossilien aus sehr jungen Ablagerungen als echte Fossilien angesehen und dementsprechend bearbeitet werden, selbst wenn diese noch rezent bekannten Arten zuzuordnen sind.

Im vorliegenden Teil der Arbeit werden aus Gründen der Übersichtlichkeit die nachgewiesenen Fossilien in Form von Tabellen namentlich erwähnt; an anderer Stelle werden die genannten Arten eingehend beschrieben und abgebildet. Auf diese Weise wird es ermöglicht, die Bestimmungen im $Z_{w}$ eifelsfall zu überprüfen und eventuell richtigzustellen.

\section{Die Fauna}

Die Untersuchung der tierischen Fossilien aus den „Krefelder Schichten“ von Schacht Tönisberg ergab, daß sich die Fauna aus Mollusken, Ostrakoden, Bryozoen und Vertebraten zusammensetzt. Die Mollusken waren aus den „Krefelder Schichten“ anderer Fundpunkte bereits weitgehend bekannt. Die Vertebraten kannte man nur zum Teil; als neue Funde kommen hier die Reste von Fischen hinzu. Ostrakoden und Bryozoen werden aus diesen Ablagerungen zum ersten Mal beschrieben.

\section{A. Mollusken}

Wie bereits P. G. Krause (1912) bemerkte, muß eine Menge Sedimentmaterial untersucht werden, um aus den „Krefelder Schichten“ eine Molluskenfauna zu erhalten. Diese Feststellung konnte auch bei dem Material aus Schacht Tönisberg getroffen werden, denn außer den im Schacht horizontweise entnommenen Proben wurden einige $100 \mathrm{~kg}$ des interglazialen Feinsandes auf der Halde durchgesiebt. 
$\mathrm{T}$ a belle 7

Mollusken aus den holstein-interglazialen „Krefelder Schichten“ der Eisrandbildungen am Niederrhein. Die Zahlen beziehen sich auf die Anmerkungen.

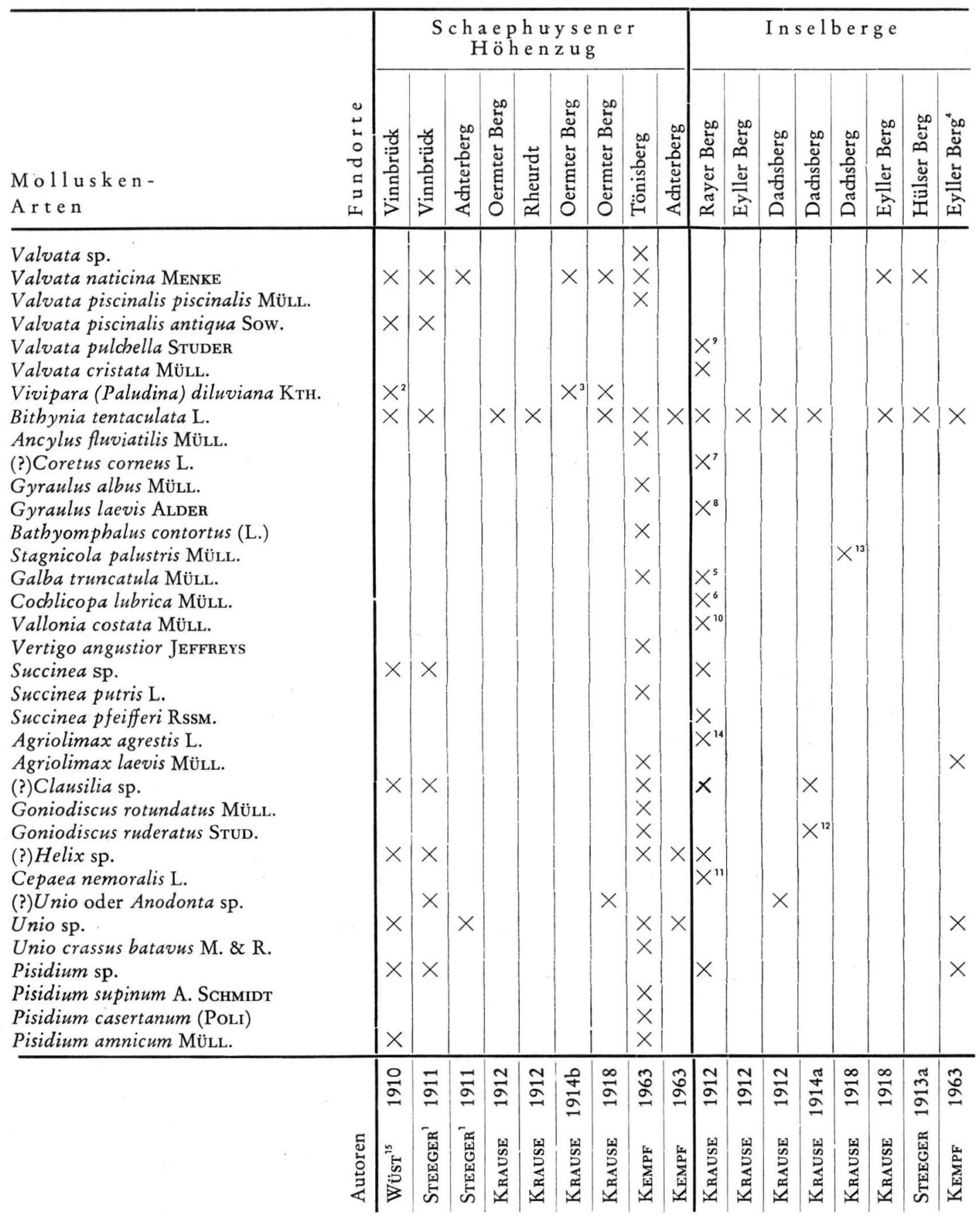


Fast alle Mollusken entstammen dem feinsandigen und schluffigen Bereich der „Krefelder Schichten" in situ. Dabei fanden sich doppelklappige Exemplare von Unio in einem Horizont besonders angereichert. Die tonigen Sedimente lieferten nur Deckel von Bithynia tentaculata und artlich nicht bestimmbare Jugendexemplare der Gattung Valvata. Zusätzlich wurden noch Sandproben aus einer Kiesgrube am Achterberg (nahe dem Südende des Schaephuysener Höhenzuges) untersucht, von wo A. STEEgER (1911) bereits einige Mollusken gemeldet hatte.

Alle nunmehr aus den „Krefelder Schichten“ bekannten Mollusken werden in Tab. 7 zusammengestellt. Außer den Namen der Fossilien wird auch angegeben, von welchen Fundpunkten, durch welche Autoren und in welchem Jahr die einzelnen Arten bekanntgemacht wurden.

Bei der Benennung der Mollusken erwies es sich als zweckmäßig, nicht die modernste, sondern die Molluskenfauna Deutschlands von D. GEYER (3. Aufl., 1927) zugrunde zu legen, weil die meisten der bisher aus dem niederrheinischen Holstein-Interglazial bekannten Arten nach D. Geyer (allerdings 1. Aufl., 1909) bestimmt worden waren. Zu den Arbeiten von P. G. KRAuSE wurden die Mollusken wahrscheinlich durch H. MEnzeL nach S. CLEssin (1884) bestimmt. Auf diese Weise wurden in der Literatur für die verschiedenen Fundpunkte holstein-zeitlicher Mollusken faunistische Unterschiede durch Synonyme vorgetäuscht. In den Anmerkungen zu Tabelle 7 werden die Synonyme der Arbeiten von P. G. Krause namentlich aufgeführt.

Einige der wirklich bestehenden Unterschiede dürften auf die Bestimmung der Fossilfunde durch verschiedene Bearbeiter zurückzuführen sein. Leider fehlen in fast allen

Anmerkungen zu Tabelle 7 :

1 Die von A. SteEger gesammelten Mollusken wurden wahrscheinlich durch E. Wüst bestimmt. Es ist möglich, daß es sich dabei sogar um die gleichen Fossilien handelt, die in W. Wunstorf \& G. Fliegel (1910) angegeben werden. Aus der Literatur sind die damaligen Verhältnisse nicht eindeutig zu erkennen, besonders deshalb nicht, weil die interglazialen Ablagerungen mit ihrer Molluskenführung ziemlich gleichzeitig von mehreren Geologen der Preußischen Geologischen Landesanstalt Berlin aufgefunden worden waren und ein Prioritätsstreit entstand, wer der erste Entdecker gewesen sei. G. FliEgeL nahm mit dem Fundort Vinnbrück die Prioritätsrechte für sich in Anspruch; wahrscheinlich hatte P. G. Krause in den Inselbergen diese Ablagerungen aber bereits vor G. FLIEGEL richtig erkannt.

2 Ursprünglich als Paludina cf. diluviana bestimmt; nach P. G. KRAUSE (1914b) konnte die Art, die von diesem Fundpunkt in einem Exemplar vorlag, später eindeutig bestimmt werden.

3 Die Hauptfundstelle der Vivipara (Paludina) diluviana mit über 1000 Exemplaren.

4 Vgl. Kapitel V.

5 als: Limnaeus (Limnophysa) truncatula MüLL. var. oblonga.

6 als: Cionella (Zua) lubrica MüLler.

7 als: cf. Planorbis (Coretus) corneus LiNNE.

8 als: Planorbis glaber JefFreys.

9 als: Valvata macrostoma STEENB.

10 als: Helix (Vallonia) costata MülLER.

11 als: Helix (Trachea) nemoralis LinNe.

12 als: Patula ruderata STUDER.

13 als: Limnaea palustris MüLLER.

14 als: Limax (Agriolimax) agrestis LinNe.

15 in: W. Wunstorf \& G. Fliegel 1910. 
älteren Arbeiten Abbildungen und ausführliche Beschreibungen, auch ist über den Verbleib des Fossilmaterials zu diesen Arbeiten nichts bekannt; Differenzen solcher Art können daher nicht geklärt werden.

Einige weitere Unterschiede dürften auf die verschiedenartige fazielle Ausbildung der interglazialen Sedimente an den entsprechenden Fundpunkten zurückzuführen sein. So wurde z. B. Vivipara (Paludina) diluviana am Südende des Schaephuysener Höhenzuges bei Vinnbrück nur in einem Exemplar, im nahegelegenen Schacht Tönisberg überhaupt nicht nachgewiesen; am Nordende des Schaephuysener Höhenzuges kam diese Schnecke dagegen im Bereich des Oermter Berges mit über 1000 Exemplaren vor.

Eine ökologische und klimatische Ausdeutung der Molluskenfauna ist schwierig und mit vielen Unsicherheiten belastet. Die sandigen Sedimente im Bereich der „Krefelder Schichten" in situ weisen auf Flußablagerungen hin. Dafür spricht auch das Vorkommen einiger Gastropoden- und Lamellibranchiaten-Arten, und zwar Ancylus fluviatilis, Valvata naticina, Valvata piscinalis piscinalis, Unio crassus batavus, Pisidium amnicum, Pisidium casertanum und Pisidium supinum. Einige der genannten Arten kommen auch in Seen vor, aber meist nur dann, wenn diese so groß sind, daß durch Windeinwirkung das Wasser stärker durchbewegt werden kann. Die flächenhafte Erstreckung der „Krefelder Schichten " - soweit sie bisher überhaupt bekannt ist - macht die Annahme jedoch unwahrscheinlich, daß es sich um Ablagerungen eines größeren Sees handelt. Vielmehr müssen wir annehmen, daß die „Krefelder Schichten“ in tieferen Teilen aus Flußablagerungen, in höheren Teilen aus Altwassersedimenten mit entsprechenden Verlandungsbildungen bestehen.

Bei der Beurteilung der Molluskenfauna aus den sandigen Sedimenten muß mit $\mathrm{Zu}-$ sammenschwemmungen gerechnet werden. Eingeschwemmt sind vor allem die Landschnecken, die nach ihrer Individuenzahl neben den Wasserschnecken aber nur eine untergeordnete Rolle spielen. Die Reichweite der Zusammenschwemmungen kann nicht abgegrenzt werden. Nur von Bithynia tentaculata und der Gattung Valvata, deren Reste auch in den tonigen Sedimenten in großer Zahl nachgewiesen werden konnten, können wir sagen, daß sie am Fundort gelebt haben. Die Art der Gattung Valvata, welche in den tonigen Sedimenten der "Krefelder Schichten" vorkommt, ist nicht zu bestimmen, weil nur juvenile Gehäuse gefunden wurden. Bei Bithynia tentaculata schließlich handelt es sich um eine holarktische Art, die über das holstein-zeitliche Klima nichts aussagt. Eine klimatische Ausdeutung, die an sich schon große Schwierigkeiten bereitet, weil die Mollusken sehr stark vom örtlichen Kleinklima abhängig sind, kann aus den zuvor geschilderten Gründen nicht durchgeführt werden.

Bemerkenswert ist ansonsten nur noch, daß in den "Krefelder Schichten" Valvata naticina und Vivipara (Paludina) diluviana stellenweise sehr häufig sind. Valvata naticina kommt rezent nur noch in Osteuropa vor. Auch Vivipara (Paludina) diluviana, die lange Zeit als ausgestorben galt, will man dort noch beobachtet haben.

\section{B. Ostrakoden}

Aus den holstein-interglazialen Ablagerungen vom Niederrhein werden durch die vorliegende Arbeit zum ersten Mal Ostrakoden-Funde bekanntgemacht. Bei den nachgewiesenen Arten handelt es sich ohne Ausnahme um Süßwasser-Ostrakoden. In den meisten Fällen zeigen die gefundenen Ostrakoden-Klappen völlige Übereinstimmung mit denen rezent bekannter Arten, so daß sie diesen zugeordnet werden können. In drei Fällen trifft dies allerdings nicht zu, und zwar bei Cyclocypris buckei TRIEBEL, Cyclocypris n. sp. und Ilyocypris steegeri n. sp.; rezente Vertreter dieser Arten konnten bisher nicht nachgewiesen werden.

Cyclocypris huckei wurde von E. TrIeBEL (1941a) erstmals in den holstein-interglazialen Paludinenschichten von Berlin nachgewiesen und gilt seither als Leitform für 
das Holstein-Interglazial. Diese Ansicht kann in dieser engen Fassung nicht aufrechterhalten werden, da Cyclocypris buckei vom Verfasser auch in Vergleichsproben aus den Ablagerungen der altpleistozänen Tegelen-Warmzeit nachgewiesen werden konnte. Häufiger als die Klappen dieser Art wurden in dem Material aus Schacht Tönisberg die Klappen von Cyclocypris n. sp. gefunden. Da nur juvenile Stadien nachweisbar waren, wurde von einer Benennung dieser Art vorerst abgesehen. Die Klappen von Ilyocypris steegeri, die in einer anderen Arbeit als neue Art beschrieben wird, fanden sich dagegen in weit geringerer Zahl. Sie unterscheiden sich von denen der übrigen IlyocyprisArten aber so deutlich, daß die Aufstellung und Benennung einer neuen Art berechtigt erschien. Die Bestimmung der Candona-Arten wurde vorerst zurückgestellt, denn mit überwiegender Mehrheit fanden sich nur Klappen juveniler Stadien; die wenigen adulten Exemplare lagen fast alle in Bruchstücken vor.

Eine Ubersicht über die gefundenen Ostrakoden-Arten und ihre mengenmäßige Verteilung im Profil der "Krefelder Schichten“ von Schacht Tönisberg vermittelt Tabelle 8. Daraus geht hervor, daß die Ostrakoden in den Proben aus Schacht Tönisberg nach Arten- und Individuenzahl in recht unterschiedlicher Weise vorkommen. Sehr häufig fanden sie sich nur in zwei Sammelproben aus dem obersten Profilbereich der „Krefelder Schichten " (KKS 3; vgl. Abb. 2 und Tab. 8). Ansonsten wechseln Proben miteinander ab, in denen Ostrakoden häufig, selten oder gar nicht vorhanden sind. Allgemein wurde beobachtet, daß Ostrakoden nahezu immer und zahlreich in solchen Proben vorkommen, in denen sich auch Oogonien von Characeen finden. Das trifft ebenfalls für andere Fundorte zu. So wurden z. B. in den "Krefelder Schichten“ der Inselberge (vgl. Kap. V.), in denen sich nur wenige Characeen-Oogonien fanden, nur wenige Ostrakoden-Klappen gefunden; in den „Kempener Schichten “ der Bohrungen De-Greiff-Straße in Krefeld (vgl. Kap. VI.), in denen Characeen-Oogonien fehlten, kamen auch keine Ostrakoden vor. Es sind demnach bei den holstein-interglazialen Ablagerungen am Niederrhein auch in bezug auf die Ostrakoden Faziesunterschiede zu beobachten. Bei oberflächlicher $\mathrm{Be}-$ trachtung könnten dadurch - ähnlich wie bei den Mollusken - Altersunterschiede der Ablagerungen vorgetäuscht werden.

Rückschlüsse auf das Großklima während des Holstein-Interglazials können auf Grund der Ostrakoden-Fauna nicht gezogen werden, weil deren Zusammensetzung zu stark von den Faktoren des Kleinklimas abhängig ist. Verwertbar sind dagegen die ökologischen Aussagen der Ostrakoden. In Verbindung mit dem Vorkommen von CharaceenOogonien müssen wir annehmen, daß die Sedimente in kleineren, vegetationsreichen, nicht austrocknenden Gewässern mit einer Wassertiefe von kaum mehr als $5 \mathrm{~m}$ zur Ablagerung gekommen sind. Als solche Gewässer kommen am ehesten verlandende Altwasserrinnen in Betracht.

\section{Bryozoen}

In den Proben aus Schacht Tönisberg konnten in geringer Zahl die Statoblasten (Dauerknospen) von Cristatella mucedo L. gefunden werden. Obgleich demnach Statoblasten von Süßwasser-Bryozoen fossil erhaltungsfähig sind, wurden sie bisher nur äußerst selten nachgewiesen. Auch aus dem Holstein-Interglazial vom Niederrhein waren solche noch nicht bekannt.

\section{Vertebraten}

Reste von Wirbeltieren kommen in den holstein-interglazialen Ablagerungen am Niederrhein nur spärlich vor; sie sind daher von untergeordneter Bedeutung.

Bisher wurden aus den „Krefelder Schichten“ des Hülser Berges, vom Dachsberg und von Tönisberg durch E. Wüst (in: W. Wunstorf \& G. Fliegel 1910) und P. G. Krause (1912, 1914a) folgende Funde bekanntgemacht: 1 . Knochen von Rana temporaria L. (det. Woi tersDorfF); 2. Arvicoliden-Zähne; 3. Schädelknochensplitter und zwei Zähne von 
Tabelle 8

Ostrakoden aus dem Holstein-Interglazial von Schacht Tönisberg und ihre Verteilung im Profil.

\begin{tabular}{|c|c|c|c|c|c|c|c|c|c|c|c|c|c|c|c|}
\hline 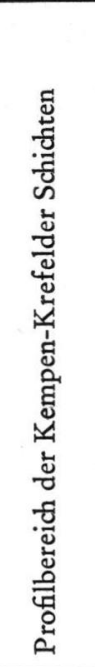 & $\begin{array}{c}\text { Teufe } \\
\text { in } \\
\text { m }\end{array}$ & 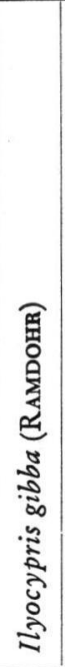 & 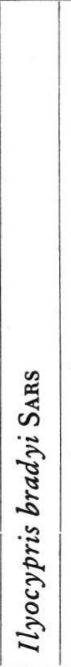 & 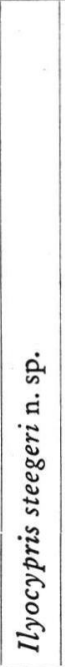 & 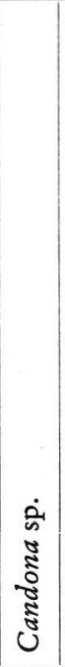 & 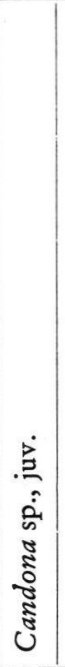 & 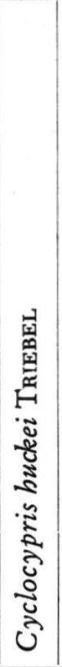 & 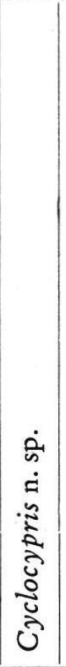 & 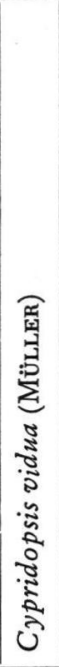 & 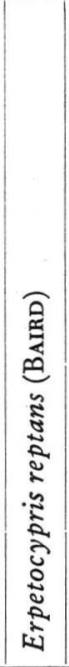 & 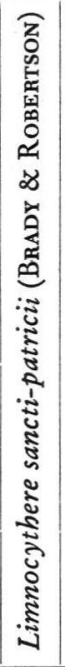 & 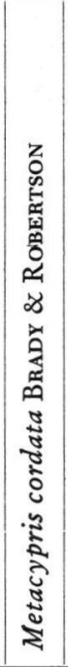 & 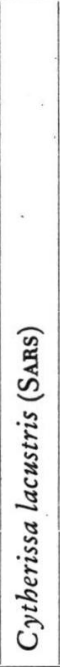 & 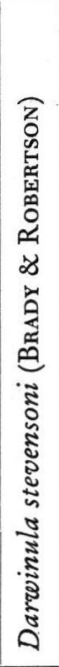 & 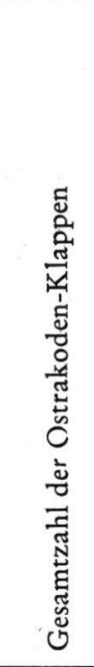 \\
\hline & $18,05-19,0$ & 41 & - & - & 6 & 86 & 8 & 12 & 11 & 29 & - & - & 1 & 1 & 195 \\
\hline $\begin{array}{l}\mathrm{K} \\
\mathrm{K}\end{array}$ & $19,0-20,0$ & 250 & 18 & 10 & - & 11 & 14 & 70 & - & 7 & 2 & - & 1 & - & 383 \\
\hline $\mathrm{s}$ & $20,0-20,15$ & - & - & - & - & 2 & - & 1 & - & 2 & - & - & - & - & 5 \\
\hline 3 & $20,15-20,45$ & 1 & - & - & - & - & - & 1 & - & - & - & - & - & - & 2 \\
\hline & 20,85 & 一 & - & - & - & 12 & - & - & 1 & - & - & - & - & - & 13 \\
\hline & 23,0 & 2 & - & - & - & - & 1 & 1 & - & 2 & - & - & 2 & - & 8 \\
\hline & 26,0 & 2 & - & - & - & - & - & - & - & - & - & - & - & - & 2 \\
\hline & 26,5 & 4 & - & - & - & 3 & 2 & 10 & 2 & - & - & - & - & - & 21 \\
\hline $\begin{array}{l}K \\
K\end{array}$ & 27,0 & 一 & - & - & - & - & - & 1 & - & - & - & - & - & - & 1 \\
\hline $\mathrm{s}$ & 27,5 & 1 & - & - & - & 25 & - & 2 & 9 & 5 & - & 8 & - & 24 & 74 \\
\hline 2 & 27,8 & - & - & - & - & - & - & - & - & 1 & - & 1 & - & - & 2 \\
\hline & 28,5 & 3 & - & 1 & - & 36 & - & 7 & - & 1 & - & - & - & 9 & 57 \\
\hline & 30,2 & 一 & - & - & - & 22 & 2 & - & - & 4 & - & 1 & - & - & 29 \\
\hline & 31,0 & 8 & - & 一 & - & 21 & 2 & 2 & - & - & - & 1 & 1 & 15 & 50 \\
\hline $\mathrm{K}$ & $31,5-32,0$ & 8 & 2 & - & 10 & 50 & - & - & - & - & - & - & - & 1 & 71 \\
\hline $\mathrm{K}$ & 32,4 & 9 & 2 & 1 & - & 80 & - & - & - & - & - & - & - & - & 92 \\
\hline S & 34,0 & 61 & 2 & 2 & 3 & 10 & - & - & - & 6 & - & - & - & - & 84 \\
\hline 1 & $34,7-37,7$ & - & - & - & 4 & - & - & - & - & - & - & 1 & - & - & 5 \\
\hline \multirow{2}{*}{ Summe } & & 390 & 24 & 14 & 23 & 358 & 29 & 107 & 23 & 57 & 2 & 12 & 5 & 50 & 1094 \\
\hline & & 35,6 & 2,2 & 1,3 & 2,1 & 32,7 & 2,6 & 9,8 & 2,1 & 5,2 & 0,2 & 1,1 & 0,5 & 4,6 & $100 \%$ \\
\hline
\end{tabular}


? Castor sp., wobei auch mit einer Zugehörigkeit zu Trogontherium minus oder Trogontherium cuvieri gerechnet wurde; 4. eine Tibia von Meles sp. (det. Schroeder, ursprünglich als ? Lepus sp. gedeutet); 5. ein Zahnstïck von Elephas cf. antiquus FALc. (det. Schroeder) und 6. von Cervus sp. ein Geweih-Ende.

Von den vorstehend genannten Fossilien konnten nur ? Rana sp. und Arvicola sp. auch im Holstein-Interglazial von Schacht Tönisberg gefunden werden. Die Reste größerer Wirbeltiere fehlten. Dafür fanden sich mehrfach Fischreste, die bisher aus den „Krefelder Schichten" noch nicht bekannt waren. Während die Knochen von ? Rana sp. und die Zähne von Arvicola sp. nur in den sandigen Sedimenten der "Krefelder Schichten " von Schacht Tönisberg gefunden wurden, kamen die Fischreste ausschließlich in der Kalkgyttja vor.

Tabelle 9

Vertebraten aus den holstein-interglazialen „Krefelder Schichten“ von Schacht Tönisberg.

\begin{tabular}{|c|c|}
\hline Arten: & Fossilfunde: \\
\hline $\mathrm{P}$ is ces & \\
\hline Cyprinus carpio L. (Karpfen) & 4 Schlundzähne \\
\hline Scardinius erythrophthalmus L. (Rotauge) & 12 Schlundzähne \\
\hline Tinca vulgaris Cuvier (Schleie) & 4 Schlundzähne \\
\hline Esox lucius L. (Hecht) & 7 Zähne \\
\hline Perca fluviatilis L. (Barsch) & 2 Schuppenbruchstücke \\
\hline $\begin{array}{l}\text { A m p h ib i a } \\
\text { ? Rana sp. (Frosch) }\end{array}$ & Knochenfragmente \\
\hline $\begin{array}{l}\text { M a m m a li a } \\
\text { Arvicola sp. (Wasserratte) }\end{array}$ & 1 Nagezahn, 4 Backenzähne \\
\hline
\end{tabular}

\section{Die Flora}

Pflanzenreste fanden sich in nahezu allen Proben aus den „Krefelder Schichten“ von Schacht Tönisberg. Gegenüber den tierischen Fossilien waren sie in größerer Arten- und Individuenzahl vertreten.

Die Bearbeitung gliedert sich in die Untersuchung der makroskopischen Pflanzenreste (vorwiegend Früchte und Samen) und in pollenanalytische Untersuchungen.

A. Makroskopische Pflanzenreste

Obgleich die „Krefelder Schichten“ bereits mehrfach aufgeschlossen wurden, sind aus diesen Ablagerungen erst wenige makroskopische Pflanzenreste bekannt. Beschrieben wurden bisher Holzstücke von Populus sp. und Salix sp. (A. SteEger 1913) sowie von einer Betulacee (P. G. Krause 1914a); ferner Makrosporangien von Azolla filiculoides Lam. (F. Florschütz 1952, H. Hiltermann 1954) und Blätter von Fagus silvatica L. (P. G. Krause 1914a. Bei diesen Fagus-Blättern dürfte es sich um eine Fehlbestimmung handeln; viel wahrscheinlicher ist es, daß in Wirklichkeit Alnus-Blätter als Funde vorgelegen haben.) $\mathrm{Da}$ in den meisten Proben aus den „Krefelder Schichten“ von Schacht Tönisberg makroskopische Pflanzenreste sehr häufig sind, ist anzunehmen, daß die bisherige Unkenntnis dieser Fossilien auf das Fehlen systematischer Sedimentuntersuchungen zurückzuführen ist.

Die Pflanzenreste sind durchweg gut erhalten. Die beste Erhaltung zeigen die Fossilien aus der Kalkgyttja; weniger gut ist die Erhaltung der Pflanzenreste in den tieferen, sandigen Profilabschnitten; noch etwas schlechter ist sie in den torfigen Schichten infolge stärkeren Setzungsdruckes. 
In der Kalkgyttja und in den torfigen Schichten fanden sich überwiegend Reste von Sumpf- und Wasserpflanzen. Die Fossilführung dieser Schichten ist deshalb als autochthon anzusehen. Ókologisch deuten Sedimente und Fossilien auf Ablagerungen verlandeter Altwässer hin. In den tieferen, sandigen Profilabschnitten treten in größerer Zahl die Reste von Landpflanzen auf, was auf Zusammenschwemmungen und - wie das Sediment - auf Flußablagerungen hinweist.

Zur Bestimmung der Pflanzenfossilien konnte in den meisten Fällen rezentes Vergleichsmaterial hinzugezogen werden. Stimmte das Fossil, z. B. ein Same, mit dem entsprechenden Teil der rezenten Pflanze überein, so wurde das Fossil mit dem Gattungs- und Artnamen der rezenten Pflanze belegt. Es ergab sich, daß die meisten fossilen Pflanzenreste aus den „Krefelder Schichten“ auf diese Weise rezent bekannten Arten zugeordnet

\section{$\mathrm{T}$ a be 11 e 10}

Makroskopische Pflanzenreste aus dem Holstein-Interglazial von Schacht Tönisberg. $\mathrm{HH}=$ sehr häufig (mehr als 50 Exemplare), $\mathrm{H}=$ häufig ( 5 bis 5,0 Exemplare), $\mathrm{S}=$ selten ( 1 bis 5 Exemplare).

1 Tectochara meriani diluviana MäDLER $\mathrm{HH}$

2 Tectochara meriani diluviana MäDLER n. ssp. ?

3 ? Chara sp.

4 Cenococcum geophilum FrIES

5 Campylium stellatum (SCHREBer) LANG \& JENSEN

\section{$\mathrm{H}$}

$\mathrm{HH}$

$\mathrm{H}$

$\mathrm{H}$

$\mathrm{HH}$

$\mathrm{HH}$

$\mathrm{H}$

$\mathrm{H}$

$\mathrm{HH}$

$\mathrm{H}$

$\mathrm{H}$

$\mathrm{H}$

$\mathrm{HH}$

$\mathrm{H}$

$\mathrm{HH}$

$\mathrm{S}$

$\mathrm{H}$

$\mathrm{S}$

$\mathrm{S}$

$\mathrm{H}$

$\mathrm{HH}$

$\mathrm{H}$

$\mathrm{HH}$

$\mathrm{HH}$

$\mathrm{H}$

$S$

$\mathrm{S}$

$\mathrm{S}$

$\mathrm{H}$

$\mathrm{H}$

$\mathrm{HH}$

$\mathrm{S}$

$\mathrm{HH}$
35 Ranunculus sceleratus LINNE H

36 Ranunculus lingua LinNe H

37 Ranunculus cf. repens LiNNE H

38 Nuphar luteum (LinNe) SмIтH $\mathrm{H}$

39 Nymphaea alba LinNe $\mathrm{H}$

40 Euryale ferox Salisbury S

41 Brasenia purpurea (Micheaux) Caspary S

42 Ceratophyllum demersum LinNe $\mathrm{H}$

43 Ceratophyllum submersum LinNE S

44 Crataegus acuticarpa

(C. \& E. M. ReID) E. M. ReID H

45 Prunus spinosa LinNe S

46 Rubus caesius LinNe S

47 Rubus sp. $\mathrm{H}$

48 Trapa cf. natans LinNe H

49 Myriophyllum spicatum LiNNE $\mathrm{H}$

50 Hippuris vulgaris LINNE $\mathrm{HH}$

51 Elatine hydropiper (LiNNE) Oeder S

52 Aldrovandia vesiculosa LINNE S

53 Sparganium ramosum Hudson $\mathrm{H}$

54 Typha cf. angustifolia LiNNe $\mathrm{HH}$

55 Alisma plantago-aquatica LiNNE $\mathrm{HH}$

56 Sagittaria sagittifolia LiNNE $\mathrm{H}$

57 Stratiotes intermedius (HARTZ)

Chandler

$S$

58 Stratiotes aloides Linne S

59 Potamogeton pusillus LinNe $\mathrm{H}$

60 Potamogeton sp. $\mathrm{HH}$

61 Najas minor AlLionI $\mathrm{HH}$

62 Najas marina LiNNE $\mathrm{HH}$

63 Najas flexilis (WILldENow) RostKovius \& SCHMIDT

64 Zannichellia palustris LINNE HH

65 Carex sp.

66 Scirpus lacustris LinNe $\mathrm{HH}$ 
werden konnten. Der Zusatz cf. wurde nur dann benutzt, wenn die Artbestimmung nicht befriedigend durchgeführt werden konnte. F. KIRCHHEIMER (1957) dagegen verwendet den Zusatz cf. mit dem Artnamen in allen Fällen, wo nur Teile einer Pflanze fossil aufgefunden wurden; auch dann, wenn diese mit den entsprechenden Teilen der rezenten Pflanze völlig übereinstimmen, weil andere Teile der fossilen Pflanze anders ausgesehen haben könnten.

Eine listenmäßige Aufstellung der in den „Krefelder Schichten“ von Schacht Tönisberg nachgewiesenen makroskopischen Pflanzenreste gibt Tabelle 10. In Kapitel VII wird außerdem versucht, die Pflanzenreste aus dem Holstein-Interglazial vom Niederrhein paläoklimatisch auszuwerten.

\section{B. Pollenanalytische Untersuchungen}

Die Kempen-Krefelder Schichten sind auf ihre Pollenführung bereits mehrfach untersucht worden. Die ersten Untersuchungen dürfte K. JESSEN 1924 durchgeführt haben; seine Ergebnisse wurden aber erst 1952 (briefliche Mitteilung an A. Steeger, in A. Steeger 1952a) im Auszug mitgeteilt. Weitere Untersuchungen wurden um 1950 und in den nachfolgenden Jahren von den Sachbearbeitern des Geologischen Landesamtes in Krefeld durchgeführt. Einige Ergebnisse sind davon veröffentlicht worden (vgl. H. KARRENBERG \& U. REIN 1951, G. v. D. BreLIE \& U. REIN 1952). Die meisten Untersuchungsergebnisse befinden sich jedoch als unveröffentlichte Berichte im Archiv des Geologischen Landesamtes in Krefeld.

In der Mehrzahl der Fälle wurden nur Einzelproben untersucht. Das lag vor allem daran, daß die interglazialen Sedimente fast immer nur als geringmächtige Ablagerungen aufgeschlossen wurden. Selten erreichten diese eine Mächtigkeit von etwa $3 \mathrm{~m}$, wie z. B. im Hülser Berg (H. KarRenberg \& U. ReIN 1951). Vom letztgenannten Aufschluß wurde eine Folge von 6 Proben untersucht, allerdings in dem weiten Abstand von etwa $50 \mathrm{~cm}$.

Stellt man die Ergebnisse der bisherigen Untersuchungen zusammen, so ergibt sich, daß zwei Gruppen von Proben zu unterscheiden sind: eine Gruppe, bei der die Abies-Pollen den verhältnismäßig hohen Anteil von 10 bis 50\% ausmachen; eine andere, bei der AbiesPollen nahezu oder völlig fehlen, dafür aber die Pinus- oder Alnus-Pollen mit mehr als $50 \%$ dominieren.

Beim Abteufen von Schacht Tönisberg wurden die „Krefelder Schichten“ in größerer Mächtigkeit aufgeschlossen. In Verbindung mit der Untersuchung der makroskopischen Pflanzenreste war es von Interesse, auch die Pollenführung kennenzulernen. Leider eigneten sich auf Grund des Sedimentcharakters nicht alle Proben für pollenanalytische Untersuchungen. So wurden z. B. die Proben der aufgeschobenen, in sich gestörten „Krefelder Schichten " nicht auf ihre Pollenführung untersucht, weil die ursprüngliche Sedimentationsfolge hier weitgehend verändert war, so daß nur mit verzerrten Pollenspektren gerechnet werden konnte. Von den Proben der beiden übrigen Profilbereiche der „Krefelder Schichten " fielen außerdem alle Proben aus, die höhere Schluff- und Feinsandgehalte aufwiesen. Besonders traf dies für die Proben der „Krefelder Schichten“ in situ zu.

Die Aufbereitung der Proben erfolgte mittels Kalilauge und Flußsäure, nachdem zuvor der Gehalt an Kalziumkarbonat mit verdünnter Salzsäure weggelöst worden war. Unter der Anleitung und Aufsicht von Dr. R. SchütrumpF wurden die Proben ausgezählt.

Von den „Krefelder Schichten“ in situ lieferten nur die obersten drei Proben brauchbare Ergebnisse, die in der nachfolgenden Tabelle dargestellt werden. Die übrigen Proben wiesen eine so geringe Pollenfrequenz auf, daß von ihrer weiteren Untersuchung abgesehen wurde.

Von den aufgeschobenen, in sich ungestörten „Krefelder Schichten“ wurden 21 Proben pollenanalytisch untersucht. Die Abstände der untersuchten Proben betragen durchweg 10 bis $20 \mathrm{~cm}$ mit zwei Ausnahmen: eine größere Lücke entstand durch das Auftreten einer 
Tabelle 11

Prozentuale Pollenverteilung von 3 Proben der „Krefelder Schichten“ in situ aus Schacht Tönisberg.

\begin{tabular}{|c|c|c|c|}
\hline $\begin{array}{l}\text { Probe: } \\
\text { Teufe: }\end{array}$ & $\begin{array}{c}220 \\
31,4 \mathrm{~m}\end{array}$ & $\begin{array}{c}221 \\
31,7 \mathrm{~m}\end{array}$ & $\begin{array}{r}222 \\
32,1 \mathrm{~m}\end{array}$ \\
\hline $\begin{array}{l}\text { Pinus } \\
\text { Picea } \\
\text { Abies } \\
\text { Salix } \\
\text { Betula } \\
\text { Quercus } \\
\text { Tilia } \\
\text { Ulmus } \\
\text { Carpinus } \\
\text { Alnus }\end{array}$ & $\begin{array}{r}25 \% \\
11 \\
8 \\
11 \\
1 \\
11 \\
- \\
2 \\
2 \\
29\end{array}$ & $\begin{array}{l}17 \% \\
9,5 \\
35 \\
1,5 \\
0,5 \\
12 \\
0,5 \\
- \\
- \\
24\end{array}$ & $\begin{array}{l}26,5 \% \\
3 \\
- \\
2,5 \\
0,5 \\
1 \\
1 \\
- \\
- \\
65,5\end{array}$ \\
\hline $\begin{array}{l}\text { Corylus } \\
\text { Ilex } \\
\text { Gramineae } \\
\text { Cyperaceae } \\
\text { Ericaceae } \\
\text { Umbelliferae } \\
\text { Myriophyllum } \\
\text { Typha angustifolia } \\
\text { Filices } \\
\text { Azolla-Mikrosporangien }\end{array}$ & $\begin{array}{r}4 \\
1 \\
- \\
1 \\
1 \\
1 \\
1 \\
5 \\
5 \\
4\end{array}$ & $\begin{array}{l}5,5 \\
- \\
- \\
- \\
- \\
- \\
- \\
- \\
2 \\
2,5\end{array}$ & $\begin{array}{l}4,5 \\
- \\
1 \\
- \\
- \\
- \\
- \\
- \\
10 \\
7\end{array}$ \\
\hline
\end{tabular}

pollenfreien Feinsandbank, eine andere dadurch, daß $1 \mathrm{~m}$ Sediment nicht untersucht wurde, weil in diesem Bereich mit einem stark abweichenden Pollenspektrum nicht mehr gerechnet werden konnte.

Aus dem Diagramm (Abb. 5) wird ersichtlich, daß die Zusammensetzung der Pollenflora über einen Bereich von nahezu $4 \mathrm{~m}$ ziemlich einheitlich ist. Relativ hohe Anteile mit durchweg 20 bis 40\% erreichen die Abies-Pollen. Ebenso hohe und höhere Werte werden von Pinus und Alnus erreicht. Die übrigen Baumpollen weisen nur selten Anteile auf, die 5\% überschreiten. Eine auffallende Ausnahme macht davon nur Quercus in den obersten Proben. Bemerkenswert ist das Auftreten von Castanea- und Pterocarya-Pollen, die zwar auch nur geringe prozentuale Anteile ausmachen, jedoch nahezu in geschlossener Kurve vorkommen, so daß sie als autochthone Elemente der Pollenflora anzusehen sind. Die Pollen von Juglans und Keteleeria konnten nicht nachgewiesen werden. Unter den Nichtbaumpollen fällt der geringe Anteil an Corylus-Pollen auf; die Werte schwanken zwischen 5 und 20\%. Bei den Farnen ist bemerkenswert, daß die Mikrosporangien von Azolla in fast allen Proben vorkommen.

Die drei Proben, welche aus den "Krefelder Schichten“ in situ untersucht wurden, weisen gegenüber diesem Diagramm einige Besonderheiten auf. In allen Proben fehlen z. B. die Pollen von Castanea und Pterocarya. Probe 222 ist zudem die einzige untersuchte Probe, in der keine Abies-Pollen nachgewiesen werden konnten; dafür erreicht 


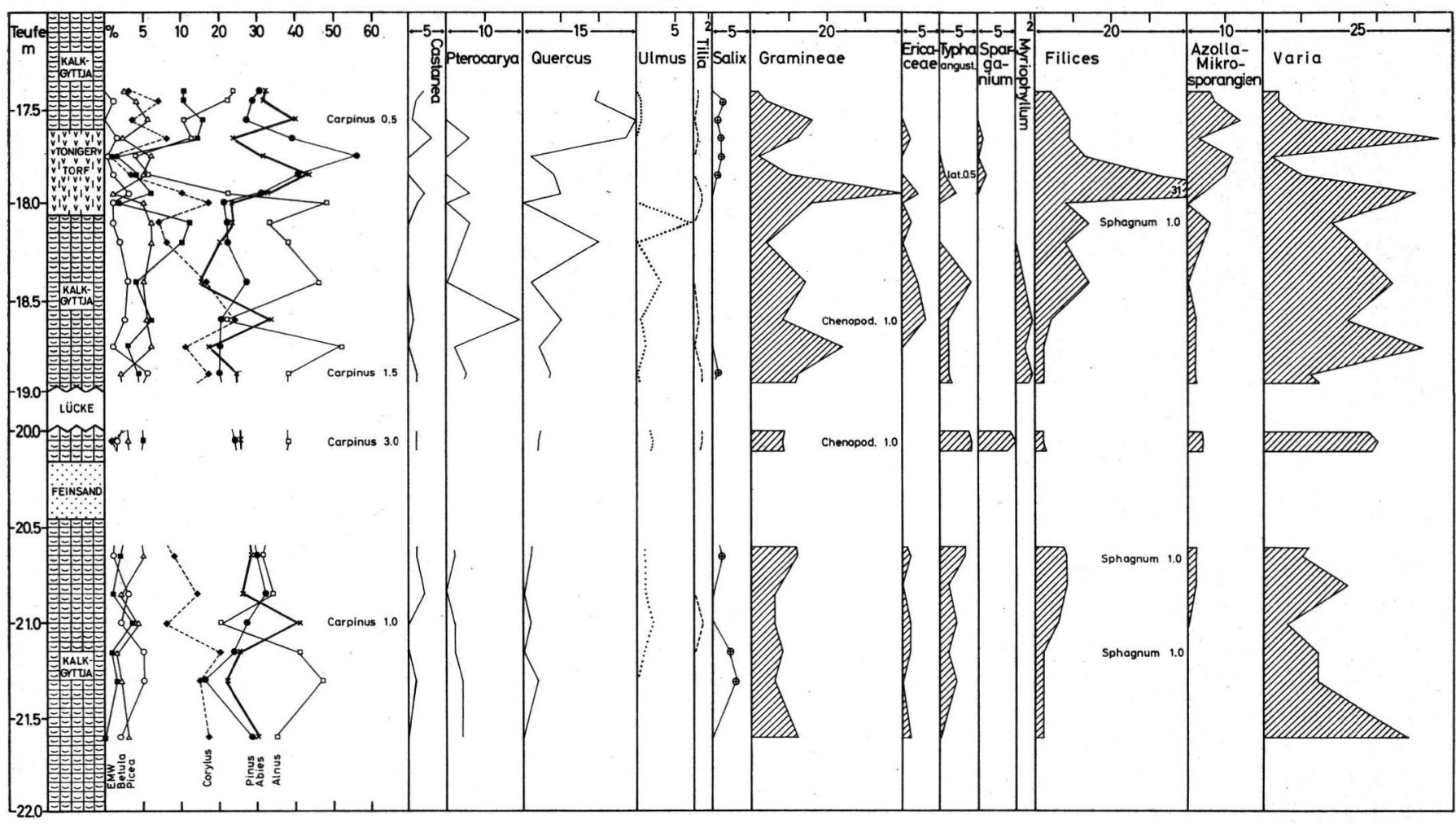

Abb. 5. Pollendiagramm der aufgeschobenen, in sich ungestörten „Krefelder Schichten “ von Schacht Tönisberg. Die Baumpollen und die Nichtbaumpollen (schraffierte Flächen sowie Corylus) sind jeweils getrennt für sich auf $100 \%$ bezogen. 
Alnus in dieser Probe über 65\%. Azolla-Mikrosporangien kommen dagegen in allen drei Proben vor.

Wie frühere Untersuchungen schon gezeigt haben, lassen sich also bei den KempenKrefelder Schichten zweierlei Proben unterscheiden: solche, die hohe Anteile an AbiesPollen aufweisen, und solche, in denen Abies-Pollen fehlen. Da diese beiden Arten von Proben nicht miteinander abwechselnd auftreten, kann darauf geschlossen werden, daß sie zwei unterschiedliche Vegetationsabschnitte des Holstein-Interglazials am Niederrhein kennzeichnen. Von unten nach oben folgt dabei im Profil auf einen Abies-freien Abschnitt ein Abies-reicher, der im oberen Teil höhere Werte von Quercus-Pollen und AzollaMikrosporangien aufweist, damit also eine Verbesserung des Klimas andeutet.

Der Abies-freie Abschnitt ist bei dem untersuchten Material aus Schacht Tönisberg nur durch eine Probe vertreten. Der Übergang zum Abies-reichen Abschnitt erfolgt plötzlich, indem innerhalb von $40 \mathrm{~cm}$ der Anteil an Abies-Pollen von 0 auf 35\% ansteigt. Wahrscheinlich ist das auf eine Lücke in der Sedimentationsfolge zurückzuführen. Der in diesem Profilbereich rasche Wechsel von tonigem Torf mit schluffiger Kalkgyttja deutet darauf hin, daß eine beginnende Verlandung immer wieder durch erneute Überschwemmung unterbrochen wurde. Dabei wird in geringem Maß auch eine Erosion stattgefunden haben, die Lücken in der Sedimentationsfolge verursachte.

Für den Abies-reichen Abschnitt muß mit einer Sedimentmächtigkeit von über $5 \mathrm{~m}$ gerechnet werden. Zwei Möglichkeiten können diese große Mächtigkeit erklären: entweder dauerte der Zeitabschnitt sehr lange an, oder die Sedimentationsgeschwindigkeit war durch tektonische Absenkung des Gebietes vielleicht begünstigt - verhältnismäßig groß.

Sedimentcharakter und Polleninhalt der Kempen-Krefelder Schichten deuten darauf hin, daß es sich bei diesen Sedimenten um Ablagerungen aus dem Bereich eines großen Flußsystems, und zwar des damals noch ungebändigten Rheins handelt. Die Voraussetzungen für die Entstehung einer Verlandungsfolge, welche das gesamte Holstein-Interglazial umfaßt hätte, waren denkbar ungünstig. Nur wo Flußschlingen abgeschnitten wurden und verlandeten, konnten organische Reste in größerer Menge angehäuft werden. $\mathrm{Da}$ der Fluß seinen Lauf aber immer wieder wechselte, wurden uns nur relativ kurze Abschnitte des gesamten Interglazials überliefert. Schwierig ist es nun, diese Teilabschnitte als holstein-zeitlich $\mathrm{zu}$ erkennen und in der richtigen Reihenfolge zusammenzusetzen.

Versucht man, die beiden bisher bekannten Abschnitte der Kempen-Krefelder Schichten nur auf Grund der pollenanalytischen Untersuchungen zu datieren, so ergibt sich, daß sie durch das Vorkommen von Picea-Pollen als interglaziale Ablagerungen gekennzeichnet sind. Gegenüber dem Eem-Interglazial ist der Abies-reiche Abschnitt gut unterschieden durch die hohen Anteile an Abies-Pollen und durch das Vorkommen von Pterocarya, Castanea und Azolla. Der Abies-freie Abschnitt dagegen ist, wenn Pterocarya und Castanea fehlen, nur durch das Vorkommen von Azolla unterscheidbar.

Von den Ablagerungen prae-holstein-interglazialer Warmzeiten ist der Tegelen-Ton durch das Vorkommen von Fagus und durch eine größere Zahl von Tertiär-Relikten gekennzeichnet, zu denen neben Pterocarya auch Tsuga, Carya und Eucommia gehören. Ablagerungen der Waal- und der Cromer-Warmzeit sind bisher im Niederrheingebiet nicht genügend aufgefunden und untersucht worden, um für diese charakteristische Merkmale angeben zu können.

Aus der Pollenführung allein kann also bereits mit einiger Sicherheit auf das holsteininterglaziale Alter der Kempen-Krefelder Schichten geschlossen werden. Solange jedoch mit dem Vorkommen etwas älterer Interglaziale (Cromer- und Waal-Interglazial) gerechnet werden muß, ist es ratsam, mehr als bisher auch die makroskopischen Pflanzen- 


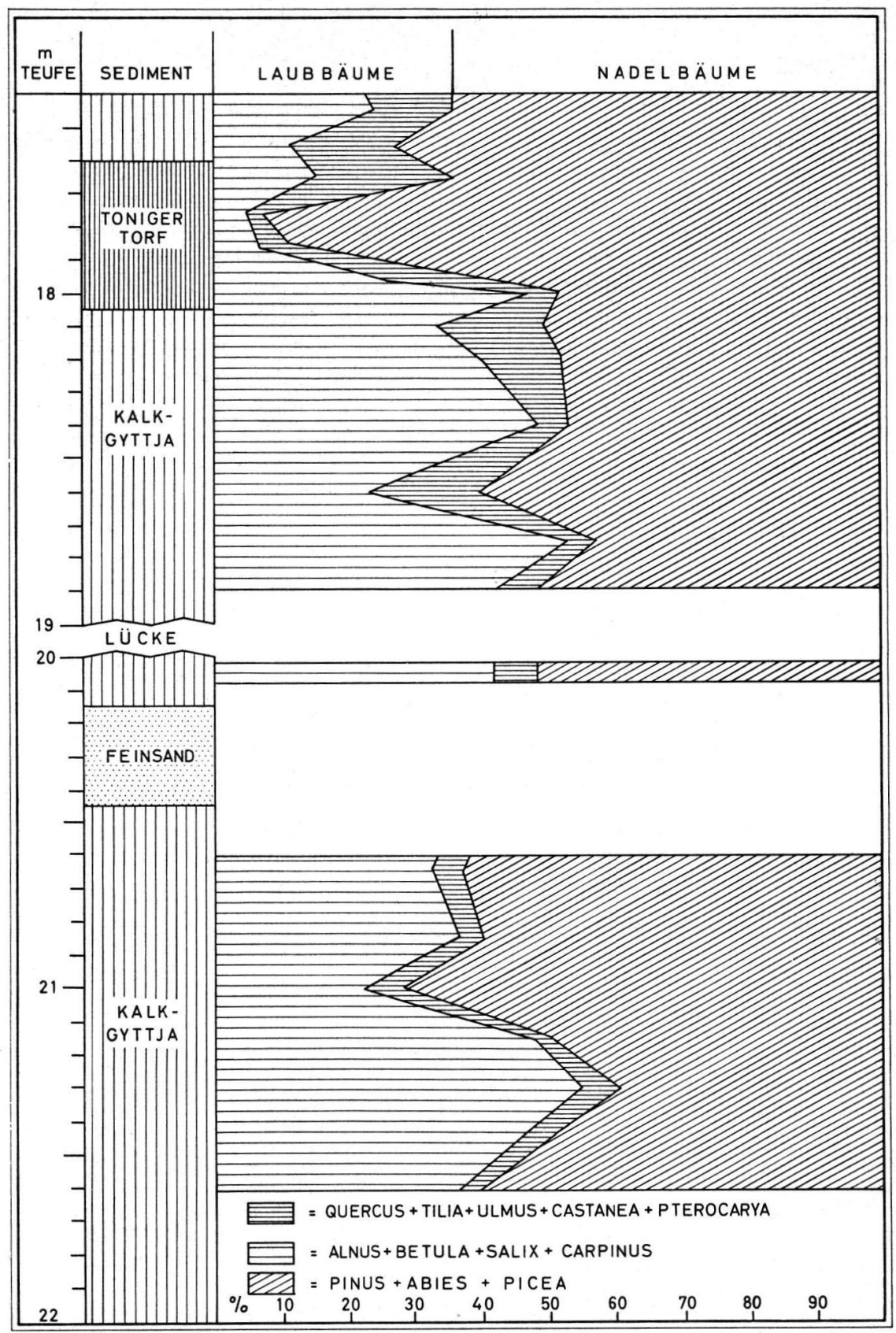

Abb. 6. Graphische Darstellung der prozentualen Anteile von Laubbäumen und Nadelbäumen im Pollendiagramm der aufgeschobenen, in sich ungestörten "Krefelder Schichten“ von Schacht Tönisberg. 
reste zu berücksichtigen. Außerdem sollte in jedem Fall versucht werden, die stratigraphische Stellung der Sedimente im Hangenden und Liegenden zu ermitteln, um auf diese Weise ein größeres $\mathrm{Maß}$ an Sicherheit bei der zeitlichen Einstufung der interglazialen Sedimente zu erhalten.

Abschließend soll noch auf den hohen Anteil der Nadelbäume im Pollenspektrum der Kempen-Krefelder Schichten besonders hingewiesen werden. $\mathrm{Da}$ in den Pollenspektren neben Pinus meist auch Abies reichlich vertreten ist, wogegen die Pollen von Picea nur in geringer Menge vorkommen, macht der Gesamtanteil der Nadelhölzer meist mehr als $50 \%$, in einigen Fällen sogar bis zu 90\% aus (vgl. Abb. 6). Von den meisten Autoren wird ein hoher Anteil an Nadelbaum-Pollen als ein Hinweis auf kühleres Klima gedeutet. $\mathrm{Da}$ im vorliegenden Fall die Gattung Abies sehr stark an der Menge des NadelbaumPollens beteiligt ist, kann jedoch weniger auf ein kühleres, als vielmehr auf ein humideres Klima geschlossen werden (vgl. Kap. VII).

\section{Charakteristische Fossilien aus den holstein-interglazialen Ablagerungen am Niederrhein}

Bisher war es vielfach auch bei pleistozänen Ablagerungen üblich, nach Leitfossilien zu suchen. Mit ihrer Hilfe sollten die entsprechenden Sedimente dann altersmäßig leicht $\mathrm{zu}$ erkennen sein. Leider stellte sich später häufig heraus, daß sich das Leitfossil eines Interglazials auch in älteren oder jüngeren Interglazialen fand, wodurch der eigentliche Charakter des Leitfossils verlorenging; oder es kam überhaupt so selten vor, daß es oft gar nicht gefunden werden konnte. Aus diesem Grunde ist es wenigstens im Pleistozän empfehlenswert, statt einer geringen Zahl von seltenen oder fraglichen Leitfossilien eine größere Zahl von charakteristischen Fossilien aus den verschiedensten Tier- und Pflanzengruppen für ein bestimmtes Interglazial anzugeben.

Für das Holstein-Interglazial am Niederrhein können nach den vorliegenden Untersuchungen folgende charakteristische Fossilien genannt werden:

Mollusken :

Ostrakoden :

Thallophyten:

Pteridophyten:

Spermatophyten:
Valvata naticina MENKE

Vivipara (Paludina) diluviana KunTH

Ilyocypris steegeri $\mathrm{n}$. sp.

Cyclocypris huckei TRIEBEL

Cyclocypris n. sp.

Tectochara meriani diluviana MäDLER

Azolla interglacialica Nikitin

Abies alba MILLER

Euryale ferox SALISBURY

Brasenia purpurea (MICHEAUX) CASPARY

Crataegus acuticarpa (REID) REID

Aldrovandia vesiculosa LiNNE

Vitis silvestris GMELIN

Stratiotes intermedius (HARTz) CHANDLER

Najas flexilis (WILldenow) RostK. \& SCHMidt

Je mehr der vorstehend genannten Arten gemeinsam in einem Sediment vorkommen, um so sicherer kann man auf das holstein-interglaziale Alter der Ablagerung schließen. 


\section{Vergleichende Untersuchungen in den „Krefelder Schichten“ der Inselberge}

Als Inselberge bezeichnet man im Arbeitsgebiet eine Reihe von Einzelbergen, die etwa $5 \mathrm{~km}$ nordöstlich des Schaephuysener Höhenzuges liegen und sich parallel zu diesem von NW nach SE erstrecken (vgl. Abb. 1). Wie sich aus ihrem inneren Aufbau ergab, sind sie Reste eines Stauchmoränenwalles. Leider sind bei den meisten Inselbergen die früher vorhanden gewesenen Aufschlüsse weitgehend verfallen. Nur der Eyller Berg macht hiervon eine Ausnahme, so daß er allein für vergleichende Untersuchungen geeignet ist.

Der Aufbau des Eyller Berges wurde erstmals bekannt, als beim Neubau der Bahnlinie Moers-Geldern sein Nordende durchstochen wurde (vgl. P. G. KRAuse 1918). In späteren Jahren begann die Zeche Friedrich Heinrich am Eyller Berg mit dem Abbau von Kies und Sand, die unter Tage zum Versatz und später über Tage zu Bauzwecken verwandt wurden. Die Aufschlüsse entstanden im zentralen Teil des Inselberges, und zwar von seiner Nordostflanke her. Dabei wurde - wie am Nordende des Berges - eine intensive Verschuppung von Sand- und Kieslagen mit Tonhorizonten festgestellt. Die Schuppen fallen alle nach NE ein, woher also der einseitige Druck herzuleiten ist, der vom Inlandeis der Saale-Eiszeit bewirkt wurde.

Die aufgeschlossenen Tonhorizonte, welche auf eine Erstreckung von 400 Metern 7 bis 11 mal auftreten, sind infolge Oxydation durch oberflächennahes Grundwasser stark verwittert. Der ursprüngliche Kalkgehalt ging weitgehend verloren; der Fossilinhalt wurde nahezu ganz zerstört. Bisher konnten nur wenige Opercula von Bithynia tentaculata und Gehäuse von Valvata naticina in diesem Ton nachgewiesen werden (P. G. KRAUSE 1912, 1918). Die zeitliche Einstufung der Tonhorizonte als „Krefelder Schichten“ des HolsteinInterglazials wurde dadurch aber wahrscheinlich gemacht.

Die Sande und Kiese, die sich zwischen den Tonhorizonten finden, weisen Quarzgehalte von 33 bis 42\% auf (J. D. DE Jong 1956, G. C. MAarleveld 1956). Sie werden deshalb der Unteren Mittelterrasse zugerechnet. Den Aufbau des Eyller Berges erklärte man sich daraufhin so, daß durch den Druck des Inlandeises die „Krefelder Schichten“ mit den auflagernden Sanden und Kiesen der Unteren Mittelterrasse intensiv verschuppt worden seien.

Die großen Aufschlüsse im Eyller Berg sollen in den nächsten Jahren mit Schutt wieder zugefüllt werden. Um die Einwirkung der Schuttmassen auf das Grundwasser überprüfen zu können, mußten einige Beobachtungsbrunnen angelegt werden. Das Probenmaterial dieser Brunnenbohrungen wurde durch Herrn Markscheider REICHEL vom Steinkohlenbergwerk Friedrich-Heinrich-A.G., Kamp-Lintfort, für wissenschaftliche Untersuchungen freundlicherweise zur Verfügung gestellt, wofür an dieser Stelle herzlich gedankt sei.

Zur Untersuchung lagen Probenserien von 7 Bohrungen vor. Davon wurden die Bohrungen E 1 bis E 6 am Außenrand des Eyller Berges, die Bohrung E IV weiter bergeinwärts von der Sohle des Kiesgrubenaufschlusses aus abgeteuft. Leider erreichte keine der Bohrungen den tertiären Untergrund der pleistozänen Sedimente.

Die Lagepunkte der einzelnen Bohrungen, ihre unterschiedlichen vertikalen Reichweiten und die erschlossenen Schichten ergeben sich aus Abb. 7.

Alle erfolgversprechenden Sedimente wurden mit $\mathrm{H}_{2} \mathrm{O}_{2}$ aufbereitet und geschlämmt. Die Schlämmrückstände wurden getrocknet und auf ihre Fossilführung untersucht. Dabei erwiesen sich die Sedimente der Bohrungen E 2 und E 6 als fossilleer. In der fossilführenden Schicht von Bohrung E 5 fand sich nur ein Kalkplättchen von Agriolimax. Es ist sehr wahrscheinlich, daß es sich bei diesem Sediment um Schwemmlöß handelt und nicht um eine holstein-interglaziale Ablagerung. Die Fossilien aus den übrigen Bohrungen werden in Tabelle 12 namentlich zusammengestellt. 


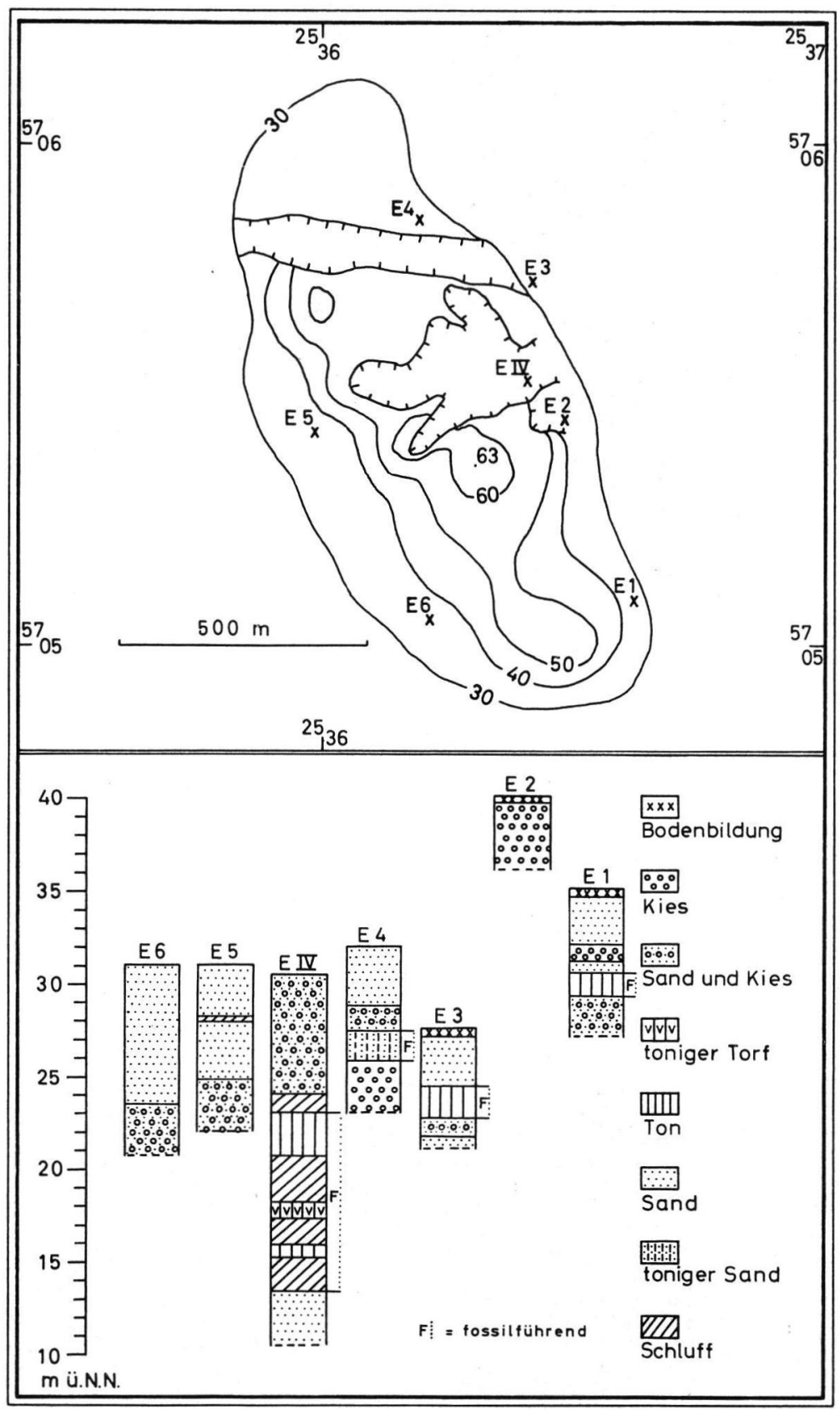

Abb. 7. Bchrprofile vom Eyller Berg bei Moers. 


\section{Tabelle 12}

Fossilien aus den holstein-interglazialen Ablagerungen des Eyller Berges. $\mathrm{H}=$ häufig (mehr als

5. Exemplare), $\mathrm{S}=$ selten ( 1 bis 5 Exemplare), $-=$ fehlend.

\begin{tabular}{|c|c|c|c|c|c|}
\hline Fo & Bohrung & E 1 & E 3 & E 4 & E IV \\
\hline 1 & Valvata naticina & - & - & - & $S$ \\
\hline 2 & Bithynia tentaculata & - & $\mathrm{S}$ & $\mathrm{S}$ & $\mathrm{H}$ \\
\hline 3 & Agriolimax laevis & - & - & - & $\mathrm{S}$ \\
\hline 4 & Unio sp. & - & $\mathrm{S}$ & - & $\mathrm{S}$ \\
\hline 5 & Pisidium sp. & - & - & - & $\mathrm{S}$ \\
\hline 6 & Ilyocypris gibba & $\mathrm{S}$ & - & - & - \\
\hline 7 & Erpetocypris reptans & - & - & - & $\mathrm{S}$ \\
\hline 8 & Fischschuppen-Bruchstücke & - & - & - & $\mathrm{S}$ \\
\hline 9 & Cypriniden-Schlundzähne & $\mathrm{S}$ & - & - & $\mathrm{H}$ \\
\hline 10 & ? Rana sp. & - & - & - & $\mathrm{S}$ \\
\hline 11 & Tectochara meriani diluviana & - & - & - & $\mathrm{H}$ \\
\hline 12 & Chara sp. & - & - & - & $\mathrm{H}$ \\
\hline 13 & Campylium stellatum & $\mathrm{S}$ & $\mathrm{S}$ & - & $\mathrm{S}$ \\
\hline 14 & Azolla interglacialica & $\mathrm{S}$ & $\mathrm{H}$ & $\mathrm{H}$ & $\mathrm{H}$ \\
\hline 15 & Salvinia natans & $\mathrm{S}$ & $\mathrm{S}$ & $\mathrm{S}$ & $\mathrm{S}$ \\
\hline 16 & Abies alba & - & - & - & $\mathrm{S}$ \\
\hline 17 & Ranunculus aquatilis & - & $\mathrm{S}$ & $\mathrm{S}$ & $\mathrm{H}$ \\
\hline 18 & Ranunculus sceleratus & $\mathrm{S}$ & - & $\mathrm{H}$ & $\mathrm{H}$ \\
\hline 19 & Ranunculus lingua & - & $\mathrm{S}$ & - & $\mathrm{S}$ \\
\hline 20 & Nuphar luteum & $\mathbf{S}$ & - & $\mathrm{S}$ & - \\
\hline 21 & Nymphaea alba & $S$ & - & - & $\mathrm{S}$ \\
\hline 22 & Ceratopbyllum demersum & $\mathrm{S}$ & - & $\mathrm{H}$ & $\mathrm{S}$ \\
\hline 23 & Rubus caesius & - & - & - & $\mathrm{S}$ \\
\hline 24 & Rubus sp. & - & $\mathrm{H}$ & - & - \\
\hline 25 & Myriophyllum spicatum & - & - & $\mathrm{S}$ & $\mathrm{H}$ \\
\hline 26 & Hippuris vulgaris & - & - & $\mathrm{S}$ & - \\
\hline 27 & Aldrovandia vesiculosa & - & - & $\mathrm{S}$ & - \\
\hline 28 & Vitis silvestris & - & - & - & $\mathrm{S}$ \\
\hline 29 & Hydrocotyle vulgaris & - & $\mathrm{S}$ & - & - \\
\hline 30 & Oenantbe aquatica & $\mathrm{S}$ & $\mathrm{S}$ & $\mathrm{S}$ & $\mathrm{S}$ \\
\hline 31 & Alnus glutinosa & $\mathrm{H}$ & - & - & - \\
\hline 32 & Alnus incana & $\mathrm{S}$ & - & - & - \\
\hline 33 & Alnus sp. & $\mathrm{S}$ & $\mathrm{S}$ & - & $\mathrm{S}$ \\
\hline 34 & Urtica dioica & $\mathrm{S}$ & $\mathrm{H}$ & $\mathrm{S}$ & S \\
\hline 35 & Urtica sp. & - & - & - & $\mathrm{S}$ \\
\hline 36 & Rumex maritimus & $\mathrm{S}$ & - & $\mathrm{S}$ & $\mathrm{S}$ \\
\hline 37 & Rumex bydrolapatbum & $\mathrm{S}$ & - & - & - \\
\hline 38 & Lycopus europaeus & - & - & - & $\mathrm{S}$ \\
\hline 39 & Mentha sp. & - & $\mathrm{S}$ & - & - \\
\hline 40 & Solanum dulcamara & - & $\mathrm{S}$ & - & $\mathrm{S}$ \\
\hline 41 & Sambucus nigra & $\mathrm{S}$ & - & - & $\mathrm{S}$ \\
\hline 42 & Alisma plantago-aquatica & - & $\mathrm{S}$ & $\mathrm{S}$ & $\mathrm{S}$ \\
\hline 43 & Sagittaria sagittifolia & - & $\mathrm{H}$ & $\mathrm{S}$ & - \\
\hline 44 & Stratiotes intermedius & - & $\mathrm{S}$ & $\mathrm{S}$ & - \\
\hline 45 & Potamogeton pusillus & - & - & - & S \\
\hline 46 & Potamogeton sp. & - & - & - & $S$ \\
\hline 47 & Najas minor & - & - & $\mathrm{S}$ & $\mathrm{H}$ \\
\hline 48 & Najas marina & - & - & - & $S$ \\
\hline 49 & Najas flexilis & - & - & $\bar{c}$ & $\mathrm{H}$ \\
\hline 50 & Zannichellia palustris & - & - & $\mathrm{S}$ & $\mathrm{H}$ \\
\hline 51 & Scirpus sp. & - & - & - & S \\
\hline 52 & Carex sp. & $\mathrm{S}$ & $\mathrm{S}$ & $\mathrm{S}$ & S \\
\hline 53 & Sparganium ramosum & - & S & 一 & - \\
\hline
\end{tabular}

Auf Grund der nun bekannten Fossilführung kann gesagt werden, daß es sich bei den tonigen Einschaltungen vom Eyller Berg tatsächlich um die „Krefelder Schichten“ des Holstein-Interglazials handelt. Für den stratigraphischen Aufbau ergibt sich, vor allem auf Grund von Bohrung E IV, daß nur höhere Teile der „Krefelder Schichten“ mit den 
auflagernden Sanden und Kiesen der Unteren Mittelterrasse verschuppt wurden. Die tiefsten Ablagerungen, welche durch die Bohrungen aufgeschlossen wurden, zeigen einen allmählichen Übergang zu gröberkörnigen Sedimenten, wie dies auch im Profil von Schacht Tönisberg zu beobachten war. Es ist deshalb anzunehmen, daß die tiefsten erbohrten Ablagerungen "Krefelder Schichten" in situ darstellen.

Die fossilführenden Sedimente von Bohrung E 4 lieferten zwar reichlich Fossilien, die auf ein holstein-interglaziales Alter der Ablagerungen hinweisen; der Sedimentcharakter spricht jedoch eindeutig dagegen. Hier liegt entweder eine Fließerde vor oder wahrscheinlicher noch eine Grundmoräne, von der holstein-interglaziale Sedimente aufgenommen wurden.

Bemerkenswert ist noch, daß durch die obigen Untersuchungen nur im zentralen Teil und an der Ostflanke des Eyller Berges „Krefelder Schichten“ nachgewiesen werden konnten; an der Westflanke fehlen sie. Diese Tatsache ist mit von Bedeutung für die Vorstellungen über die Entstehung der Stauchmoränenwälle am Niederrhein (vgl. Kap. VIII.).

\section{Vergleichende Untersuchungen in den „Kempener Schichten“}

Aus dem Untergrund der Gegend von Krefeld sind seit nahezu 100 Jahren tonige und torfige Sedimente bekannt. Fossilien wurden aus diesen Ablagerungen wohl erstmals von E. KöNIGs (1908) gemeldet, aber nicht bestimmt und ihr Vorkommen falsch ausgedeutet. Erst durch K. Bertsch, A. Steeger \& U. Steusloff (1931) wurde die Fossilführung genauer untersucht, wobei sich eindeutig ein interglaziales Alter der Ablagerungen ergab.

A. Steeger (1931b) hatte Bedenken, diese Ablagerungen mit den „Krefelder Schichten“ der Stauchmoränenwälle oder mit den „Moerser Schichten“ aus dem PattbergSchacht 1 bei Repelen gleichzusetzen und gab ihnen daher den besonderen Namen „Kempener Schichten". Als solche erwiesen sich von den anfangs beschriebenen Vorkommen im Lauf der Zeit nur die Schichten aus den Bohrungen Kempener Feld und Heideck bei Krefeld. Die Schichten aus der Bohrung Neuwerk bei Mönchen-Gladbach wurden später (A. STEEger 1952a) mit dem Sondernamen "Neuwerker Schichten" belegt, weil sie sich durch das Vorkommen von Fagus-Pollen (bis zu 10\%) auszeichneten. Die Proben, welche aus der Bohrung Neuwerk untersucht wurden, konnten erst nachträglich von der Halde aufgesammelt werden. Es muß daher mit einer Verunreinigung durch rezente Fagus-Pollen gerechnet werden. Ansonsten spricht das Vorkommen von Fagus-Pollen neben Samen von Stratiotes intermedius für ein altpleistozänes Alter dieser interglazialen Schichten. Es ist sehr zu wünschen, daß die „Neuwerker Schichten“ einer erneuten Untersuchung zugänglich gemacht werden.

Obgleich die „Kempener Schichten“ im Untergrund der Gegend von Krefeld weit verbreitet sind und seit 1931 durch zahlreiche Bohrungen aufgeschlossen wurden, sind seit der Arbeit von K. Bertsch, A. Steeger \& U. Steusloff (1931) nur noch pollenanalytische Untersuchungen einzelner Proben aus diesen Ablagerungen durchgeführt worden. Unsere Kenntnis von der Fossilführung der „Kempener Schichten“ blieb daher auf eine kleine Molluskenfauna und einzelne Pollenspektren beschränkt.

Die pollenanalytischen Untersuchungen der „Kempener Schichten“ zeigten das gleiche Ergebnis wie die der „Krefelder Schichten“: neben Proben mit hohen Anteilen an AbiesPollen kamen solche vor, in denen Abies-Pollen fast oder völlig fehlten. Auch die übrigen Baumpollen zeigten in beiden Ablagerungen eine ähnliche Verteilung, so daß H. KARRENBERG \& U. REIN (1951) nicht zögerten, diese beiden interglazialen Horizonte gleichzusetzen. Unter der älteren Bezeichnung „Krefelder Schichten“" wurden sie vereint; die 
Bezeichnung „Kempener Schichten“ sollte in Wegfall kommen. Dieses Vorgehen war insofern unglücklich, als die Diskussionen um die Altersstellung der "Kempener Schichten“ nicht aufhörten. Unter der Bezeichnung „Krefelder Schichten“ konnte jetzt aber zweierlei verstanden werden: einmal die Bezeichnung von A. STEEGER (1927b, 1931b, 1952a), zum anderen die Ausdeutung durch H. Karrenberg \& U. ReIN (1951).

Die Sedimente im Liegenden der „Kempener Schichten“ sind auf Grund von sedimentpetrographischen Untersuchungen als Ablagerungen der Mittleren Mittelterrasse gedeutet worden (J. D. DE Jong 1956, C. G. MaArleveld 1956). H. Karrenberg \& U. Rein (1951), die diese Sedimente noch als Hauptterrassen-Ablagerungen angesehen hatten, stellten bei der Untersuchung einer großen Zahl von Bohrungen aus dem Bereich der Stadt Krefeld fest, daß die Sedimente im Liegenden der „Kempener Schichten “ einen einheitlichen Aufbau zeigen: ihre Basis wird stets von Feinsanden des marinen Tertiärs gebildet; die tieferen Horizonte sind grobkiesig; nach oben hin nimmt die Korngröße allmählich ab; der Übergang zu den interglazialen Sedimenten (Feinsande, Tone, Torfe) erfolgt fast unmerklich, so daß eine basale Begrenzung der "Kempener Schichten “ ohne eingehende Untersuchung von Probenmaterial nicht möglich ist. Daraus wurde gefolgert, daß die „Kempener Schichten“ aus einer älteren Sedimentationsfolge hervorgehen und diese abschließen.

Uber den „Kempener Schichten“ lagern mit scharfer Grenze Kiese und Sande der Krefelder Mittelterrasse, deren zeitliche Stellung noch nicht eindeutig festgelegt werden konnte. K. N. Tноме $(1958,1959)$ fand einleuchtende Gründe dafür, daß die Sedimente der Krefelder Mittelterrasse zur Zeit der größten Inlandeis-Ausdehnung während des Drenthe-Stadiums der Saale-Eiszeit zur Ablagerung kamen, als der Rhein durch das Inlandeis nach Westen abgedrängt worden war und ein breites Hochwasserbett bildete. K. H. KaISER dagegen (K. H. Kaiser \& R. SchütrumpF 1960, K. H. KaISER 1961) und W. PAas (1961) nehmen an, daß die Sedimente der Krefelder Mittelterrasse erst während des Warthe-Stadiums der Saale-Eiszeit abgelagert wurden, während E. Mückenhausen (1954) wie einige Vorgänger die Krefelder Mittelterrasse in die Weichsel-Eiszeit eingliedert.

Auf die unterschiedliche Altersstellung der Krefelder Mittelterrasse durch die einzelnen Autoren ist es zurückzuführen, daß auch das Alter der „Kempener Schichten “ immer wieder diskutiert wurde. Drei Möglichkeiten kamen dabei aus obigen stratigraphischen Gründen in Betracht: entweder vertreten die „Kempener Schichten“ das Holstein-Interglazial, das Gerdau-Interstadial (? Ohe-Interglazial) oder gar das Eem-Interglazial. Von einigen Autoren (A. STEeger 1931b, 1952a; K. H. Kaiser \& R. SchütrumpF 1960, K. H. KAISER 1961) wurde neben stratigraphischen Gründen als Einwand gegen ein holsteinzeitliches Alter der "Kempener Schichten“ eine Faunenverschiedenheit gegenüber den „Krefelder Schichten" geltend gemacht.

Um die Diskussionen über die zeitliche Stellung der „Kempener Schichten“ einem Ende näherzubringen, erschien es vor allem ratsam, die Fossilführung dieser Schichten besser kennenzulernen. Gelegenheit dazu wurde geboten, als 1960 bei den Baugrunduntersuchungen für den geplanten Neubau des Geologischen Landesamtes in Krefeld, De-GreiffStraße, zwei Bohrungen niedergebracht wurden, welche die "Kempener Schichten “ in einer Mächtigkeit von etwa $5 \mathrm{~m}$ durchteuften. Die Proben dieser Bohrungen wurden freundlicherweise von Herrn Dr. J. KaLterherberg für paläontologische Untersuchungen zur Verfügung gestellt, wofür an dieser Stelle bestens gedankt sei.

Die Lage der Bohrungen ist folgende: Meßtischblatt Krefeld (Nr. 4605), R 37400 , H 89610 und R 37410, H 89690. Die Geländehöhe beträgt 39 m ü.N.N.; es wurden Teufen von 18,6 bzw. $18,7 \mathrm{~m}$ unter Gelände erreicht, wobei von oben nach unten nachstehende Schichtenfolgen aufgeschlossen wurden: 


$$
\begin{array}{ll}
\text { Bohrung 1 } & \multicolumn{2}{c}{\text { Bohrung 2 }} \\
0-0,4 \mathrm{~m} & 0-0,2 \mathrm{~m} \\
-1,05 \mathrm{~m} & -0,9 \mathrm{~m} \\
-11,85 \mathrm{~m} & -11,15 \mathrm{~m} \\
-16,95 \mathrm{~m} & -16,4 \mathrm{~m} \\
& \\
-18,6 \mathrm{~m} & -18,7 \mathrm{~m}
\end{array}
$$

\section{Mutterboden;}

gelblichbrauner Lößlehm: weichsel-eiszeitlich;

gelblichbrauner Grob-, Mittel- und Feinsand mit Feinund Mittelkies: Krefelder Mittelterrasse;

Wechsellagerung von tonigem Torf mit tonigem und humosem, z. T. kalkhaltigem Schluff, der in tieferen Lagen in Feinsand übergeht: „Kempener Schichten“;

grauer Fein-, Mittel- und Grobsand mit etwas Feinkies: Mittlere Mittelterrasse.

Schichtenverzeichnisse früherer Bohrungen, die nur wenige hundert Meter von den beiden vorstehend beschriebenen Bohrungen entfernt niedergebracht wurden, zeigen, daß die Ablagerungen der Mittleren Mittelterrasse zur Tiefe hin grobkörniger werden und im untersten Teil auch eine sekundäre Fossilführung aufweisen. Die Grenze der pleistozänen Ablagerungen zu den Feinsanden des marinen Tertiärs wurde $550 \mathrm{~m}$ östlich unserer Bohrungen bei $33 \mathrm{~m}$ Teufe erbohrt.

Von den "Kempener Schichten“ wurden 10 Proben aus der Bohrung 1 und weitere 18 Proben aus der Bohrung 2 untersucht; alle Proben erwiesen sich als mehr oder weniger stark fossilführend. Weitere 5 Proben wurden von den Ablagerungen der Mittleren Mittelterrasse untersucht; sie waren alle fossilleer. Die basale Grenze der interglazialen Sedimente wurde daraufhin dort gezogen, wo die Fossilführung beginnt.

Die Fossilführung besteht in der Hauptsache aus Pflanzenresten, wobei Früchte und Samen überwiegen. Daneben kommen Reste von einigen Gastropoden und ganz untergeordnet auch solche von Wirbeltieren vor. Eine Ubersicht über die nachgewiesenen Gattungen und Arten vermittelt Tabelle 13.

$$
\text { Tabelle } 13
$$

Fossilien aus den „Kempener Schichten“ der Bohrungen De-Greiff-Straße in Krefeld; $\mathrm{H}=$ häufig (mehr als 5 Exemplare), $\mathrm{S}=$ selten (1-5 Exemplare).

$\begin{aligned} 1 & \text { Valvata sp. } \\ 2 & \text { Bithynia tentaculata } \\ 3 & \text { Succinea sp. } \\ 4 & \text { Agriolimax sp. } \\ 5 & \text { ? Clausilia sp. } \\ 6 & \text { ? Helix sp. } \\ 7 & \text { ? Rana sp. } \\ 8 & \text { Fischschuppen-Bruchstücke } \\ 9 & \text { Azolla interglacialica } \\ 10 & \text { Salvinia natans } \\ 11 & \text { Ranunculus aquatilis } \\ 12 & \text { Ranunculus sceleratus } \\ 13 & \text { Ranunculus lingua } \\ 14 & \text { Ranunculus cf. repens } \\ 15 & \text { Nuphar luteum } \\ 16 & \text { Ceratophyllum demersum } \\ 17 & \text { Rubus sp. } \\ 18 & \text { Elatine hydropiper } \\ 19 & \text { Vitis silvestris }\end{aligned}$

$\begin{array}{llll}\mathrm{S} & 20 & \text { Hydrocotyle vulgaris } & \mathrm{S} \\ \mathrm{H} & 21 & \text { Oenanthe aquatica } & \mathrm{H} \\ \mathrm{S} & 22 & \text { Alnus glutinosa } & \mathrm{H} \\ \mathrm{H} & 23 & \text { Alnus incana } & \mathrm{S} \\ \mathrm{H} & 24 & \text { Alnus sp. } & \mathrm{H} \\ \mathrm{H} & 25 & \text { Urtica dioica } & \mathrm{H} \\ \mathrm{S} & 26 & \text { Urtica sp. } & \mathrm{H} \\ \mathrm{S} & 27 & \text { Stellaria sp. } & \mathrm{S} \\ \mathrm{H} & 28 & \text { Lycopus europaeus } & \mathrm{H} \\ \mathrm{H} & 29 & \text { Mentha sp. } & \mathrm{S} \\ \mathrm{H} & 30 & \text { Solanum dulcamara } & \mathrm{S} \\ \mathrm{H} & 31 & \text { Bidens tripartitus } & \mathrm{H} \\ \mathrm{S} & 32 & \text { Alisma plantago-aquatica } & \mathrm{H} \\ \mathrm{H} & 33 & \text { Sagittaria sagittifolia } & \mathrm{S} \\ \mathrm{S} & 34 & \text { Stratiotes intermedius } & \mathrm{H} \\ \mathrm{S} & 35 & \text { Carex sp. } & \mathrm{H} \\ \mathrm{H} & 36 & \text { Typha cf. angustifolia } & \mathrm{H} \\ \mathrm{S} & 37 & \text { Sparganium ramosum } & \mathrm{H} \\ \mathrm{S} & & & \end{array}$

Durch G. v. D. Brelie (1960b) wurden vier Proben aus der Bohrung 1 und eine Probe aus der Bohrung 2 pollenanalytisch untersucht (vgl. Tabelle 14). Diese Untersuchungen zeigen, daß alle Proben durch die Vorherrschaft von Alnus charakterisiert sind. Die Pollen von Abies konnten nur in einer Probe mit 1\% nachgewiesen werden, so daß die aufgeschlossenen Ablagerungen dem Abies-freien Abschnitt der „Kempener Schichten“ zugeordnet werden müssen. Auf holstein-interglaziales Alter deutet nur das Vorkommen 
von Castanea in einer Probe mit 1\% hin; ansonsten könnten die Proben ebensogut eeminterglazialen Ablagerungen entstammen. Zieht man jedoch die Ergebnisse der Untersuchung makroskopischer Pflanzenreste aus diesen Schichten hinzu, so ergeben sich aus dem gemeinsamen Vorkommen von Azolla interglacialica, Vitis silvestris und Stratiotes intermedius aber deutliche Hinweise auf das holstein-interglaziale Alter der Sedimente, solange diese Pflanzen in eindeutig jüngeren interglazialen Ablagerungen nicht nachgewiesen werden können.

\section{Tabelle 14}

Pollenspektren von 5, Proben der „Kempener Schichten“ aus den Bohrungen De-Greiff-Straße in Krefeld.

\begin{tabular}{|c|c|c|c|c|c|}
\hline & 53815 & 816 & 817 & 818 & 819 \\
\hline Pinus & 17 & 20 & 33 & 43 & $16 \%$ \\
\hline Picea & - & 2 & 1 & - & - \\
\hline Abies & - & - & - & - & 1 \\
\hline Salix & 16 & - & 1 & 1 & 13 \\
\hline Betula & 1 & - & 1 & 2 & - \\
\hline Alnus & 62 & 78 & 60 & 53 & 66 \\
\hline Quercus & 2 & - & - & 1 & 1 \\
\hline Tilia & - & - & 2 & - & 1 \\
\hline Ulmus & 1 & - & 1 & - & 1 \\
\hline Carpinus & 1 & - & - & - & - \\
\hline Castanea & - & - & - & - & 1 \\
\hline Corylus & - & 2 & 2 & 1 & $3 \%$ \\
\hline Ilex & - & - & 1 & - & - \\
\hline Gramineae & 6 & - & 1 & 2 & 3 \\
\hline Cyperaceae & 1 & - & - & - & 2 \\
\hline Nymphaea & 1 & - & - & - & 1 \\
\hline Sparganium & 3 & - & - & 2 & 9 \\
\hline Typha & 1 & - & - & 1 & 1 \\
\hline Filices & 1 & 6 & 1 & 5 & - \\
\hline Sphagnum & 1 & - & 1 & 1 & - \\
\hline
\end{tabular}

$\mathrm{Zu}$ besprechen bliebe noch die Molluskenfauna, die sich von derjenigen aus den „Krefelder Schichten " erheblich unterscheiden soll. Nachgewiesen wurden bisher nur Gastropoden, von denen U. Steusloff (in K. Bertsch, A. Steeger \& U. Steusloff 1931) folgende Arten bestimmen konnte:

Goniodiscus rotundatus MüLL.

Eulota fruticum MüLL.

Fruticicola cf. bispida L.

Monacha incarnata MüLL.

Helicodonta obvoluta MüLL.

Arianta arbustorum L.

Cepaea nemoralis L.

Cepaea hortensis MüLl.

Clausilia Laciniaria) biplicata MoNTAGU

Succinea sp.

Vallonia costata MüLL.

Ena montana DRAPARNAUD

Cocblicopa lubrica MüLL.

Stagnicola palustris MüLL.

\begin{tabular}{|c|c|}
\hline \multicolumn{2}{|c|}{ 5. Exemplare } \\
\hline & \\
\hline & \\
\hline & \\
\hline \multirow{2}{*}{$\begin{array}{l}2 \\
4\end{array}$} & $\begin{array}{c}\text { Exemplare } \\
2 \\
2 \\
1 \\
1\end{array}$ \\
\hline & \multirow{2}{*}{ 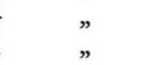 } \\
\hline & \\
\hline \multirow{2}{*}{\multicolumn{2}{|c|}{ ” }} \\
\hline & \\
\hline \multicolumn{2}{|r|}{$"$} \\
\hline \multirow{2}{*}{\multicolumn{2}{|c|}{ " }} \\
\hline & \\
\hline & " \\
\hline & \\
\hline
\end{tabular}

Hierzu können aus den „Kempener Schichten“ der Bohrungen De-Greiff-Straße in Krefeld noch folgende Arten hinzugefügt werden:
$V$ alvata sp.
Bitbynia tentaculata L.
Agriolimax sp.

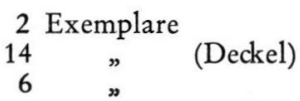

Alle gesperrt gedruckten Gattungen und Arten sind auch aus den „Krefelder Schichten" bekannt. 
Bei den Arten, die durch U. STeusloff nachgewiesen wurden, handelt es sich ausschließlich um Landschnecken. Diese Tatsache ist bemerkenswert, weil die Ablagerungen aus limnisch-fluviatilen Sedimenten bestehen. Die Gastropoden sind also im Hochwassergenist eines Altwassers aus den damaligen Auenwäldern des Rheins zusammengeschwemmt worden und stellen daher ein allochthones Element dieser Ablagerungen dar. Ein altersmäßiger Unterschied gegenüber den „Krefelder Schichten“ ergibt sich daraus keineswegs, zumal dort 50\% dieser Gastropoden ebenfalls nachgewiesen werden konnten. Der vorhandene Unterschied ist vielmehr rein faziell bedingt. Daß bei fortgesetzter Aufsammlung und Untersuchung der Fauna aus den „Kempener Schichten “ eine größere Übereinstimmung mit den Funden aus den „Krefelder Schichten“ erzielt wird, ergibt sich zum Beispiel aus den Funden, welche die Bohrungen De-Greiff-Straße erbrachten. Durch diese wurden für die „Kempener Schichten“ erstmals Wasserschnecken, also autochthone Elemente dieser Ablagerungen nachgewiesen.

Für eine Gleichsetzung der „Kempener Schichten“ mit den „Krefelder Schichten“ lassen sich folgende Gründe anführen:

1. Die „Kempener Schichten“ gehen wie die „Krefelder Schichten“ ohne scharfe Grenze aus der älteren Sedimentationsfolge der Mittleren Mittelterrasse hervor und schließen diese ab.

2. Eine scharfe Grenze, wie sie für eine Erosionsdiskordanz gefordert werden muß, findet sich nur an der Oberkante der „Kempener Schichten“. Die Altersstellung der Krefelder Mittelterrasse hat daher wenig Einfluß auf die zeitliche Einstufung der „Kempener Schichten".

3. Pollenanalytische Untersuchungen zeigen, daß sowohl „Kempener“ als auch „Krefelder Schichten " einen Abies-reichen und einen Abies-freien Abschnitt aufweisen.

4. Der Nachweis von Azolla interglacialica, Vitis silvestris und Stratiotes intermedius in den „Kempener Schichten “ spricht für deren Einstufung in das Holstein-Interglazial, solange diese Pflanzen in eindeutig jüngeren Ablagerungen nicht nachgewiesen werden können.

5. Ein altersmäßiger Faunenunterschied zwischen „Kempener“ und „Krefelder Schichten " existiert nicht. Die vorhandenen Unterschiede sind vielmehr rein faziell bedingt oder in der geringeren Erforschung der „Kempener Schichten“ begründet.

Aus den vorstehend genannten Gründen werden die „Kempener Schichten“ mit den „Krefelder Schichten“ gleichgesetzt. Als Bezeichnung für diese holstein-interglazialen Ablagerungen am Niederrhein wird der Name Kempen-Krefelder Schichten vorgeschlagen.

In der nachfolgenden Tabelle wird die stratigraphische Stellung der mittel- und jungpleistozänen Ablagerungen des Niederrheingebietes so dargestellt, wie sie sich nach den durchgeführten Untersuchungen ergibt.

\section{Klimatische Verhältnisse im Niederrheingebiet während des Holstein-Interglazials}

Für die Beurteilung der klimatischen Verhältnisse am Niederrhein während des Holstein-Interglazials können hauptsächlich nur die gefundenen Pflanzenreste herangezogen werden. Die Ostrakoden und Mollusken sind so sehr vom örtlichen Kleinklima abhängig, $\mathrm{daß}$ sie für solche Betrachtungen weitgehend auszuschalten sind.

Im Niederrheingebiet entspricht die durch Fossilfunde belegte Flora des HolsteinInterglazials weitgehend der heutigen (vgl. Tabelle 16), woraus sich folgern läßt, daß auch das damalige Klima weitgehend dem der Jetztzeit entsprach, also daß der atlantischozeanische Typ der gemäßigten Breiten vorherrschend war. 
Tabelle 15

Stratigraphische Gliederung der Ablagerungen des Mittel- und Jungpleistozäns am Niederrhein.

\begin{tabular}{|c|c|c|c|c|}
\hline \multirow{4}{*}{ 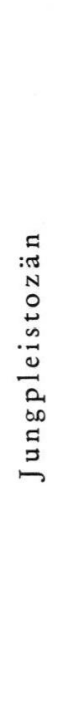 } & \multicolumn{2}{|c|}{ Weichsel- (Würm-) Glazial } & $\begin{array}{l}-\frac{\text { Jüngere }}{\mathrm{E}} \\
--\frac{-}{\text { Altere I }} \\
--\frac{-}{\text { Weez }}\end{array}$ & $\begin{array}{l}\frac{\text { derterrasse }}{-----} \\
\text { ion } \\
\text { derterrasse } \\
------ \\
\text { chichten }\end{array}$ \\
\hline & \multirow{3}{*}{$\begin{array}{l}\text { Saale- } \\
\text { (Riß-) } \\
\text { Glazial }\end{array}$} & $\begin{array}{l}\text { Warthe- } \\
\text { Stadium }\end{array}$ & \multicolumn{2}{|c|}{$\begin{array}{c}\text { Weezer Schichten } \\
---------\end{array}$} \\
\hline & & $\begin{array}{c}\text { Gerdau- } \\
\text { Interstadial }\end{array}$ & \multicolumn{2}{|c|}{ Erosion } \\
\hline & & $\begin{array}{l}\text { Drenthe- } \\
\text { Stadium }\end{array}$ & $\begin{array}{c}\text { Krefelder } \\
\text { Mittel- } \\
\text { terrasse } \\
-\frac{-}{\text { Erosion }} \\
-\frac{--1-}{\text { Untere }}\end{array}$ & $\begin{array}{l}\text { Inlandeis am } \\
\text { Niederrhein. } \\
\text { Bildung der } \\
\text { Endmoränen } \\
\text { - telterrasse }\end{array}$ \\
\hline 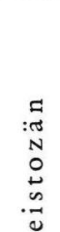 & \multicolumn{2}{|c|}{ Holstein-Interglazial } & \multirow{3}{*}{\multicolumn{2}{|c|}{$\begin{array}{c}\text { Erosion } \\
---------- \\
\text { Kempen-Krefelder Schichten } \\
---------- \\
\text { "Moerser Schichten" } \\
\text { Mittlere Mittelterrasse } \\
---------- \\
\text { Erosion } \\
\text { Obere Mittelterrasse } \\
\text { ? }--------\end{array}$}} \\
\hline $\begin{array}{l}\stackrel{n}{a} \\
\stackrel{0}{ \pm} \\
\stackrel{ \pm}{\Sigma}\end{array}$ & \multicolumn{2}{|c|}{ Elster- (Mindel-) Glazial } & & \\
\hline & \multicolumn{2}{|c|}{ Cromer-Interglazial } & & \\
\hline
\end{tabular}

Unterschiede ergeben sich insofern, als einige der Interglazial-Pflanzen in der heutigen Flora fehlen. Dabei handelt es sich vor allem um Wasserpflanzen (Trapa natans, Aldrovandia vesiculosa, Najas minor, Najas marina, Najas flexilis, Elatine bydropiper und Salvinia natans), eine Pflanze des Auenwaldes (Vitis silvestris) sowie Abies alba und Physalis alkekengi. Selbstverständlich fehlen der heutigen Flora auch die rezent noch nicht bekannten Pflanzen Azolla interglacialica, Stratiotes intermedius, Crataegus acuticarpa und Tectochara meriani diluviana.

Die Tatsache, daß etliche Wasserpflanzen heute nicht mehr im Niederrheingebiet vorkommen, ist zum Teil der vom Menschen intensiv durchgeführten Entwässerung zuzuschreiben. Dies wird dadurch bewiesen, daß einige der heute nicht mehr vorhandenen Wasserpflanzen (z. B. Trapa natans, Najas minor, Najas marina, Elatine hydropiper) in historischer Zeit noch beobachtet worden sind (vgl. Tabelle 16). Viele WasserpflanzenStandorte sind erst in den letzten Jahrzehnten verlorengegangen oder in ihrer Ausdeh- 
Tabe 11 e 16

Vergleichende Betrachtung der im Holstein-Interglazial von Tönisberg nachgewiesenen Pflanzenarten mit ihrem rezenten Vorkommen im Niederrheingebiet, wie es durch Florenbeschreibungen der letzten 120 Jahre belegt ist. ( $\mathrm{H}=$ häufig, $\mathrm{S}=$ selten, $\mathrm{A}=$ nur angepflanzt, $-=$ fehlend.)

\begin{tabular}{|c|c|c|c|c|c|c|c|c|c|c|c|c|}
\hline & & 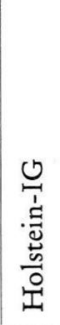 & 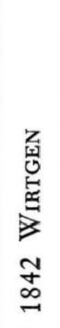 & 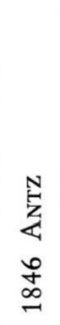 & 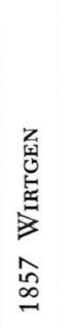 & 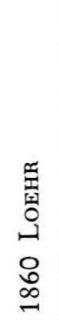 & 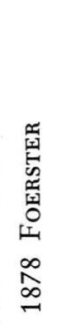 & $\begin{array}{l}\text { 䍃 } \\
\text { 兽 } \\
\stackrel{2}{\infty} \\
\infty \\
\infty\end{array}$ & 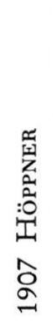 & 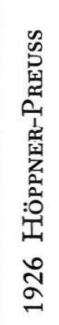 & 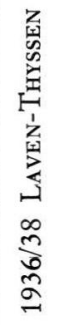 & 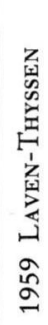 \\
\hline 1 & Tectochara meriani diluviana & $\mathrm{H}$ & - & - & - & - & - & 一 & - & - & - & - \\
\hline 2 & Campylium stellatum & $\mathrm{H}$ & $\mathrm{S}$ & $\mathrm{S}$ & $\mathrm{S}$ & $S$ & $S$ & $S$ & $S$ & $S$ & $\mathrm{~S}$ & $S$ \\
\hline 3 & Salvinia natans & $\mathrm{H}$ & - & - & - & - & $\mathrm{S}$ & - & - & - & - & - \\
\hline 4 & Azolla interglacialica & $\mathrm{H}$ & - & - & - & - & 一 & - & - & - & - & - \\
\hline 5 & Abies alba & $\mathrm{H}$ & A & $\mathrm{A}$ & $\mathrm{A}$ & A & $\mathrm{A}$ & A & A & A & $\mathrm{A}$ & $\mathrm{A}$ \\
\hline 6 & Betula pubescens & $\mathrm{H}$ & $\mathrm{H}$ & $\mathrm{H}$ & $\mathrm{H}$ & $\mathrm{H}$ & $\mathrm{H}$ & $\mathrm{H}$ & $\mathrm{H}$ & $\mathrm{H}$ & $\mathrm{H}$ & $\mathrm{H}$ \\
\hline 7 & Alnus glutinosa & $\mathrm{H}$ & $\mathrm{H}$ & $\mathrm{H}$ & $\mathrm{H}$ & $\mathrm{H}$ & $\mathrm{H}$ & $\mathrm{H}$ & $\mathrm{H}$ & $\mathrm{H}$ & $\mathrm{H}$ & $\mathrm{H}$ \\
\hline 8 & Alnus incana & $\mathrm{H}$ & $\mathrm{H}$ & $\mathrm{A}$ & $\mathrm{H}$ & $\mathrm{H}$ & $\mathrm{H}$ & $\mathrm{A}$ & A & $\mathrm{H}$ & $\mathrm{H}$ & $\mathrm{H}$ \\
\hline 9 & Carpinus betulus & $\mathrm{H}$ & $\mathrm{H}$ & $\mathrm{H}$ & $\mathrm{H}$ & $\mathrm{H}$ & $\mathrm{H}$ & $\mathrm{H}$ & $\mathrm{H}$ & $\mathrm{H}$ & $\mathrm{H}$ & $\mathrm{H}$ \\
\hline 10 & Urtica dioica & $\mathrm{H}$ & $\mathrm{H}$ & $\mathrm{H}$ & $\mathrm{H}$ & $\mathrm{H}$ & $\mathrm{H}$ & $\mathrm{H}$ & $\mathrm{H}$ & $\mathrm{H}$ & $\mathrm{H}$ & $\mathrm{H}$ \\
\hline 11 & Urtica urens & $\mathrm{H}$ & $\mathrm{H}$ & $\mathrm{H}$ & $\mathrm{H}$ & $\mathrm{H}$ & $\mathrm{H}$ & $\mathrm{H}$ & $\mathrm{H}$ & $\mathrm{H}$ & $\mathrm{H}$ & $\mathrm{H}$ \\
\hline 12 & Rumex maritimus & $\mathrm{H}$ & $\mathrm{S}$ & - & $\mathrm{H}$ & $\mathrm{S}$ & $\mathrm{H}$ & $\mathrm{H}$ & $\mathrm{H}$ & $\mathrm{H}$ & $\mathrm{S}$ & $\mathrm{S}$ \\
\hline 13 & Rumex bydrolapatbum & $\mathrm{S}$ & $\mathrm{H}$ & $\mathrm{H}$ & $\mathrm{H}$ & $\mathrm{H}$ & $\mathrm{H}$ & $\mathrm{H}$ & $\mathrm{H}$ & $\mathrm{H}$ & $\mathrm{H}$ & $\mathrm{S}$ \\
\hline 14 & Chenopodium polyspermum & $\mathrm{H}$ & $\mathrm{H}$ & $\mathrm{H}$ & $\mathrm{H}$ & $\mathrm{H}$ & $\mathrm{H}$ & $\mathrm{H}$ & $\mathrm{H}$ & $\mathrm{H}$ & $\mathrm{H}$ & $\mathrm{H}$ \\
\hline 15 & Stellaria media & $\mathrm{S}$ & $\mathrm{H}$ & $\mathrm{H}$ & $\mathrm{H}$ & $\mathrm{H}$ & $\mathrm{H}$ & $\mathrm{H}$ & $\mathrm{H}$ & $\mathrm{H}$ & $\mathrm{H}$ & $\mathrm{H}$ \\
\hline 16 & Acer campestre & $\mathrm{H}$ & $\mathrm{H}$ & $\mathrm{H}$ & $\mathrm{H}$ & $\mathrm{H}$ & $\mathrm{H}$ & $\mathrm{H}$ & $\mathrm{H}$ & $\mathrm{H}$ & $\mathrm{H}$ & $\mathrm{H}$ \\
\hline 17 & Vitis silvestris & $\mathrm{H}$ & - & - & - & - & - & - & - & - & - & - \\
\hline 18 & Cornus sanguinea & $\mathrm{H}$ & $\mathrm{H}$ & $\mathrm{H}$ & $\mathrm{H}$ & $\mathrm{H}$ & $\mathrm{H}$ & $\mathrm{H}$ & $\mathrm{H}$ & $\mathrm{H}$ & $\mathrm{H}$ & $\mathrm{H}$ \\
\hline 19 & Hydrocotyle vulgaris & $\mathrm{H}$ & $\mathrm{H}$ & $\mathrm{H}$ & $\mathrm{H}$ & $\mathrm{H}$ & $\mathrm{H}$ & $\mathrm{H}$ & $\mathrm{H}$ & $\mathrm{H}$ & $\mathrm{H}$ & $\mathrm{H}$ \\
\hline 20 & Oenanthe aquatica & $\mathrm{H}$ & $\mathrm{H}$ & $\mathrm{H}$ & $\mathrm{H}$ & $\mathrm{H}$ & $\mathrm{H}$ & $\mathrm{H}$ & $\mathrm{H}$ & $\mathrm{H}$ & $\mathrm{H}$ & $\mathrm{H}$ \\
\hline 21 & Solanum dulcamara & $\mathrm{S}$ & $\mathrm{H}$ & $\mathrm{H}$ & $\mathrm{H}$ & $\mathrm{H}$ & $\mathrm{H}$ & $\mathrm{H}$ & $\mathrm{H}$ & $\mathrm{H}$ & $\mathrm{H}$ & $\mathrm{H}$ \\
\hline 22 & Physalis alkekengi & $\mathrm{S}$ & $\mathrm{S}$ & - & $\mathrm{S}$ & - & A & - & A & A & $\mathrm{A}$ & $\mathrm{A}$ \\
\hline 23 & Atropa belladonna & $\mathrm{S}$ & $\mathrm{H}$ & $\mathrm{H}$ & $\mathrm{H}$ & $\mathrm{H}$ & $\mathrm{H}$ & - & - & $\mathrm{S}$ & $\mathrm{S}$ & $\mathrm{S}$ \\
\hline 24 & Verbena officinalis & $\mathrm{S}$ & $\mathrm{H}$ & $\mathrm{H}$ & $\mathrm{H}$ & $\mathrm{H}$ & $\mathrm{H}$ & $\mathrm{H}$ & $\mathrm{H}$ & $\mathrm{H}$ & $\mathrm{H}$ & $\mathrm{H}$ \\
\hline 25 & Ajuga reptans & $\mathrm{H}$ & $\mathrm{H}$ & $\mathrm{H}$ & $\mathrm{H}$ & $\mathrm{H}$ & $\mathrm{H}$ & $\mathrm{H}$ & $\mathrm{H}$ & $\mathrm{H}$ & $\mathrm{H}$ & $\mathrm{H}$ \\
\hline 26 & Lycopus europaeus & $\mathrm{H}$ & $\mathrm{H}$ & $\mathrm{H}$ & $\mathrm{H}$ & $\mathrm{H}$ & $\mathrm{H}$ & $\mathrm{H}$ & $\mathrm{H}$ & $\mathrm{H}$ & $\mathrm{H}$ & $\mathrm{H}$ \\
\hline 27 & Sambucus nigra & $\mathrm{H}$ & $\mathrm{H}$ & $\mathrm{H}$ & $\mathrm{H}$ & $\mathrm{H}$ & $\mathrm{H}$ & $\mathrm{H}$ & $\mathrm{H}$ & $\mathrm{H}$ & $\mathrm{H}$ & $\mathrm{H}$ \\
\hline 28 & Bidens tripartitus & $\mathrm{S}$ & $\mathrm{H}$ & $\mathrm{H}$ & $\mathrm{H}$ & $\mathrm{H}$ & $\mathrm{H}$ & $\mathrm{H}$ & $\mathrm{H}$ & $\mathrm{H}$ & $\mathrm{H}$ & $\mathrm{H}$ \\
\hline 29 & Ranunculus aquatilis & $\mathrm{H}$ & $\mathrm{H}$ & $\mathrm{H}$ & $\mathrm{H}$ & $\mathrm{H}$ & $\mathrm{H}$ & $\mathrm{H}$ & $\mathrm{H}$ & $\mathrm{H}$ & $\mathrm{H}$ & $\mathrm{H}$ \\
\hline 30 & Ranunculus sceleratus & $\mathrm{H}$ & $\mathrm{H}$ & $\mathrm{H}$ & $\mathrm{H}$ & $\mathrm{H}$ & $\mathrm{H}$ & $\mathrm{H}$ & $\mathrm{H}$ & $\mathrm{H}$ & $\mathrm{s}$ & $\mathrm{S}$ \\
\hline 31 & Ranunculus lingua & $\mathrm{H}$ & $\mathrm{H}$ & $\mathrm{H}$ & $\mathrm{H}$ & $\mathrm{H}$ & $\mathrm{H}$ & $\mathrm{H}$ & $\mathrm{H}$ & $\mathrm{H}$ & $\mathrm{S}$ & $\mathrm{S}$ \\
\hline 32 & Ranunculus cf. repens & $\mathrm{H}$ & $\mathrm{H}$ & $\mathrm{H}$ & $\mathrm{H}$ & $\mathrm{H}$ & $\mathrm{H}$ & $\mathrm{H}$ & $\mathrm{H}$ & $\mathrm{H}$ & $\mathrm{H}$ & $\mathrm{H}$ \\
\hline 33 & Nuphar luteum & $\mathrm{H}$ & $\mathrm{H}$ & $\mathrm{H}$ & $\mathrm{H}$ & $\mathrm{H}$ & $\mathrm{H}$ & $\mathrm{H}$ & $\mathrm{H}$ & $\mathrm{H}$ & $\mathrm{H}$ & $\mathrm{S}$ \\
\hline & Nymphaea alba & $\mathrm{H}$ & $\mathrm{H}$ & $\mathrm{S}$ & $\mathrm{H}$ & $\mathrm{H}$ & $\mathrm{H}$ & $\mathrm{H}$ & $\mathrm{H}$ & $\mathrm{H}$ & $\mathrm{H}$ & $\mathrm{S}$ \\
\hline
\end{tabular}




\begin{tabular}{|c|c|c|c|c|c|c|c|c|c|c|c|c|}
\hline & & 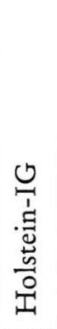 & 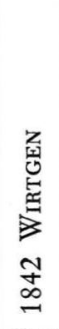 & \begin{tabular}{l}
$N$ \\
\multirow{2}{z}{} \\
$<$ \\
0 \\
+ \\
$\infty$ \\
-
\end{tabular} & 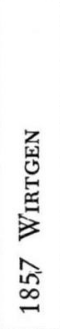 & $\begin{array}{l}\text { 평 } \\
\text { 잉 } \\
\text { 웅 } \\
\infty\end{array}$ & 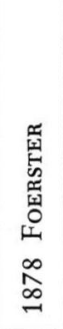 & $\begin{array}{l}\text { 恿 } \\
\text { 舀 } \\
\infty \\
\infty \\
\infty \\
\infty\end{array}$ & 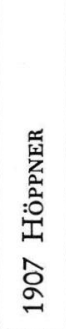 & 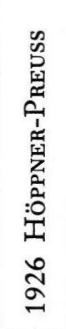 & 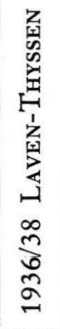 & 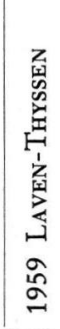 \\
\hline 35 & Euryale ferox & $\mathrm{S}$ & - & - & - & - & - & - & - & - & - & . \\
\hline 36 & Brasenia purpurea & $\mathrm{S}$ & - & - & - & - & - & - & - & - & - & - \\
\hline 37 & Ceratophyllum demersum & $\mathrm{H}$ & $\mathrm{H}$ & $\mathrm{H}$ & $\mathrm{H}$ & $\mathrm{H}$ & $\mathrm{H}$ & $\mathrm{H}$ & $\mathrm{H}$ & $\mathrm{H}$ & $\mathrm{S}$ & S \\
\hline 38 & Ceratophyllum submersum & $S$ & $S$ & - & $\mathrm{S}$ & $\mathrm{S}$ & $\mathrm{H}$ & - & - & $\mathrm{S}$ & - & S \\
\hline 39 & Crataegus acuticarpa & $\mathrm{H}$ & - & - & - & - & - & - & - & - & - & - \\
\hline 40 & Prunus spinosa & $\mathrm{S}$ & $\mathrm{H}$ & $\mathrm{H}$ & $\mathrm{H}$ & $\mathrm{H}$ & $\mathrm{H}$ & $\mathrm{H}$ & $\mathrm{H}$ & $\mathrm{H}$ & $\mathrm{H}$ & $\mathrm{H}$ \\
\hline 41 & Rubus caesius & S & $\mathrm{H}$ & $?$ & $\mathrm{H}$ & $\mathrm{H}$ & $\mathrm{H}$ & $\mathrm{H}$ & $\mathrm{H}$ & $\mathrm{H}$ & $\mathrm{H}$ & $\mathrm{H}$ \\
\hline 42 & Trapa cf. natans & $\mathrm{H}$ & $\mathrm{S}$ & - & $\mathrm{S}$ & $\mathrm{S}$ & S & - & - & - & - & - \\
\hline 43 & Myriophyllum spicatum & $\mathrm{H}$ & $\mathrm{H}$ & $\mathrm{H}$ & $\mathrm{H}$ & $\mathrm{H}$ & $\mathrm{H}$ & $\mathrm{H}$ & - & $\mathrm{S}$ & $\mathrm{S}$ & S \\
\hline 44 & Hippuris vulgaris & $\mathrm{H}$ & $\mathrm{H}$ & $\mathrm{S}$ & $\mathrm{S}$ & $\mathrm{H}$ & $\mathrm{H}$ & - & $\mathrm{S}$ & $\mathrm{S}$ & - & - \\
\hline 45 & Elatine bydropiper & S & $\mathrm{S}$ & - & $\mathrm{S}$ & $\mathrm{H}$ & - & - & - & $\mathrm{S}$ & - & - \\
\hline 46 & Aldrovandia vesiculosa & $S$ & - & - & - & - & - & - & - & - & - & - \\
\hline 47 & Sparganium ramosum & $\mathrm{H}$ & $\mathrm{H}$ & $\mathrm{H}$ & $\mathrm{H}$ & $\mathrm{H}$ & $\mathrm{H}$ & $\mathrm{H}$ & $\mathrm{H}$ & $\mathrm{H}$ & $\mathrm{H}$ & $\mathrm{H}$ \\
\hline 48 & Typha cf. angustifolia & $\mathrm{H}$ & $\mathrm{H}$ & $\mathrm{H}$ & $\mathrm{H}$ & $\mathrm{H}$ & $\mathrm{H}$ & $\mathrm{H}$ & $\mathrm{H}$ & $\mathrm{H}$ & $\mathrm{H}$ & $\mathrm{H}$ \\
\hline 49 & Alisma plantago-aquatica & $\mathrm{H}$ & $\mathrm{H}$ & $\mathrm{H}$ & $\mathrm{H}$ & $\mathrm{H}$ & $\mathrm{H}$ & $\mathrm{H}$ & $\mathrm{H}$ & $\mathrm{H}$ & $\mathrm{H}$ & $\mathrm{H}$ \\
\hline 50 & Sagittaria sagittifolia & $\mathrm{H}$ & $\mathrm{H}$ & $\mathrm{H}$ & $\mathrm{S}$ & $\mathrm{H}$ & $\mathrm{H}$ & $\mathrm{H}$ & $\mathrm{H}$ & $\mathrm{H}$ & $\mathrm{H}$ & $\mathrm{H}$ \\
\hline 51 & Stratiotes intermedius & $\mathrm{S}$ & - & - & - & - & - & - & - & - & - & - \\
\hline 5,2 & Stratiotes aloides & $\mathrm{S}$ & $\mathrm{S}$ & - & - & - & $\mathrm{S}$ & $\mathrm{H}$ & $\mathrm{S}$ & $S$ & - & - \\
\hline 53 & Potamogeton pusillus & $\mathrm{H}$ & $\mathrm{H}$ & $\mathrm{H}$ & $\mathrm{H}$ & $\mathrm{H}$ & $\mathrm{H}$ & $\mathrm{S}$ & $\mathrm{H}$ & $\mathrm{H}$ & $\mathrm{S}$ & $\mathrm{S}$ \\
\hline 54 & Najas minor & $\mathrm{H}$ & - & - & - & - & $\mathrm{S}$ & - & - & $\mathrm{S}$ & - & - \\
\hline 55 & Najas marina & $\mathrm{H}$ & $\mathrm{S}$ & - & $\mathrm{S}$ & - & $\mathrm{S}$ & - & - & - & - & - \\
\hline 5,6 & Najas flexilis & $\mathrm{H}$ & - & - & - & - & - & - & - & - & - & - \\
\hline 57 & Zannichellia palustris & $\mathrm{H}$ & $\mathrm{H}$ & $\mathrm{H}$ & $\mathrm{S}$ & $\mathrm{S}$ & $\mathrm{S}$ & $\mathrm{S}$ & $\mathrm{H}$ & $\mathrm{S}$ & - & $S$ \\
\hline 58 & Scirpus lacustris & $\mathrm{H}$ & $\mathrm{H}$ & $\mathrm{H}$ & $\mathrm{H}$ & $\mathrm{H}$ & $\mathrm{H}$ & $\mathrm{H}$ & $\mathrm{H}$ & $\mathrm{H}$ & $\mathrm{H}$ & $\mathrm{H}$ \\
\hline
\end{tabular}

nung erheblich eingeengt worden. Die Tendenz hält noch an, so daß mit dem Verschwinden weiterer Wasserpflanzen-Arten aus unserem Gebiet gerechnet werden muß.

Damit sind aber noch nicht alle Unterschiede zwischen der holstein-interglazialen und der heutigen Flora unseres Gebietes begründet. Das Vorkommen von Vitis silvestris und die starke Beteiligung der Erle an der damaligen Vegetation weist auf ausgedehnte Auenwälder hin, die heute am Niederrhein fast ganz fehlen. Während des Holstein-Interglazials muß demnach das Klima humider gewesen sein als heute. Eine erhöhte Bodenfeuchtigkeit kann, wie es E. Zimmermann (1928) getan hat, mit einem Anstieg des Grundwassers infolge tektonischer Absenkung des Gebietes erklärt werden. Das reichliche Vorkommen von Abies dürfte daneben aber auch auf eine höhere Luftfeuchtigkeit hinweisen. Diese kann durch eine größere Niederschlagsmenge und durch stärkere Verdunstung unter Einwirkung eines wärmeren Klimas erklärt werden.

Für die Niederschlagsmenge im Niederrheingebiet ist vor allem der Höhenunterschied zwischen der Ebene und dem gebirgigen Hinterland maßgebend. Wollen wir für das 
Holstein-Interglazial eine größere Höhendifferenz und damit verbunden höhere Niederschläge annehmen, so finden wir diese Annahme bestätigt. Denn zur Mittelterrassen-Zeit wurde das Mittel- und Niederrheingebiet von einer allgemeinen Heraushebung betroffen. Die Flüsse schnitten sich daraufhin tief in das Gebirge ein; zeitweise wurde diese Talerosion auch von Wiederaufschotterungen unterbrochen. Aus der unterschiedlichen Höhenlage und Mächtigkeit solcher Ablagerungen im Mittel- und Niederrheingebiet können wir auf eine größere Höhendifferenz zwischen diesen beiden Gebieten im Vergleich zur Jetztzeit schließen. Größere Höhenunterschiede bestanden dabei sowohl in der Fließrichtung des Rheins als auch quer dazu von Osten nach Westen. Das niederrheinische Tiefland blieb also innerhalb der allgemeinen Hebung zurück, je nördlicher um so stärker.

Auf die Einwirkung eines etwas wärmeren Klimas im Holstein-Interglazial weisen vor allem einige Wasserpflanzen hin. Neben den Najas-Arten, Aldrovandia vesiculosa und Trapa natans sind es die Wasserfarne Salvinia und Azolla, die in stärkerem Maße wärmeliebend sind. Zwar können letztere adventiv auch heute in Deutschland (C. WETter 1950, A. Schlömer 1953) und in den Niederlanden (F. Florschütz 1938, J. M. v. D. VLERK \& F. FlonschüTz 1950) gedeihen, jedoch findet ihre Vermehrung überwiegend vegetativ statt. Hinweise auf wärmeres Klima geben ferner Physalis alkekengi sowie die durch Pollen nachgewiesenen Gattungen Castanea und Pterocarya.

Von anderer Seite wird häufig die starke Vorherrschaft der Nadelbäume und der geringe Anteil der Komponenten des Eichenmischwaldes in den Pollendiagrammen holstein-interglazialer Ablagerungen als Hinweis auf ein kälteres Klima als das der Jetztzeit gewertet. Wie die pollenanalytischen Untersuchungen zeigten, überwiegt auch in den Kempen-Krefelder Schichten der Nadelwald, wogegen die Komponenten des Eichenmischwaldes nur untergeordnet auftreten. Die Ursache dürfte auf den Einfluß eines mehr als heute humiden Klimas zurückzuführen sein, wodurch die Verbreitung des Nadelwaldes begünstigt, die des Eichenmischwaldes eingeschränkt wurde.

E. ZIMmERMANN (1935) nahm für das niederrheinische Holstein-Interglazial (damals "Hauptterrassenton“) eine durchschnittliche Jahrestemperatur von $+8^{\circ} \mathrm{C}$ an. $\mathrm{Da}$ in der niederrheinischen Bucht jetztzeitlich eine durchschnittliche Jahrestemperatur von $+10^{\circ} \mathrm{C}$ zu beobachten ist, muß nach obigen Ausführungen für das Holstein-Interglazial eine noch etwas höhere Temperatur angenommen werden. Inwieweit die nach Ablagerung des Holstein-Interglazials folgenden Eiszeiten (Saale und Weichsel) durch die zweifellos bewirkten Pflanzenareal-Verschiebungen Unterschiede zwischen der damaligen und der jetzigen Flora hervorgerufen haben, ist nach dem heutigen Stand der Kenntnisse nicht zu beurteilen.

Zusammenfassend kann gesagt werden, daß im Niederrheingebiet das Klima des Holstein-Interglazials weitgehend dem der Jetztzeit entsprach, wobei höhere Niederschläge und etwas höhere Temperaturen allerdings auch einigen Pflanzen Lebensmöglichkeit verliehen, die heute im Gebiet nicht mehr vorkommen.

\section{Zur Entstehung der Stauchendmoränen am Niederrhein}

Seit man erkannt hatte, daß es sich bei den Erhebungen am Niederrhein um Stauchendmoränen oder Reste von solchen handelt, sind verschiedene Ansichten zur Entstehung dieser Gebilde geäußert worden. Im wesentlichen wurden folgende vier Möglichkeiten in Erwägung gezogen:

1. (z. B. G. FLIEgEL 1909) Die Wälle entstanden im Verlauf von Stillstandslagen während des Eisrückzugs. Durch Schub und Druck wurde dabei der Untergrund zu Endmoränenwällen aufgestaucht.

2. (z. B. A. Steeger 1913c) Die Wälle wurden beim Vorrücken des Inlandeises gebildet, und zwar dadurch, daß an Terrassenkanten die Ablagerungen des Rheins zusammengestaucht wurden. 
3. (A. ZöLler 1942) Die Wälle entstanden während der Eisbedeckung. Durch tektonische Vorgänge wurde ein Streifen des Untergrundes horstartig hochgehoben und währenddessen subglazial gestaucht (diese Entstehungsmöglichkeit wurde nur für die Inselberge des Moerser Lobus in Erwägung gezogen).

4. (K. N. Thомe 1958, 1959) Unter der Eisbelastung scherten die oberflächennahen gefrorenen Kiese und Sande über ungefrorenen tonigen Horizonten des Holstein-Interglazials oder des Tertiärs ab und wurden vor dem Eisrand zu Wällen hochgestaucht.

Die letztgenannte Möglichkeit dürfte mit großer Wahrscheinlichkeit die wirkliche Entstehungsursache sein. Dafür sprechen sowohl die Lagerungsverhältnisse im Pleistozänprofil von Schacht Tönisberg als auch die Beobachtungen, die beim Abteufen dieses Schachtes in Verbindung mit dem Gefrierverfahren gemacht werden konnten (z. B. unterschiedliches Gefrieren toniger und sandiger bzw. kiesiger Schichten, Sohlenhebungen, usw.). In einigen Punkten können die Vorstellungen über die Entstehungsvorgänge, wie sie K. N. Tноме $(1958,1959)$ dargestellt hat, ergänzt werden.

Die Eisrandbildungen, welche im Arbeitsgebiet angetroffen werden (vgl. Abb. 1), gehören dem sogenannten Moerser Lobus an (vgl. K. N. Thome 1958). Zwei Staffeln sind hier zu unterscheiden: eine innere, welche die Inselberge umfaßt, und eine äußere, die nahezu ausschließlich vom Schaephuysener Höhenzug gebildet wird. K. N. Thоме (1959) bezeichnete die innere als Kamper, die äußere als Neußer Staffel. Für die zeitliche Entstehung dieser beiden Staffeln wurde angenommen, daß beim ersten Eisvorstoß ins Niederrheingebiet während des Drenthe-Stadiums der Saale-Eiszeit die äußere (Neußer) Staffel gebildet wurde; nachdem sich das Inlandeis wieder etwas zurückgezogen hatte, soll bei einem erneuten Vorstoß während des Drenthe-Stadiums die innere (Kamper) Staffel gebildet worden sein. Mehrere Gründe sprechen jedoch dafür, daß im Gegensatz zu diesen bisherigen Ansichten zuerst die Kamper Staffel und erst später die Neußer Staffel gebildet wurde.

Als erstes sind hier die Unterschiede in der Erhaltung und im Aufbau dieser beiden Staffeln anzuführen. Während die Neußer Staffel mit dem Schaephuysener Höhenzug noch ein großes und gut erhaltenes Stück einer Stauchendmoräne aufweisen kann, sind die Eisrandbildungen der Kamper Staffel nur noch als Inselberge erhalten. Im inneren Aufbau zeigen die Inselberge eine stärkere Verschuppung als sie im Schaephuysener Höhenzug zu beobachten ist.

Zweitens ist die Verbreitung von Ablagerungen der Krefelder Mittelterrasse von Bedeutung. Diese Terrasse wurde von K. N. Thome (1958) mit einleuchtender Begründung zeitlich in das Drenthe-Stadium der Saale-Eiszeit eingeordnet; andere Autoren sehen sie als jünger an. Für die Ansicht von K. N. Thомe spricht vor allem die Tatsache, daß sich die Ablagerungen der Krefelder Mittelterrasse nur westlich und südlich der Linie finden, die im Niederrheingebiet den weitesten Inlandeis-Vorstoß nach Westen charakterisiert. Die Krefelder Mittelterrasse ist also nur westlich und südlich der Neußer Staffel verbreitet. Wäre die Kamper Staffel nun jünger als die Neußer Staffel, wie es bisher angenommen wurde, so müßten sich Ablagerungen dieser Mittelterrasse auch zwischen den beiden Staffeln finden.

Ein weiterer Grund findet sich in der Entstehungsursache der Stauchendmoränen. Als wahrscheinlichste ist dabei die von K. N. ThOme $(1958,1959)$ dargestellte Möglichkeit anzusehen, wonach Unterschiede in der Gefrornis des Dauerfrostbodens durch eingelagerte ungefrorene Tonhorizonte von mehreren Metern Mächtigkeit eine Aufstauchung des Untergrundes durch das vorrückende Inlandeis ermöglichten. Wenn diese Deutungsart richtig ist, dann muß die Kamper Staffel älter sein als die Neußer Staffel, denn die Möglichkeit, auf solche Weise den Untergrund zu Endmoränenwällen aufzustauchen, war nur beim erstmaligen Vorrücken des Inlandeises gegeben. Auffallend ist, daß die Neußer Staffel mit der Westgrenze der Verbreitung der Kempen-Krefelder Schichten zusammen- 
fällt. Auch die Kamper Staffel ist an das Vorkommen von Kempen-Krefelder Schichten gebunden. Es hat den Anschein, als würden die beiden Staffeln nicht nur ehemalige Eisrandlagen markieren, sondern auch holstein-zeitliche Flußläufe nachzeichnen.

Zusammenfassend kann man sagen, daß die angeführten Gründe für folgende Vorgänge sprechen: Das aus östlicher Richtung in das Niederrheingebiet vorstoßende Inlandeis stauchte zuerst den Endmoränenwall der Kamper Staffel auf. Durch weitere Eiszufuhr wurde dieser Wall durchbrochen und bis auf die erhaltenen Inselberge wieder zerstört. Weiter westlich wurde schließlich die äußere (Neußer) Staffel hochgestaucht, die vom Eis nicht mehr um- oder überflossen wurde und somit die äußerste Grenze des InlandeisVorstoßes in das Niederrheingebiet markiert. Der Rückzug des Inlandeises aus dem Niederrheingebiet dürfte passiv verlaufen sein durch allgemeine Toteisbildung.

\section{Dank}

Die vorliegende Arbeit entstand als Dissertation am Geologischen Institut der Universität Köln. Angeregt wurde sie von meinem verehrten Lehrer Prof. Dr. M. Schwarzbach, dem ich für sein Vertrauen und seine ständige Hilfsbereitschaft besonders herzlich danken möchte.

Die Proben aus Schacht Tönisberg wurden vom Verfasser eigenhändig entnommen. Besonders gefördert wurde diese Tätigkeit von den Herren Markscheider HogardT, Markscheider HüskEN, Dipl.-Ing. Keck und Vermessungssteiger Hennig. Die $\mathrm{Ni}$ ed e r r he in is che BergoterksA. G. stellte außerdem Wohnraum, Verpflegung und Materialien für einige Monate zur Verfügung. Es ist mir eine angenehme Pflicht, allen bestens zu danken. Dank gebührt auch der $\mathrm{S} \mathrm{ch} \mathrm{a} \mathrm{ch} \mathrm{t} \mathrm{b} \mathrm{a} \mathrm{u}$ Thyssen A. G., welche die zahlreichen Befahrungen des Schachtes bereitwilligst ermöglichte.

Bei der Bearbeitung der pleistozänen Tier- und Pflanzenreste unterstützten mich tatkräftig die Herren Prof. Dr. H. Weyland (Bestimmung der Moose) und Dr. Th. Kruckow (Bestimmung der Fischzähne). Herrn Dr. K. KILPPER sei für die erste Einführung in die Bestimmung der Pflanzenreste gedankt und für seine Bemühungen um die Beschaffung rezenten Vergleichsmaterials. Herr Dr. G. Schultz half durch die Übersetzung russischer Fachliteratur; außerdem stand er mir sowie besonders auch Herr Dr. R. SchütrumpF bei den pollenanalytischen Untersuchungen mit Rat und Tat zur Seite, wofür bestens gedankt sei. Die wenigen nordischen Geschiebe bestimmte Herr Prof. Dr. J. Hesemann; ihm habe ich ferner dafür zu danken, daß er mir das Archivmaterial des Geologischen Landesamtes von Nordrhein-Westfalen in Krefeld zugänglich machte und die Verwertung einschlägiger Unterlagen erlaubte.

Für nützliche Hinweise und anregende Diskussionen habe ich ferner folgenden Herren zu danken: Dr. W. van den Bold, Prof. Dr. K. Brunnacker, Dr. K. Diebel, Prof. Dr. U. Jux, Dr. K. H. Kaiser, Dr. G. Lüttig, Dr. K. Mädler, Prof. Dr. H. Murawski, Dr. K. N. Thome und Dr. E. Triebel.

Zum Schluß möchte ich ferner nicht versäumen, meiner Frau und meinen Eltern zu danken, ohne deren Unterstützung die vorliegende Arbeit hätte nicht durchgeführt werden können.

\section{Schriftenverzeichnis}

AhorNer, L.: Untersuchungen zur quartären Bruchtektonik der niederrheinischen Bucht. - Eiszeitalter und Gegenwart 13, 24-105, 23 Abb., 4 Taf., Óhringen 1962.

Ahrens, W.: Albert Steeger in memoriam. - Fortschr. Geol. Rheinl. u. Westf. 4, I-X, 1 Abb., Krefeld 1959.

Anderson, H.-J.: Zur Stratigraphie und Paläogeographie des marinen Oberoligozäns und Miozäns am Niederrhein auf Grund der Mollusken-Faunen. - Fortschr. Geol. Rheinl. u. Westf. 1, 277-295, 1 Taf., 2 Abb., Krefeld 195,8a. - - Die Pectiniden des niederrheinischen Chatt. Fortschr. Geol. Rheinl. u. Westf. 1: 297-321, 3 Taf., Krefeld 1958b.

Antz, C. C.: Flora von Düsseldorf. - 124 S., Düsseldorf 1846.

Bertsch, K. \& Steeger, A.: Jungdiluviale pflanzenführende Ablagerungen am nördlichen Niederrhein. - Sitz.Ber. ü. d. Vers. d. Niederrh. Geol. Ver. f. 1926, 20, 49-65, Bonn 1927.

Bertsch, K., Steeger, A. \& Steusloff, U.: Fossilführende Schichten in der sogenannten Krefelder Mittelterrasse. - Sitz.Ber. ü. d. Vers. d. Niederrh. Geol. Ver. f. 1929, 23, 1-20, Bonn 1931.

Boschneidgen, H.: Urstromtäler am Niederrhein. - 26 S., 1 Abb., 1 Karte, Crefeld 1904.

Braun, F. J.: Die Terrassengliederung am linken Niederrhein zwischen Geldern und Kalkar. Geol. en Mijnb. (N.S.) 18, 374-378, 3 Abb., s'Gravenhage 1956. - - Endmoränen, Terrassen und holozäne Ablagerungen bei Xanten am Niederrhein. - Fortschr. Geol. Rheinl. u. Westf. 4, 247-254, 1 Taf., 2 Abb., 1 Tab., Krefeld 1959. 
Braun, F. J. \& Quitzow, H. W.: Die erdgeschichtliche Entwicklung der niederrheinischen Landschaft. - Niederrh. Jb. 5, 1-15, Krefeld 1961.

Brelie, G. v. D.: Probleme der stratigraphischen Gliederung des Pliozäns und Pleistozäns am Mittel- und Niederrhein. - Fortschr. Geol. Rheinl. u. Westf. 4, 371-388, 2 Tab., Krefeld 1959. - - Pollenanalytische Untersuchung eines interglazialen Tones aus der Stauchmoräne bei Tönisberg. - Unveröffentlichter Ber. im Archiv d. Geol. Landesamtes in Krefeld 1960a. - - Pollenanalytische Untersuchung der Bohrungen 1 und 2, Amtsneubau, Krefeld, De-Greiff-Straße. - Unveröffentlichter Ber. im Archiv d. Geol. Landesamtes in Krefeld 1960b.

Brelie, G. v. D., Kilpper, K. \& TeichmülleR, R.: Das Pleistozänprofil von Frimmersdorf an der Erft. - Fortschr. Geol. Rheinl. u. Westf. 4, 179-196, 10 Taf., 6 Abb., 2 Tab., Krefeld 1959.

Brelie, G. v. D. \& Rein, U.: Die Interglazialbildungen im Niederrheinischen Diluvium. - Der Niederrhein 19, 63-68, Krefeld 1952. - - Pollenanalytische Untersuchungen zur Gliederung des Pleistozäns am linken Niederrhein. - Geol. en Mijnb. (N.S.) 18, 423-425, 1 Abb., s'Gravenhage 1956.

Breuer, E.: Das Klima des Niederrheins und seiner Umgebung. - Deutsch. Meteorol. Jb. f. 1916-29, 22-35, 17-75, 3 Kart., 8 Taf., 12 Tab., Aachen 1930.

Clessin, S.: Deutsche Exkursions-Molluskenfauna. - 2. Aufl., 663 S., Nürnberg 1884.

DEChen, H. von: Orographisch-geognostische Ubersicht des Regierungsbezirkes Düsseldorf. 251 S., Iserlohn 1864. - - Uber das Vorkommen nordischer Geschiebe oder erratischer Blöcke in Rheinland und Westf. - Verh. Naturhist. Ver. Rheinl. u. Westf. 36, 82-87, (Correspondenzbl.), Bonn 1879.

Dechen, H. von \& Rauff, H.: Geologische und mineralogische Literatur der Rheinprovinz und der Provinz Westfalen sowie einiger angrenzender Gegenden. - Verh. Naturhist. Ver. Rheinl. u. Westf. 44, 1-294, Bonn 1887.

Düro, F. \& Kalterheriberg, J.: Gutachten über die Baugrundverhältnisse beim geplanten Neubau des geologischen Landesamtes in Krefeld, De-Greiff-Straße. - Unveröffentl. Ber. im Archiv d. Geol. Landesamtes in Krefeld 1961.

Ellermann, C.: Beitrag zur Stratigraphie und Mikropaläontologie des niederrheinischen Oligozäns. - Diss. Münster 1937.

Erberich, G.: Sedimentpetrographische Untersuchungen an rezenten Rheinsanden vom Mainzer Becken bis an die holländische Grenze. - Decheniana 95 A, 1-40, 2 Taf., Bonn 1937.

Fliegel, G.: Neue Beiträge zur Geologie des niederrheinischen Tieflandes. - Jb. Preuß. Geol. Landesanst. f. 1912, 33, 418-452, Berlin. 1913.

Fliegel, G. \& Stoller, J.: Jungtertiäre und altdiluviale pflanzenführende Ablagerungen im Niederrheingebiet. - Jb. Preuß. Geol. Landesanst. f. 1910, 31, 1, 227-257, Berlin 1910.

Foerster, A.: Flora excursoria des Regierungsbezirkes Aachen sowie der angrenzenden Gebiete der belgischen und holländischen Provinz Limburg. - XXX und 468 S., Aachen 1878.

Gams, H.: Beiträge zur Mikrostratigraphie und Paläontologie des Pliozäns und Pleistozäns von Mittel- und Osteuropa und Westsibirien. - Ecl. Geol. Helv. 28: 1-31, 7 Taf., Basel 1935.

GeYER, D.: Quartärmollusken und Quartärklima. - Geol. Rundschau 15, 341-352, Berlin 1924.

Grebe, H.: Die Mikro- und Megaflora ... vom Swisterberg bei Weilerswist ... - Geol. Jb. 70, 535-574, 3 Taf., 8 Abb., Hannover 1955.

Gurlt, A.: Übersicht über das Tertiär-Becken des Niederrheins. - 47 S., 1 Karte, Bonn 1872.

HArTz, N.: Bidrag til Danmarks tertiaere og diluviale Flora. - Danm. Geol. Unders. (R. 2) 20, I-X, 1-292, 34 Abb., Kobenh. 1909.

Herrenkohl, F. G.: Verzeichnis der phanerogamen und kryptogamen Gefäßpflanzen der Flora von Cleve u. Umgebung. - Verh. Naturhist. Ver. Rheinl. u. Westf. 28, 124-232, Bonn 1871.

Hiltermann, H.: Neue Funde von Azolla im Pleistozän Deutschlands. - Geol. Jb. 68, 653-658, 1 Abb., Hannover 1954.

Hoeppner, H.: Flora des Niederrheins. - 343 S., Krefeld 1907.

Hoeppner, H. \& Preuss, H.: Flora des Westfälisch-Rheinischen Industriegebietes. - Wissenschaft. Heimatbuch f. d. Westf.-Rh. Industriebez. 6a, 381 S., Dortmund 1926.

Holzapfel, E.: Beschreibung des Bergreviers Düren: Geologischer Teil. - S. 11-130, Bonn 1902.

Jessen, K. \& Mrtthers, V.: Stratigraphical and Paleontological Studies of Interglacial FreshWater-Deposits in Jutland and Northwest-Germany. - Danm. Geol. Unders., 2. R., 48, 379 S., 40 Taf., Kopenhagen 1928.

JoNG, J. D. DE: Sedimentpetrographische Untersuchungen in Terrassenschottern im Gebiet zwischen Krefeld und Kleve. - Geol. en Mijnb., N.S., 18, 389-394, 5 Abb., s'Gravenhage 1956. -On the Correlation of Needian in the Netherlands and Holstein Deposits in Western Germany. - Geol. en Mijnb., N.S. 19, 286-287, s'Gravenhage 1957. 
KAISER, K. H.: Geologische Untersuchungen über die Hauptterrasse in der Niederrheinischen Bucht. - Sonderveröff. Geol. Inst. Univers. Köln 1, 1-68, 17 Abb., 8 Tab., 1 Karte, Köln 1956. - - Die Höhenterrassen der Bergischen Randhöhen und die Eisrandbildungen an der Ruhr. - Sonderveröff. Geol. Inst. Univers. Köln 2, 1-39, 8 Abb., 5 Tab., 1 Karte, Köln 1957. - Gliederung und Formenschatz des Pliozäns und Quartärs am Mittel- und Niederrhein ... - Köln und die Rheinlande, Festschr. z. 33. Dtsch. Geographentag 1961 in Köln, 236-278, 6 Abb., 7 Tab., 3 Karten, Wiesbaden 1961.

KAISER, K. H. \& SChÜTRUMPF, R.: Zur Gliederung mittel- und jungpleistozäner Schichten in der Niederrheinischen Bucht. - Eiszeitalter u. Gegenwart 11, 166-185, 5 Abb., 2 Tab., OOhringen 1960.

Kalterherberg, J. \& Karrenberg, H.: Zur Methodik und Auswertung von Korngrößenuntersuchungen im Niederrheinischen Tertiär. - Fortschr. Geol. Rheinl. u. Westf. 1, 33-35, Krefeld 1958.

KARRENBERG, H.: Verbreitung und Lagerung von Haupt- und Mittelterrasse am Niederrhein (Vortragsreferat). - Z. D. G. G. 103, 118, Hannover 1951.

Karrenberg, H. \& Rein, U.: Die interglazialen Schichten von Krefeld. - Niederrh. Jb. 3, 3-7, Krefeld 1951.

Keilhack, K.: Geologie der Braunkohle. - In: Handb. f. d. Dtsch. Braunkohlenbergbau, 3. Aufl., Bd. 1, 61-92, Halle 1927.

KempF, E. K.: Das Holstein-Interglazial von Tönisberg im Rahmen des Niederrheinischen Pleistozäns. - Unveröffentl. Diplomarbeit, Geologisches Institut Köln, 1-196, 9 Taf., 1963.

Kirchieimer, F.: Flora und Gliederung des Pliozäns in Mitteleuropa. - Zentralbl. f. Min. etc. 5 B, 141-167, Stuttgart 1940.

Königs, E.: Neue geologische Funde aus der Nähe von Crefeld. - Jahresber. Naturwiss. Ver. Crefeld f. 1893/94, 21-24; Crefeld 1893/94. Ebenfalls: Verh. Naturhist. Ver. Rheinl. u. Westf. 50, 519-523, Bonn 1893. - - Die geologische Vergangenheit unserer Gegend unter Vorzeigung zahlreicher darauf bezüglicher Funde. - Jahresber. Naturwiss. Ver. Crefeld f. 1894/95, 52-73, 6 Taf., Crefeld 1895. - - Die Eiszeit und ihre Spuren in der Nachbarschaft von Krefeld. - Jahresber. Naturwiss. Ver. Krefeld f. 1901/02, 45-64, 1 Abb., Krefeld 1902. - - Die Krefelder Gegend zur Tertiär- und Quartärzeit. - Festschr. Naturwiss. Ver. Krefeld 185,8-1908, 103-124, Krefeld 1908.

Krause, P. G.: Über einen fossilführenden Horizont im Hauptterrassendiluvium des Niederrheins. - Jb. Preuß. Geol. Landesanst. f. 1909, 30, 2, 91-108, 1 Taf., Berlin 1912. - - Einige Beobachtungen im Tertiär und Diluvium des westlichen Niederrheingebietes. - Jb. Preuß. Geol. Landesanst. f. 1911, 32, 2, 126-159, 1 Abb., Berlin 1914a. - - Paludina (Vivipara) diluviana KUNTH aus dem älteren Interglazial des Niederrheins. - Z.D.G.G. 66, Monatsber. 2, 93-97, Berlin 1914b. - - Weitere Beobachtungen im Tertiär und Diluvium des Niederrheins. - Jb. Preuß. Geol. Landesanst. f. 1917, 38, 1, 183-200, Berlin 1918.

Laven, L. \& Thyssen, P.: Die Flora des Kölner Wandergebietes. - Wiss. Mitt. d. Ver. f. Naturu. Heimatkde. Köln 1, 149-268, Köln 1936/38. - - Flora des Köln-Bonner Wandergebietes. - Decheniana 112, 1-179, 1 Titelbild, 1 Karte, 17 Taf., Bonn 1959.

Linstow, O. v.: Die Verbreitung des Bibers im Quartär. - Abh. u. Ber. Mus. f. Nat.- u. Heimatk. Magdeburg 1, 215-387, 2 Kart., Magdeburg.

Loenr, M-J.: Botanischer Führer zur Flora von Köln. - XV u. 323 S., Köln 1860.

LoRIÉ, J.: De Verhouding tusschen den Rijn en het Landijs. - Tijdschr. Kon. Nederl. Aardr. Gen. 19, (Ser. 2) 296-327, 1 Karte, Leiden 1920.

MaArleveld, G. C.: Ergebnisse von Kies-Analysen im Niederrheingebiet. - Geol. en Mijnb. (N.S.) 18, 411-415, s'Gravenhage 1956.

Meigen, W.: Flora von Wesel. - Beil. z. Jahresber. d. Gymnasiums zu Wesel Nr. 425, VIII u. 44 S., Wesel 1886.

MenzeL, H.: Fossilführende Glazial- und Interglazialablagerungen und ihre Leitkonchylien in Deutschland. - Z. f. Gletscherkunde 9, 161-187, Leipzig 1915.

Mückenhausen, E.: Fossile Böden im nördlichen Rheinland. - Z. f. Pflanzenernährung, Düngung, Bodenkunde 65 (110), 81-103, Weinheim und Berlin 195.4.

PAAs, W.: Rezente und fossile Böden auf niederrheinischen Terrassen und deren Deckschichten. Eiszeitalter und Gegenwart 12, 165-230, 32 Abb., Ơhringen 1961.

QuaAs, A.: Beiträge zur Geologie der Niederrheinischen Bucht. I. Das geologische Alter der Braunkohlenablagerungen von Ompert und Helenabrunn, des Lied- und des Hülserberges. Z. D. G. G. 62, 576-586, Berlin 1911. - - Beiträge zur Geologie der Niederrheinischen Bucht. III. Zur Gliederung der Hauptterrasse. IV. Zur Wertung der fossilführenden Schichten der Hauptterrasse. - Z. D. G. G. 68, 138-160, Berlin 1917. 
Quitzow, H. W.: Die Terrassengliederung im Niederrheinischen Tieflande. - Geol. en Mijnb. (N.S.) 18, 357-373, 7 Abb., s'Gravenhage 1956. - - Hebung und Senkung am Mittel- und Niederrhein während des Jungtertiärs und Quartärs. - Fortschr. Geol. Rheinl. u. Westf. 4, 389-400, 4 Taf., 1 Abb., 1 Karte, Krefeld 1959.

Quitzow, H. W. \& ZonNEveld, J. I. S.: Vorläufiges Ergebnis der Terrassenuntersuchungen im Maas- und Niederrheingebiet. - Geol. en Mijnb. (N.S.) 18, 428, 1 Tab., 1 Karte, s'Gravenhage 1956.

RaufF, H. \& M.: Sachregister zu dem von $H$. von Dechen und H. Rauff herausgegebenen chronologischen Verzeichnis der geol. und mineral. Literatur der Rheinprovinz und der Provinz Westfalen . . . - Verh. Naturhist. Ver. Rheinl. u. Westf. 52, I-XI u. 1-274, Bonn 1896.

ReIN, U.: Pollenanalytische Untersuchungen zur Pliozän-Pleistozängrenze am linken Niederrhein. (Vorläufige Mitteilung). - Geol. Jb. f. 1949, 65, 773-778, Hannover 19511a. - - Uber Interglazialbildungen im niederrheinischen Diluvium (Vortragsreferat). - Z. D. G. G. 103, 117-118, Hannover 1951b. - - Die pollenstratigraphische Gliederung des Pleistozäns in Nordwestdeutschland. 1. Die Pollenstratigraphie im älteren Pleistozän. - Eiszeitalter u. Gegenwart 6, 16-24, Öhringen 1955.

Richter, R.: „Liegend“ und „Hangend“. - Senck. leth. 35, 263-267, Frankfurt 1954.

Scharf, W.: Das norddeutsche Diluvium in eistektonischer Betrachtung vom Standpunkte der Gefügekunde. - Jb. Preuß. Geol. Landesanst. f. 1932, 53, 828-850, 3 Abb., Berlin 1933.

Schlömer, A.: Ein verwilderter Wasserfarn, Azolla filiculoides. - Nat. u. Volk 83, 131-134, 2 Abb., Frankfurt 1953.

Schultz, G.: Zur Geologie der Braunkohlen bei Zülpich (Niederrheinische Bucht). - N. Jb. Geol. Paläont., Abh. 116, 89-118, 1 Taf., 5 Abb., Stuttgart.

Schwarzbach, M.: Das Klima der Vorzeit. - 2. Aufl., 275, S., 134 Abb., Stuttgart 1961.

Staring, W. C. H.: De bodem van Nederland. - Teil 2, Haarlem 1860.

SteEger, A.: Uber eine fossilführende Schicht im Diluvium bei Tönisberg. - Sitz.-Ber. dtsch. Lehrerver. f. Naturkde, Bez.-Gruppe Crefeld, in: Niederrheinische Volkszeitung v. 21.12.1911, Krefẻld oder Düsseldorf 1911. - - Über das (sekundäre) Vorkommen oberoligozäner mariner Muscheln und Schnecken in diluvialen Flußkiesen am Niederrhein. - Versammlungsber. Lehrerver. f. Naturk., Bez.-Gruppe Krefeld, Oktober 1913; wahrscheinlich in: Niederrheinische Volkszeitung, Oktober 1913, Krefeld oder Düsseldorf 1913a. - - Der geologische Aufbau und die Entstehung des Hülserberges. - Mitt. d. Naturwiss. Mus. zu Krefeld, S. 1-24, 2 Karten, 11 Abb., Krefeld 1913b. - - Beiträge zur Geologie des Niederrheins. I. Beziehungen zwischen Terrassenbildung und Glazialdiluvium im nördlichen niederrheinischen Tieflande. - Abh. d. Ver. f. naturwiss. Erforsch. d. Niederrheins 1: 137-163, Krefeld 1913c. - - Neue Beiträge zur Geologie des Hülserberges. I. - Die Heimat 1, 125-127, 4 Abb., Krefeld. - - Das glaziale Diluvium des Niederrheinischen Tieflandes. Beiträge I-VII. - Ber. ü. d. Vers. d. Niederrh. Geol. Ver. f. 1923, 1-46, Bonn (Naturhist. Ver.). Ferner: Diss. Köln 1923, 1925a. - - Uber Bimssteinvorkommen am unteren Niederrhein. - Ber. ü. d. Vers. d. Niederrh. Geol. Ver. f. 1925, 1-8, Bonn 1925b. - - Die Gesteinsgruppe auf dem Hülser Berg. - Die Natur am Niederrhein 3, 32-35, 1 Abb., Krefeld 1927a. - - Die Flußterrassen- und Endmoränenlandschaft zwischen Krefeld, Moers und Geldern. I. - Die Natur am Niederrhein 5, 8-17, 8 Abb., Krefeld 1929. - - Die Flußterrassen- und Endmoränenlandschaft zwischen Krefeld, Moers und Geldern. II. - Die Natur am Niederrhein 7, 6-22, 17 Abb., Krefeld 1931a. - - Siehe Bertsch, K. Steeger, A. \& Steusloff, U. 1931b. - - Zum geologischen Aufbau der Tönisberger Höhen. - Die Heimat 18, 3-6, 6 Abb., Krefeld 1939. - - Der Nieper Altrhein. - Der Niederrhein 17, 6-10, 3 Abb., Krefeld 1949. - - 100 Jahre Eiszeitforschung am Niederrhein. - Der Niederrhein 19, 57-63, 86-87, Krefeld 1952a. - - Die Endmoränenlandschaft zwischen Krefeld und Nymwegen (Vortragsreferat). - Z. D. G. G. 103: 116117, Hannover 1952b. - - Wie der Hülser Berg entstand. - Hülser Heimatblätter 1, 33-38, 2 Abb., Hüls 195,4.

Steeger, A. \& Breddin, H.: Bericht über den Lehrausflug am 19. 11. 1933 von Moers über Egelsberg, Hülserberg zu den Hinsbecker Höhen und Krieckenbecker Seen an der westlichen Landesgrenze. - Ber. Vers. Niederrhein. Geol. Ver. f. 1932/33, 137-139, Bonn (Naturhist. Ver.).

Tesch, P.: Over Pleistoceen en Plioceen in den Nederlandschen Bodem (II). - Tydschr. Kon. Nederl. Aardr. Gen., Ser. 2, 28, 628-644, 3 Abb., Leiden 1911.

Tноме, K. N.: Die Begegnung des nordischen Inlandeises mit dem Rhein. - Geol. Jb. 76, 261-308, 11 Abb., Hannover 1958. - - Eisvorstoß und Flußregime am Niederrhein und ZuiderSee im Jungpleistozän. - Fortschr. Geol. Rheinl. u. Westf. 4, 197-246, 1 Taf., 19 Abb., 5 Tab., Krefeld 1959. 
Thомson, P. W.: Die fossilen Früchte und Samen in der niederrheinischen Braunkohlenformation. Fortschr. Geol. Rheinl. u. Westf. 2, 5,49-553, 3 Taf., Krefeld 1958.

Vinken, R.: Sedimentpetrographische Untersuchung der Rheinterrassen im östlichen Teil der Niederrheinischen Bucht. - Fortschr. Geol. Rheinl. u. Westf. 4, 127-170, Krefeld 1959.

VLERK, J. M. v. D. \& FlorschüTZ, F.: Nederland in het Ijstijdvak. - 287 S., 98 Abb., 40 Taf., Utrecht 1950. - - The Palaeontological Base of the Subdivision of the Pleistocene in the Netherlands. - Verh. Kon. Nederl. Akad. Wetensch., Afd. Natuurkde, 1. Reihe 20, Nr. 2, 58 S., 4 Taf., 29 Tab., Amsterdam.

VodicKová-KNEBLOvÁ, V.: Entwicklung der Vegetation im Elster-Saale-Interglazial im SuchâStonava-Gebiet. - Anthropozoikum 9 (f. 1959), 129-174, 2 Abb., 10 Taf., Praha 1960.

Weber, C. A.: Versuch eines Úberblicks über die Vegetation der Diluvialzeit in den mittleren Regionen Europas. - Allg.-verständl. naturwiss. Abh. 22, 1-31, Berlin 1900.

Wetter, C.: Ein tropischer Wasserfarn im Rhein. - Natur u. Volk 80, 140-142, 3 Abb., Frankfurt 1950.

Weyland, H., Thomson, P. W. \& Manke, H.: Die Pflanzenreste der Tongyttjaschicht des Flözes IV der Grube Liblar, Bez. Köln, und ihre ökologische Auswertung. - Palaeontographica 96 B, 98-105, 2 Tab., Stuttgart.

Wirtgen, P.: Prodromus der Flora der preußischen Rheinlande. - XII u. 208 S., 1 Taf., Bonn 1842. - - Flora der preußischen Rheinprovinz und der zunächst angränzenden Gegenden. XXII u. 563 S., 2 Taf., Bonn 1857.

Woldstedt, P.: Die Stellung des Niederrheingebietes im Rahmen des europäischen Quartärs. - Der Niederrhein 19, 55,-56, Krefeld 1952. - - Das Eiszeitalter. Grundlinien einer Geologie des Quartärs. 1954: Bd. 1. Die allgemeinen Erscheinungen des Eiszeitalters. - 2. Aufl., Stuttgart. 1958: Bd. 2: Europa, Vorderasien und Nordafrika im Eiszeitalter. - 2. Aufl., Stuttgart 1954/5,8. - - Norddeutschland und angrenzende Gebiete im Eiszeitalter. - Geogr. Handb. 4, 2. Aufl., 467 S., 97 Abb., Stuttgart 1955.

WolfF, W.: Tertiär, diluviale Schotter und Löß auf Blatt Euskirchen. - Jb. Preuß. Geol. Landesanst. f. 1904, 25, 5.49-553, Berlin 1907.

Wunstorf, W. \& Fliegel, G.: Die Geologie des Niederrheinischen Tieflandes. - Der Bergbau auf der linken Seite des Niederrheins, Festschrift z. 11. dtsch. Bergmannstage in Aachen, 215-383, 6 Abb., 3 Taf., 1 Karte, Berlin 1910.

Zimmermann, E.: Alluviale Senkungen am Niederrhein, abgeleitet aus der Verbreitung der Flachmoore. - Jb. Preuß. Geol. Landesanst. f. 1928, 49, 1, 279-303, 1 Abb., 2 Taf., Berlin 1928. - - Der Hauptterrassenton der "Inselberge“" und des Schaephuysener Bergzuges westlich Moers kein Tegelenton. - Jb. Preuß. Geol. Landesanst. f. 1934, 55, 15,1-167, Berlin 1935.

ZöLLER, A.: Die Entstehung der Stauchmoränen am Niederrhein und ihre Bedeutung für die Kenntnis des tieferen Untergrundes. - Ber. Reichsamt Bodenforsch., Jg. 1941, 187-194, 3 Abb., Wien 1942.

Zonneveld, J. I. S.: Litho-stratigrafische eenheden in het Nederlandse Pleistoceen. - Meded. Geol. Stichting f. 1958, N.S. 12, 31-64, 10 Abb., 1 Tab., 2 Taf., Maastricht 1959.

A u B rdem wurden folgende Karten benutzt:

Geologische Karte von Preußen und benachbarten deutschen Ländern $1: 25,000$ mit Erläuterungen: Blätter Kempen, Krefeld, Nieukerk, Moers und Rheinberg.

Geologische Ubersichtskarte von Deutschland 1:200000: Blatt Cleve-Wesel von F. IsERT \& H. Uduuft; Blatt Erkelenz-Düsseldorf von W. Schriel; Blatt Aachen-Köln von W. SCHRIEL.

Geologische Ubersichtskarte von Nordrhein-Westfalen 1:500000 (E. SchröDER), 2. Aufl., Krefeld 1956.

Amtliche topographische Karte 1:25000 des Landes Nordrhein-Westfalen: Blätter 4604 Kempen, 4605 Krefeld, 4504 Nieukerk, 4505 Moers und 4405 Rheinberg.

Amtliche topographische Karte 1:50000 des Landes Nordrhein-Westfalen: Blatt L 4504 Moers (vierfarbige sowie hydrographisch-morphologische Ausgabe).

Karte des Deutschen Reiches 1:100000 (topographisch): Großblatt 82b Krefeld-Essen.

Manuskr. eingeg. 1. 8. 1965.

Anschrift des Verf.: Dipl.-Geologe Dr. E. K. Kempf, Geolog. Institut der Universität, 5 Köln, Zülpicher Straße 49. 